\title{
Analysis of Potential Materials for the Control Rod Sleeves of the Next Generation Nuclear Plant
}

\author{
Jill K. Wright \\ W.R. Lloyd \\ October 2006
}

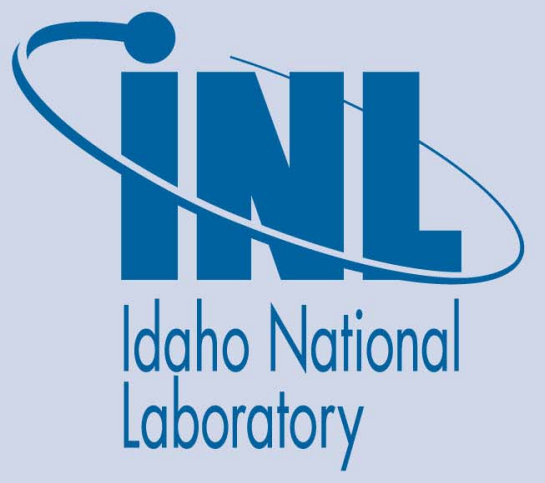

The INL is a U.S. Department of Energy National Laboratory operated by Battelle Energy Alliance 


\title{
Analysis of Potential Materials for the Control Rod Sleeves of the Next Generation Nuclear Plant
}

\author{
Jill K. Wright \\ W.R. Lloyd
}

October 2006

\begin{abstract}
Idaho National Laboratory
Idaho Falls, Idaho 83415
\end{abstract}

Prepared for the

U.S. Department of Energy

Office of Nuclear Energy

Under DOE Idaho Operations Office

Contract DE-AC07-05ID14517 


\section{SIGNATORS}

Prepared by:

Jill K. Wright, Staff Engineer

Industrial Processes and Applied Technology Department Date

Idaho National Laboratory

Reviewed by:

Kevan Weaver

NGNP R\&D Technical Deputy and Materials Manager (Interim)

Date

Idaho National Laboratory

Approved by:

Rafael Soto

NGNP Deputy Project Manager and Quality Assurance Director (Interim) Date

Idaho National Laboratory 


\begin{abstract}
An analysis is presented of potential materials for the control rod sleeves of the NGNP assuming an outlet gas temperature of $850-950^{\circ} \mathrm{C}$. Included are a review of past reactor designs and control rod performance, as weil as the two reactor design concepts under consideration for the NGNP as they pertain to control rod design and performance, and the irradiation behavior, testing, codification, cost, availability, and manufacturing issues of three materials: the two composites currently under consideration and alloy $800 \mathrm{H}$. Carbon fiber/carbon $\left(\mathrm{C}_{\mathrm{f}} / \mathrm{C}\right)$ and silicon carbide fiber/silicon carbide $\left(\mathrm{SiC}_{\mathrm{f}} / \mathrm{SiC}\right)$ have been considered the only viable choice for control rod sleeves based on the assumption that the control rods would see an environment similar to the fuel in the active core. In actuality, the control rod requirements are much less demanding than previously thought. Temperature requirements are about half, and radiation dose requirements are less than one-third of the original assumptions for both the design options. The prismatic design has potentially higher operating temperatures under certain conditions and also a slightly higher maximum depressurized conduction cool down (DCC) temperature, which could be significant in discriminating between control rod sheathing materials.
\end{abstract}

Alloy $800 \mathrm{H}$ is certainly worthy of consideration. Like all austenitic alloys $800 \mathrm{H}$ experiences radiation embrittlement, however the alloy is code qualified and has been/is being used in hightemperature gas reactor (HTGR) control rods. The primary problem with using $800 \mathrm{H}$ control rods is planning for high temperature off-normal events such as DCC. The development of ceramic composite control rods should continue, although they may not make the NGNP program deadlines due to challenges involved with achieving codification. In light of the revised design requirements, $\mathrm{C}_{f} / \mathrm{C}$ composite material has sufficient radiation properties for the NGNP control rod. The properties of $\mathrm{SiC}_{\mathrm{f}} / \mathrm{SiC}$ composite material far exceed the needs of this application, and in light of the expense, limited availability, and less-mature technology relative to $\mathrm{C}_{\mathrm{f}} / \mathrm{C}$ composites, continued research on $\mathrm{SiC}_{\mathrm{f}} / \mathrm{SiC}$ composites is difficult to justify. 
This page intentionally left blank. 


\section{EXECUTIVE SUMMARY}

The Next Generation Nuclear Plant (NGNP) is being developed to produce $\mathrm{H}_{2}$ as well as electricity. Conceptual designs call for a gas-cooled reactor with a minimum outlet temperature of $850^{\circ} \mathrm{C}$, which is required to efficiently operate the $\mathrm{H}_{2}$ generation plant. The maximum outlet temperature of $950^{\circ} \mathrm{C}$ is set by the performance limits of metallic heat exchanger materials. The current goal is for a preliminary design to be completed in about 2012 , with construction beginning about five years later. In addition to the heat exchanger alloy characterization project and graphite qualification, materials selection for the control rod sleeves has been a high priority. This report details a study of the potential materials that may be selected for the control rod sleeves and the issues associated with the selection of each material including how these issues relate to the reactor designs.

Composite materials (carbon fiber/carbon $\left[\mathrm{C}_{\mathrm{f}} / \mathrm{C}\right]$ and silicon carbide fiber/silicon carbide $\left[\mathrm{SiC}_{\mathrm{f}} \mathrm{SiC}\right]$ ) have been considered the only viable choice for control rod sleeves based on the assumption that the control rods would see a temperature $\left(1250^{\circ} \mathrm{C}\right.$ ) and irradiation environment ( $30 \mathrm{dpa}$ lifetime dose) similar to the fuel in the active core. In actuality, the control rod requirements are much less demanding than previously thought. In part, this is because the outlet temperature has been lowered from $1000^{\circ} \mathrm{C}$ to between 850 and $950^{\circ} \mathrm{C}$, but primarily because of a misunderstanding that the shutdown rods in the prismatic design would be inserted in the core during normal operation and off-normal events rather than suspended above the core. Also, liners were mistakenly thought to be required inside the control rod channels to keep graphite reflector blocks aligned. As a result, temperature requirements are about half of the original requirement, and radiation dose requirements are less than one-third of the original assumptions, which were based on modeling results for the control rods residing in the inner reflectors. The requirements are fairly similar for the pre-conceptual prismatic and Pebble Bed Reactor (PBR) designs. Although the PBR has a slightly lower fluence value, it would not impact material selection. However the prismatic design has potentially higher operating temperatures under certain conditions and also a higher maximum depressurized conduction cool down (DCC) temperature, which could be significant in discriminating between control rod sheathing materials.

Based on the reduced requirements for materials, this study has determined Alloy $800 \mathrm{H}$ is certainly worthy of consideration. The reactivity control rods for both the prismatic and pebble bed design could arguably operate under the American Society of Mechanical Engineering (ASME) code for $800 \mathrm{H}$, as it currently stands, with a maximum use temperature of $760^{\circ} \mathrm{C}$. Although (like all austenitic alloys) $800 \mathrm{H}$ experiences radiation embrittlement, the alloy is being used in high-temperature gas reactors (HTGRs) and the embrittlement can be accounted for in the component design. The primary problem with using $800 \mathrm{H}$ control rods is planning for high temperature off-normal events such as DCC. Either procedural solutions such as delayed scram or temperature testing will be required. The testing would determine if the part would deform to the point it could not be extracted from the outer reflector after exposure at $1150^{\circ} \mathrm{C}$ for 1500 hours. $800 \mathrm{H}$ will also require additional testing, including irradiation testing to fill out the database, and perhaps elevated temperature testing to extend the use temperature specified in the ASME code. However, these needs appear to be less than what will be required to codify composite materials.

The development of ceramic composite control rods should continue, even though they may not make the NGNP program deadlines due to challenges involved with achieving codification. In light of the revised design requirements of $\sim 8 \times 10^{21} \mathrm{n} / \mathrm{cm}^{2}$ for the 60 -year reactor lifetime, $\mathrm{C}_{\mathrm{f}} / \mathrm{C}$ composite material has sufficient radiation properties (up to $\sim 8 \mathrm{dpa}$ ) for the NGNP control rod. The properties of $\mathrm{SiC}_{\mathrm{f}} / \mathrm{SiC}$ composite material far exceed the needs of this application, and in light of the expense, limited availability, and less-mature technology relative to $\mathrm{C}_{\mathrm{f}} / \mathrm{C}$ composites, and the expense of developing two composites, continued research on $\mathrm{SiC}_{f} / \mathrm{SiC}$ composites is difficult to justify. Although the primary heat 
exchanger is currently limiting the outlet gas temperature to a maximum of $950^{\circ} \mathrm{C}$, a composite control rod would also be required to push the reactor temperature, and thus the efficiency, higher. At this point it would be premature to narrow the control rod material choices to one metal with significant issues to resolve; continuing composites research will help to mitigate technical risk. Continuing the composites development may also allow the NGNP program to leverage work being performed by the French, South Africans, and Japanese. The programs in these nations have expressed interest in the NGNP composites work and may collaborate in the efforts to include the composites into the ASME code and to obtain Nuclear Regulatory Commission approval so that they can market reactors in the U.S. 


\section{FORWARD}

A peer review panel of experts from outside the Idaho National Laboratory (INL) was asked to review the NGNP Preliminary Program Management Plan. ${ }^{1}$ These experts questioned the decision to consider only ceramic composites for the control rod sleeves. Metals have been used for all previous HTGRs, and alloy $800 \mathrm{H}$ (UNS N08810) is planned for the control rods in the Pebble Bed Modular Reactor (PBMR), which will have an outlet gas temperature of $900^{\circ} \mathrm{C}$. This report is the result of the inquiry by the NGNP panel of outside experts.

Progress on material selection for control rods has actually moved ahead of the issuance of this report, as the consequence of preliminary results and analyses revealed at a gathering NGNP material researchers, reactor systems experts, and industrial HTGR experts on June 21-22, 2006 in Salt Lake City. At this meeting, reduced temperature and irradiation requirements for the NGNP control rods, as well as some misconceptions about the location and function of the guide tubes and some of the control rods were presented by $\mathbf{J}$. K. Wright, the primary author of this report. Much lively discussion resulted among attendees. Shortly after this meeting, decisions were made to severely decrease funding for $\mathrm{SiC}_{\mathrm{f}} / \mathrm{SiC}$ composites.

Another meeting was held on September 7, 2006 at Oak Ridge National Laboratory (ORNL), the location of most of the NGNP composite research to date. Attendees included materials experts from INL and ORNL and from industry; unfortunately representatives from the nuclear industry were not in attendance. Initial invitations described the meeting purpose generally, as determining the path of future NGNP control rod material research. However, little was said about composites, and the meeting minutes entitled it a "Meeting to Assess Data Needs for Incoloy $800 \mathrm{H}$ for NGNP Control Rod Cladding Applications." The meeting emphasized the known He embrittlement, lack of irradiation data in many areas, and resulting scheduling difficulties in obtaining such data. In fact, it was suggested that so much data would be needed to confidently use $800 \mathrm{H}$ for control rods in the current regulatory environment that it would be more expedient to use an alloy with irradiation properties which are superior and also well documented, and try to get the alloy ASME code-qualified. (Input from PBMR and General Atomics would be interesting on this topic, as both consider $800 \mathrm{H}$ the top candidate for control rod sheathing as of 2006.) However, attendees agreed on the testing that is ultimately required for $800 \mathrm{H}$, and an initial set of post-irradiation tensile tests for screening purposes.

Regardless of the final determination of the suitability of $800 \mathrm{H}$ for this application, the recommendation of this report - that $800 \mathrm{H}$ receive further consideration - has in effect already been initiated by this meeting. The recommendation that research on $\mathrm{SiC}_{\mathrm{f}} / \mathrm{SiC}$ composites be discontinued in light of the expense, limited availability, and less-mature technology relative to $C_{f} / C$ composites, since the properties of $\mathrm{SiC}_{\mathrm{f}} / \mathrm{SiC}$ composite material far exceed the needs of this application, has also been effectively endorsed. Although the final draft of the report will be issued after these events, the background and reasoning is documented in detail, and a great deal of technical literature and reports, data and additional information has been included and evaluated. 
This page intentionally left blank. 


\section{ACKNOWLEDGMENTS}

The computer simulations and analysis of Cliff Davis and Hans Gougar, and the neutronics calculations of Hans Gougar and Jim Sterbentz are greatfully acknowledged. Their results are the primary source of the improved definitions of temperature and radiation requirements for the NGNP control rods perhaps the most important outcome of this report. In addition the authors would like to thank the following individuals for their insight, guidance, or contributions of knowledge or data: Jim Cole, Mark Holbrook, Keith Morton, Kevan Weaver, Will Windes and Richard Wright from the INL; Yutai Katoh and Lance Snead from Oak Ridge National Laboratory; Sten Caspersson from Westinghouse Electric Nuclear Power Plants; Freiderich Reitsma from PBMR; Arkal Shenoy and James Watson from General Atomics; Dennis Landini from GE Energy, Ceramic Composite Products, LLC.; Robert Shinavski from Hyper-Therm High-Temperature Composites, Inc.; Karl Verfondern from the Institute for Safety Research and Reactor Technology (ISR), Jeulich, Germany; and Kazuhiro Sawa from the Japan Atomic Energy Agency. 
This page intentionally left blank. 


\section{CONTENTS}

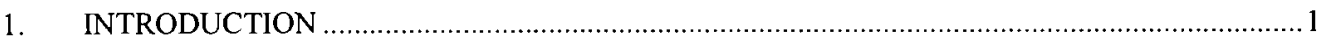

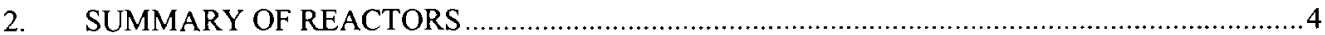

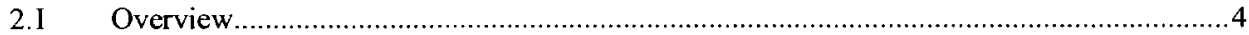

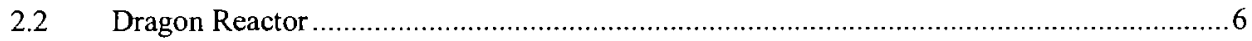

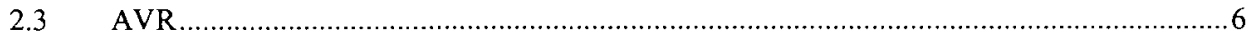

$2.4 \quad$ THTR

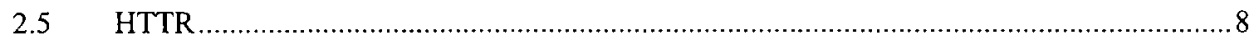

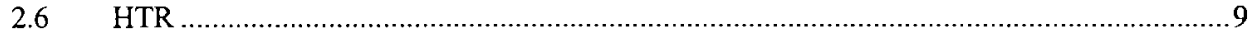

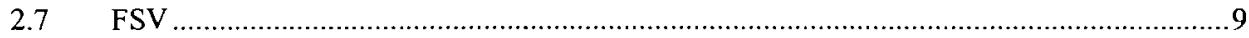

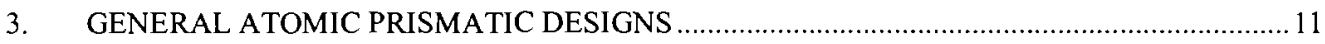

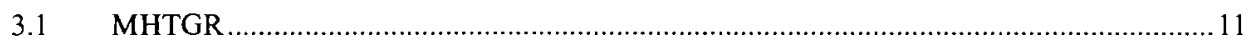

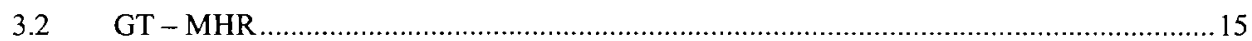

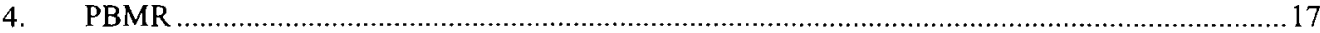

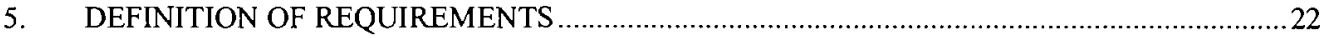

$5.1 \quad$ Temperature

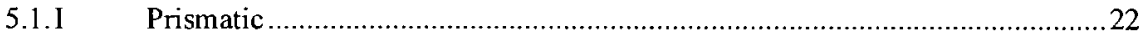

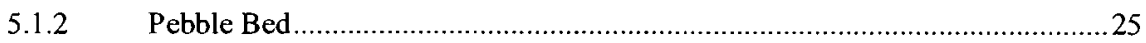

5.2 Exposure Time for Off-Normal Events .....................................................................2 27

$5.3 \quad$ Radiation Dose

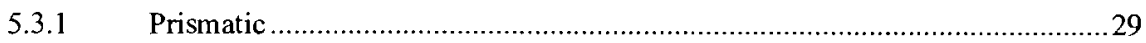

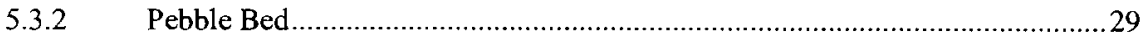

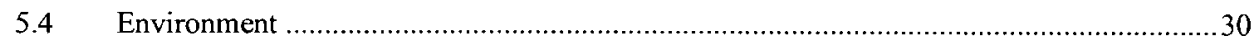

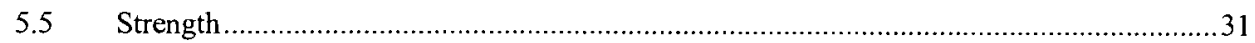

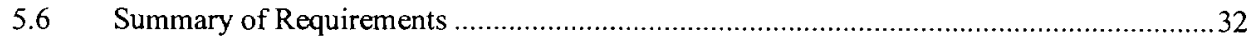

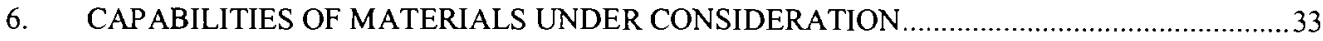

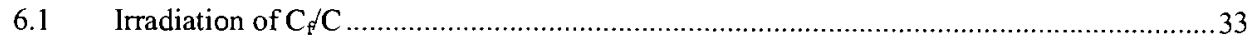

6.1.1 Graphite Irradiation Damage Mechanism ................................................... 33 
6.1.2 Complexities of Irradiation Damage to $C_{d} / C$ Composites ................................ 35

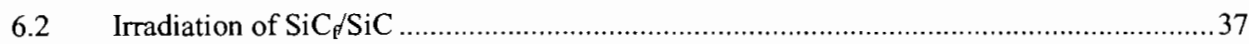

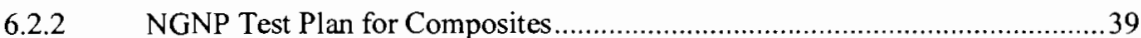

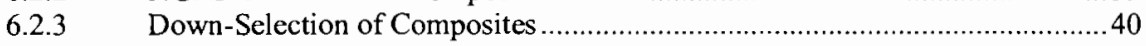

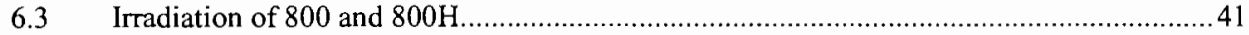

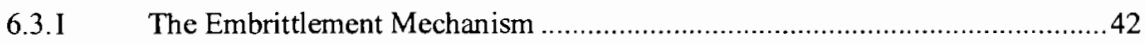

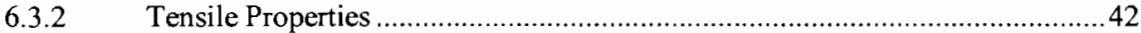

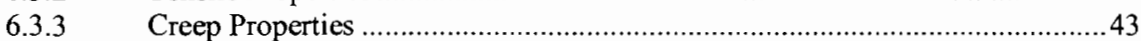

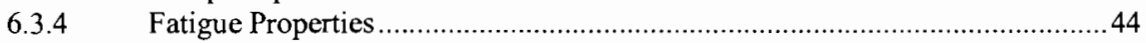

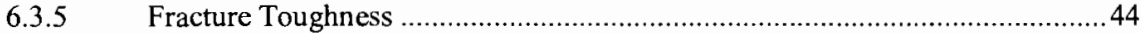

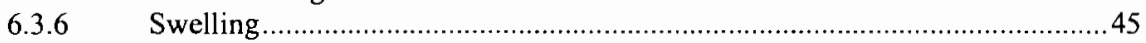

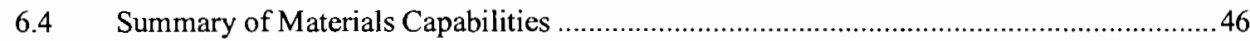

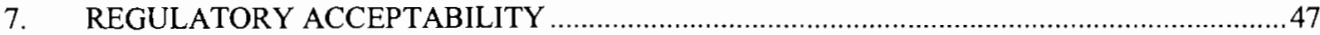

7.1 Nuclear Regulatory Commission Acceptance ….....................................................47

7.2 ASTM International Standards Development .......................................................... 48

7.3 ASME Performance Specification and Design Methodologies......................................49

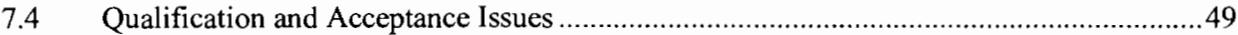

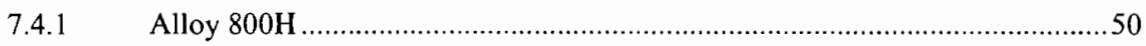

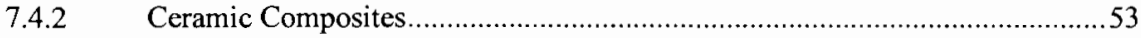

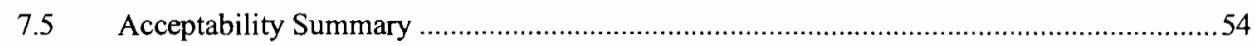

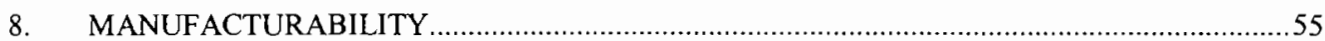

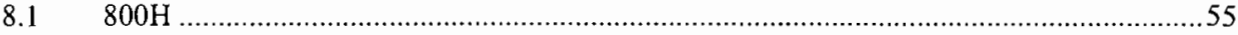

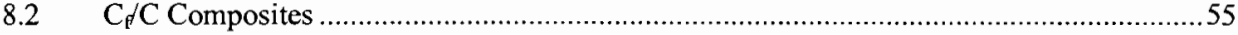

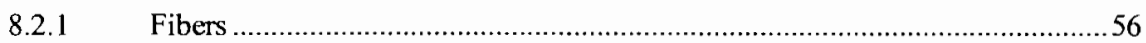

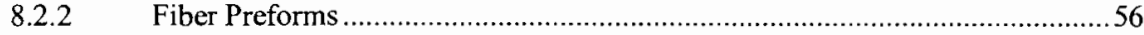

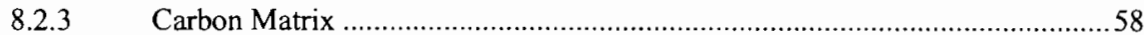

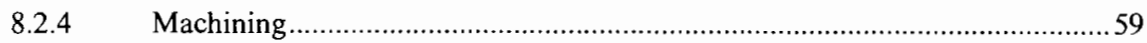

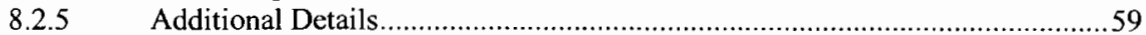

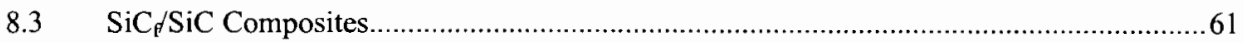

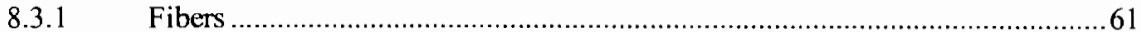

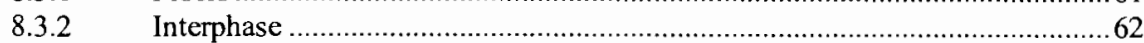

8.3.3 Matrix ........................................................... Error! Bookmark not defined,

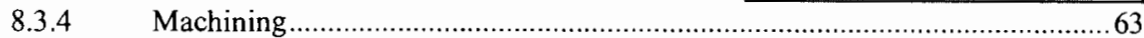

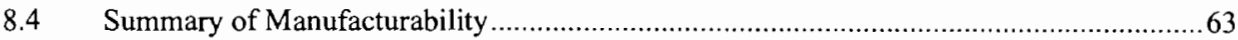

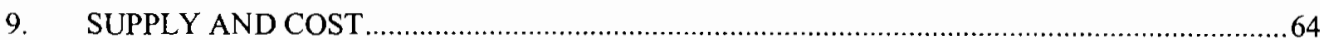

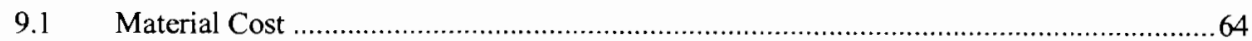




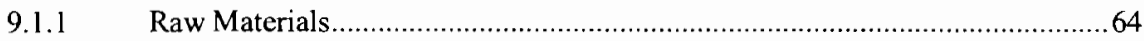

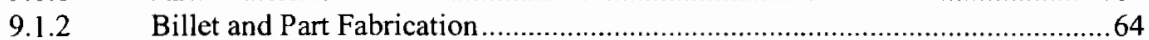

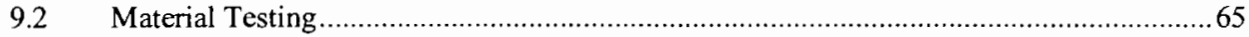

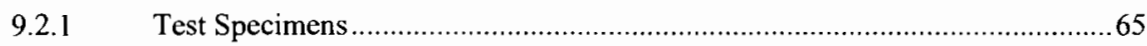

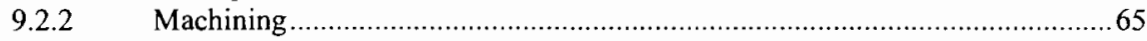

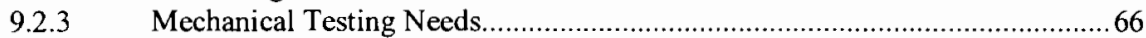

9.2.4 Testing Needed to Meet Codification Requirements.....................................66

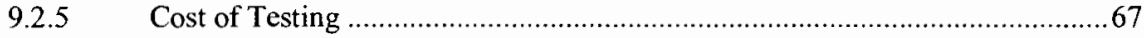

9.2.6 Cost of Joining Method Development and Qualification ..............................68

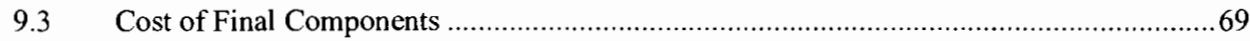

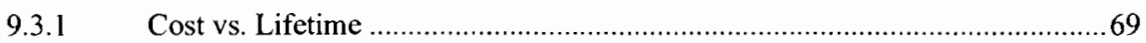

9.3.2 Reactor ShutDown/Control Rod Change-Out Cost .......................................69

9.4 Other Potential Cost-Affecting Considerations ..........................................................69

9.5 Cost of Hazardous Waste

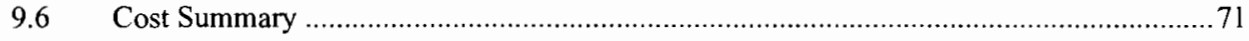

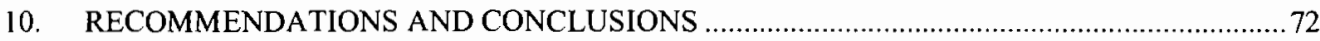

\section{FIGURES}

1. Conceptual design for the Next Generation Nuclear Plant (NGNP) reactor and power conversion systems.

2. In-core control rod used in the Thorium High-Temperature Reactor (THTR) ........................

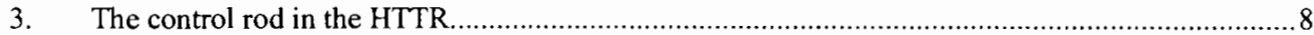

4. Schematic of Fort St. Vrain (FSV) control rod and drive assembly.................................... 10

5. Cross-section of a portion of the MHTGR-NPR control rod showing one of the canisters encasing $\mathrm{B}_{4} \mathrm{C}$ compacts, articulation, and the inner rod.

6. Diagram of the fuel handling equipment illustrating the need to move control rods to make room for refueling.

7. Cross-section of the Gas Turbine Modular High-Temperature Gas Reactor (GTMHR) core showing the location of the control rods and shutdown (startup) rods.

8. Schematic of the Pebble Bed Modular Reactor (PBMR) annular pebble bed reactor.

9. Top view of the core, showing the location of the control rod channels, fuel pebbles, small absorber sphere channels, and other features 
10. Schematic of the control rod assembly in the PBMR.

11. Axial temperature profiles of the outer reflector surface temperature for the prismatic $\operatorname{VHTR}\left(\mathrm{T}_{\text {out }}=950^{\circ} \mathrm{C}\right) . \mathrm{BAF}=$ bottom of active fuel, $\mathrm{TAF}=$ top of active fuel.

12. Outer reflector surface temperature for the prismatic VHTR $\left(\mathrm{T}_{\text {out }}=900^{\circ} \mathrm{C}\right)$.

13. Coolant channel surface temperature for the inner fuel ring in the prismatic $\operatorname{VHTR}\left(\mathrm{T}_{\text {out }}=950^{\circ} \mathrm{C}\right)$.

14. Average gas temperature in the inlet plenum during a DCC accident (Tout $=$ $\left.950^{\circ} \mathrm{C}\right)$.

15. Outer reflector temperature for the pebble-bed VHTR $\left(\mathrm{T}_{\text {out }}=950^{\circ} \mathrm{C}\right)$.

16. Outer reflector temperature for the pebble-bed VHTR $\left(\mathrm{T}_{\text {out }}=900^{\circ} \mathrm{C}\right)$.

17. Outer reflector temperature for the pebble-bed VHTR $\left(\mathrm{T}_{\text {out }}=950^{\circ} \mathrm{C}\right)$ calculated using PEBBED-THERMIX. The dotted line shows the position of the control rod during normal operation.

18. Temperature history of control rods in the prismatic reactor with 900 or $950^{\circ} \mathrm{C}$ outlet temperature during a DCC accident.

19. Temperature history of control rods in PBR with 900 or $950^{\circ} \mathrm{C}$ outlet temperature after scram due to DCC accident.

20. (a). Neutron striking a $\mathrm{C}$ atom resulting in ballistic damage to the basal plane in the form of an interstitial which creates vacancy clusters and ultimately shrinkage in the " $a$ " direction. (b). Interstitial atoms diffusing to positions between basal planes, forming a new basal plane in the graphite crystal structure and causing expansion in the " $c$ " direction.

21. Example of irradiation induced swelling in graphite, illustrating turnaround at about $15 \mathrm{dpa}$.

22. Illustration of the core-sheath microstructure of a fiber used in a $C_{f} / C$ composite.

23. Scanning Electron Micrograph photographs showing the degradation observed at 7 to 8 dpa of the shrinkage and swelling in FMI-222.

24. Bend strengths curves illustrating increased strength and elastic modulus (slope of straight-line portion of curve) after irradiation.

25. Relative density change of various fibers and CVD SiC material like that are used for the composite matrices resulting from neutron irradiation

26. The irradiated-to-non-irradiated ultimate strength ratio $\left(\mathrm{S}_{U}{ }^{\mathrm{Irad}} / \mathrm{S}_{U}{ }^{\text {Unirrad }}\right)$ measured up to $8 \mathrm{dpa}$, demonstrating the irradiation stability of different $\mathrm{SiC}_{\mathrm{f}} \mathrm{SiC}$ composite types compared to monolithic $\mathrm{SiC}$. 
27. Flow chart illustrating test plan for NGNP control rod composite research.

28. Elevated-temperature tensile test results from specimens irradiated at 400 and $600^{\circ} \mathrm{C}$

29. Creep rupture data of irradiated and unirradiated samples for 800 and Hasteloy X...................44

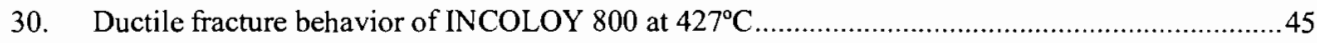

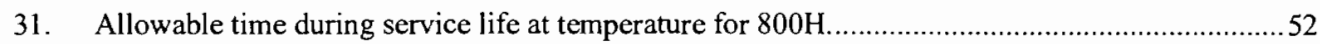

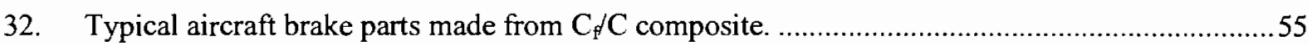

33. Types of preforms for making $\mathrm{C}_{\mathrm{f}} \mathrm{C}$ composite tubes: (a) jelly-roll, (b) T-form,

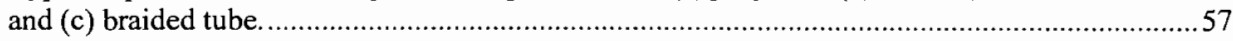

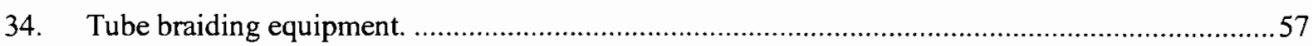

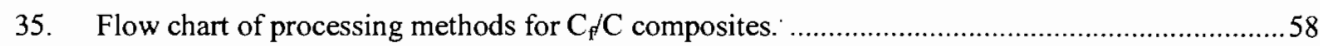

36. (a) A schematic of an annular, articulated composite control rod design presented by the Japanese. (b) schematic of a potential NGNP composite control rod design. ....................6 60

37. $\mathrm{SiC}_{\mathrm{f}} \mathrm{SiC}$ thrust chamber for liquid rocket propulsion systems. .......................................61

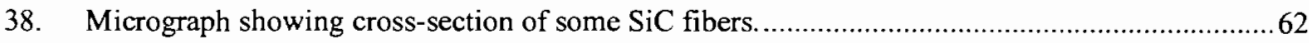

39. Multilayer $\mathrm{PyC} / \mathrm{SiC}$ interphase layer. Dark areas are fibers and light area is matrix.

\section{TABLES}

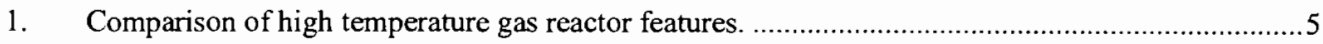

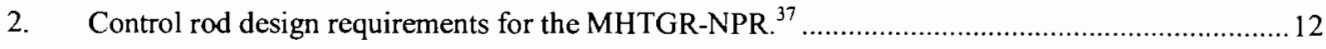

3. Comparison of PBMR to previous operating pebble bed reactors (PBRs) .............................. 18

4. Radiation flux profile at the control rod location for the NGNP prismatic reactor design.

5. Radiation flux profile at the control rod location for the NGNP pebble bed reactor design.

6. Impurities reported in the He coolant during steady-state operation of VHTRs (in ppm).

7. Expected levels of impurities in the PBMR. 


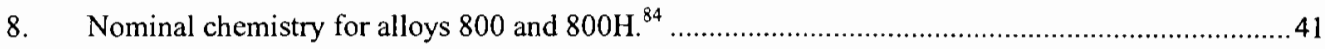

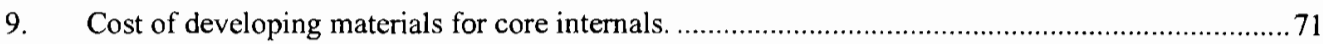

10. Comparison of operating requirements for the NGNP control rod...........................................73 


\section{ACRONYMS}

AFCI -- Advanced Fuel-Cycle Initiative

ACRS - U.S. Advisory Committee on Reactor Safeguards

AGR - Advanced Gas Reactor

ANSI - American National Standards Institute

APCS - Automated Process Control System

ASME - American Society of Mechanical Engineering

ASTM - American Society of Testing Materials

AVR - Arbeitsgemeinshaft Versuchsreaktor (PBR in Germany)

BAF - Bottom of Active Fuel Zone

B\&PV - Boiler and Pressure Vessel

$\mathrm{C}_{\mathrm{P}} / \mathrm{C}$ - carbon fiber/carbon

CVD - chemical vapor deposition

CVI - chemical vapor infiltration

DCC - Depressurized conduction cool down (same as LPCC)

DOE - U.S. Department of Energy

FCVI - forced-flow thermal-gradient chemical vapor infiltration

FSV - Fort St. Vrain

GA - General Atomics

GT-MHR - Gas Turbine-Modular Helium Reactor

HPS - Helium Purification System

HTMP - High Temperature Metallic Materials and Design Methods Project

HTGR - High Temperature Gas Reactor

HTR - High-Temperature Reactor [China]

HTTR - High-Temperature Engineering Test Reactor [Japan]

IAEA - International Atomic Energy Alliance

INL - Idaho National Laboratory

JAERI - Japan Atomic Energy Research Institute

L.PCC - Low Pressure Conduction Cool-Down

LWR - Light Water Reactor

MHTGR - Modular High-Temperature Gas Reactor

MHTGR-NPR - Modular High-Temperature Gas Reactor-New Production Reactor

NDE - nondestructive examination

NGNP - Next Generation Nuclear Plant

NRC - Nuclear Regulatory Commission

PBMR - Pebble Bed Modular Reactor [South Africa]

PBR - Pebble Bed Reactor

PyC - pyrolitic carbon

$\mathrm{QA}$ - quality assurance

RCS - Reactivity Control System

RCSS - Reactor Control and Shutdown System

RSS - Reserve Shutdown System

$\mathrm{SiC}_{\mathrm{A}} / \mathrm{SiC}$ - silicon carbide fiber/silicon carbide

TAF - Top of Active Fuel Zone

THTR - Thorium High Temperature Reactor

VHTR - Very High Temperature Gas Reactor 
This page intentionally left blank.

xviii 


\section{Analysis of Potential Materials for the Control Rod Sleeves of the Next Generation Nuclear Plant}

\section{INTRODUCTION}

The Next Generation Nuclear Plant (NGNP) is being developed to produce $\mathrm{H}_{2}$ as well as electricity. Pre-conceptual designs call for a gas-cooled reactor with a minimum outlet temperature of $850^{\circ} \mathrm{C}$, which is required to efficiently operate the $\mathrm{H}_{2}$ generation plant. The maximum outlet temperature of $950^{\circ} \mathrm{C}$ is set by the performance limits of metallic heat exchanger materials. The current goal is for a preliminary design to be completed in about 2012 with construction beginning about five years later. An artist's representation of one concept for the reactor and power conversion vessel and the associated $\mathrm{H}_{2}$ generation plants is shown in Figure 1. In this schematic, in addition to process heat being diverted to $\mathrm{H}_{2}$ production, there is a heat exchanger between the primary circuit and a secondary circuit that drives a gas turbine for electricity production.

This report provides an analysis of potential materials for the control rod sleeves of the NGNP. The initial sections examine past reactor designs and control rod performance, as well as the two reactor design concepts under consideration for NGNP in detail as they pertain to control rod design and performance. Subsequent sections provide a reevaluation of the material requirements to reflect a substantially lower temperature and radiation dose compared to the previous estimates used in planning the NGNP Materials Program. ${ }^{2}$ This report also reviews the irradiation behavior, testing, codification, cost, availability, and manufacturing issues of three materials: the two composites currently under consideration and alloy $800 \mathrm{H}$.

The NGNP materials development program faces several unique challenges, primarily related to long-term operation at very high temperatures relative to any existing water-cooled reactors and even most High-Temperature Gas Reactors (HTGRs). The desired operating temperatures are either above the usable limit of the traditional reactor component materials (based on current code), or will require the development of new materials such as ceramic composites to tolerate the anticipated operating environment. Furthermore, the material performance criteria are not well-established. A preliminary reactor design does not exist, so operational parameters, such as temperature and stress levels, are only best estimates based upon the most recent designs of the two gas-cooled reactor systems: the Pebble Bed Modular Reactor (PBMR), soon to be built in South Africa, and the Gas Turbine - Modular Helium Reactor (GT-MHR), a prismatic design that has been under development over the last decade or so by General Atomics.

Because of concurrent development of both the reactor design and high-performance materials, neither effort can provide the other with satisfactory requirements or characteristics. Newer materials are still under development and have performance data which is too limited to provide to reactor designers. Also, the U.S. Department of Energy (DOE) has only recently authorized preliminary reactor designs, and three teams will submit their analyses; thus, definitive material temperature performance requirements cannot be specified. Designers press for a material specification to which they can design. Material developers seek a performance target to which a new material must conform. It does not appear that this situation is likely to be resolved soon. This situation has resulted in multiple reactor designs, power conversion options, coolants, graphites, and multiple materials for virtually all of the reactor components still under consideration. 


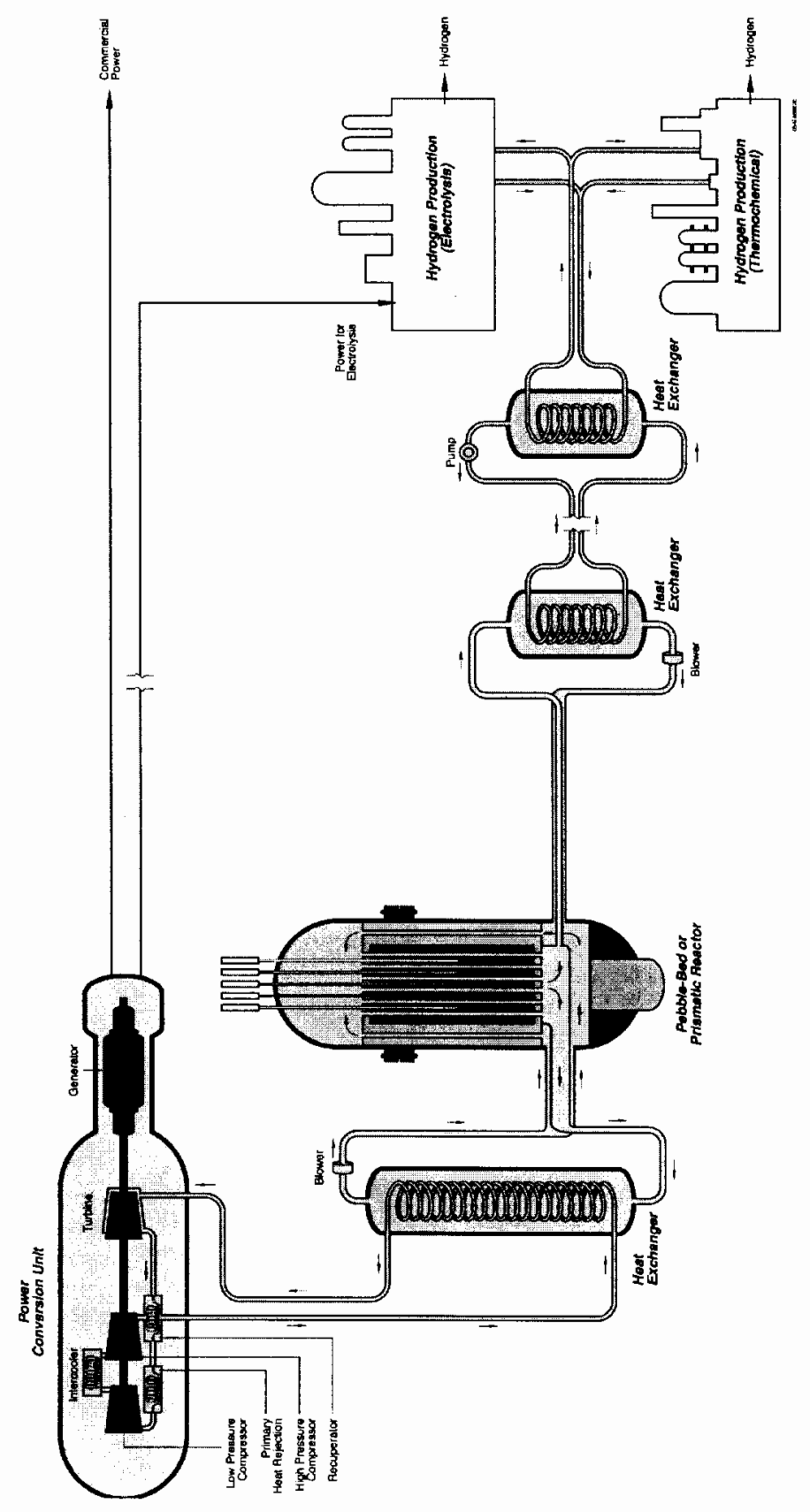

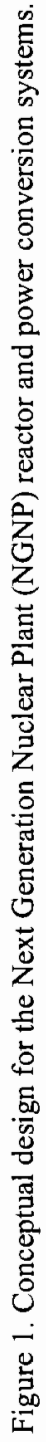


One such component is the NGNP control rod. In the original NGNP planning documents, ${ }^{2}$ it was assumed the control rods would be exposed to the maximum fuel temperature of about $1250^{\circ} \mathrm{C}$, so metals were not being considered for this application. However, as discussed in this report, this temperature turns out to be about two times more than what is actually required. In addition, the radiation dose is estimated to be less than one-third of previously reported value of $30 \mathrm{dpa}$.

The NGNP program has been supporting research on two ceramic fiber/ceramic matrix composites: carbon fiber/carbon $\left(\mathrm{C}_{\mathrm{f}} / \mathrm{C}\right)$ and silicon carbide fiber/silicon carbide $\left(\mathrm{SiC}_{\mathrm{f}} / \mathrm{SiC}\right)$. Both of these composites appear to have adequate high temperature strength and irradiation resistance to survive in the core of a HTGR, although $\mathrm{SiC}_{\mathrm{f}} / \mathrm{SiC}$ appears to have superior radiation resistance. However, composites have never been used in a reactor, and substantial time and effort will be required to get the material standardized by American Society of Testing Materials (ASTM), codified by American Society of Mechanical Engineering (ASME), and licensed by the Nuclear Regulatory Commission (NRC). This raises the issue of whether the development of the composite control rod could meet the NGNP schedule.

After a preliminary evaluation, alloy $800 \mathrm{H}$ was the only alloy considered in this report. The primary advantage a metal has over the composites is its established database and history of use in nuclear application and codification. The maximum code-qualified use temperature for $800 \mathrm{H}$ may need to be increased to enable it to be used for control rods, but this process has already been initiated under a DOE-ASME joint initiative. Of the materials in the ASME code, only $800 \mathrm{H}$ has acceptable elevated temperature radiation resistance. Alloys not currently in the code would face many of the issues the composites face and thereby risk meeting NGNP deadlines. 


\section{SUMMARY OF REACTORS}

\subsection{Overview}

A review of past gas-cooled reactors reveals much information of interest if metals are to be reconsidered as control rod sheathing materials. Historically, some nuclear reactors have had exit gas temperatures in the same range as the current plan for the NGNP. However, previous control rod designs are entirely different from those being considered for composite control rods. Also, the temperature seen by the control rods was sometimes minimized by the location of the control rod or the procedure for reactor scram.

In the past, all metallic control rods have been of an annular design with relatively thin metal sheathing filled with some form of boron carbide. No mention of welding was found in the literature and several sources give details of mechanical joining, ${ }^{3,4}$ presumably to avoid difficulties and inferior properties associated with weldments. Table 1 summarizes the features of high temperature gas reactors and the reactor designs most relevant to the NGNP and presents each reactor's history and specifications.

\subsection{Dragon Reactor}

The Dragon Reactor was the first He cooled reactor and was operated from 1964 to 1975 in Winfrith, U.K. The reactor power was controlled by He mass flow without changing the core or fuel temperatures. The Dragon Reactor design included provisions for remote removal and replacement of the control rods and fuel elements. The control rods were routinely changed every one to two years, ${ }^{5,6}$ in contrast with some of other reactors mentioned in Section 2, which did not change control rods. The Dragon Reactor design also allowed for substantial clearance between the control rods and the channels in the reflectors. ${ }^{6}$

One of the listed problems with the reactor was the oscillation and bowing of the control rods, which caused power swings and some sticking of the rods. This problem was dealt with by fitting damping restraints on articulated rods rather than replacing them. However, if the inner graphite reflector blocks bowed due to irradiation effects, they were replaced. ${ }^{7}$

The Dragon Reactor fuel typically did not exceed $1250^{\circ} \mathrm{C}$, but was operated at $1800^{\circ} \mathrm{C}$ for 80 days and at $2000^{\circ} \mathrm{C}$ for 3 days for a fission release experiment. ${ }^{7}$ The temperatures that would have resulted in the reflectors, where the control rods resided, were not reported. This source makes the general statement: "In view of the fairly conservative design of the reactor experiment, it was unlikely that any appreciable deterioration in the reactor components or structure would have occurred during its ten-year life and this was confirmed by the detailed examination of components which were removed." A maximum outlet gas temperature of $950^{\circ} \mathrm{C}$ was reported, and concern over the Nimonic liner of the outlet duct was expressed (although no damage was observed upon shutdown), but control rods were not specifically mentioned.

One source mentions concerns that the loaded and hot $\left(650^{\circ} \mathrm{C}\right)$ Nimonic control rod shield tubes might self-weld to the Monel reflector head assembly during service in the He environment. However, this problem never occurred. ${ }^{5,8}$ 


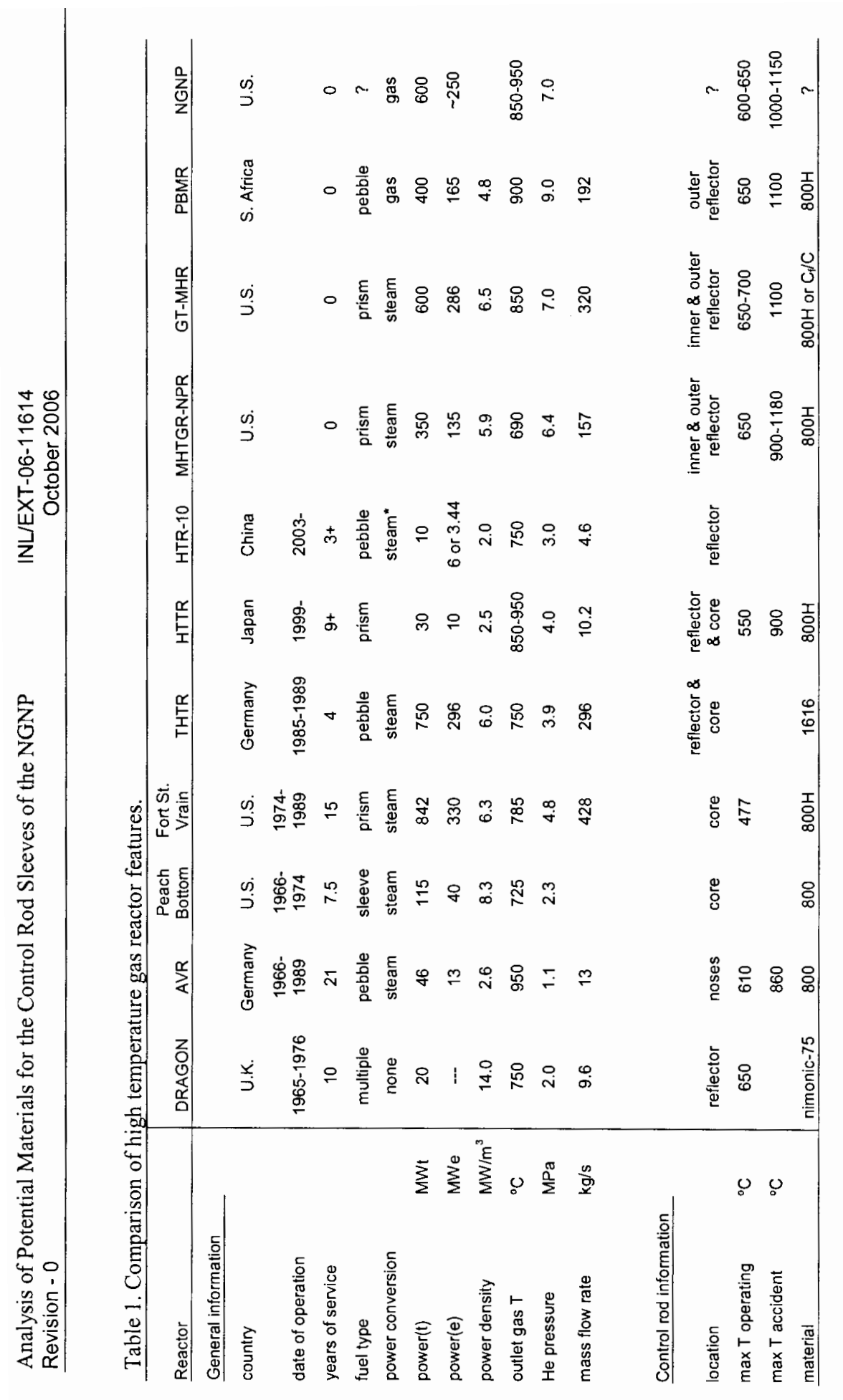


The 1971-72 report for the Dragon Reactor states: "Nimonic-75 [was] the only high-temperature metal used in construction of the Dragon Reactor Experiment..." It is assumed, based on this statement, that Nimonic-75 was the alloy used for the Nimonic control rods. Specimens of this alloy were monitored after testing in the primary circuit for 21,000 hours at full power. Test results showed minimal corrosion that had penetrated only $0.01 \mathrm{~mm}$ into the surface, despite exposure to high levels of gas impurities. ${ }^{9}$ The primary circuit operated at the reactor outlet temperature of $750^{\circ} \mathrm{C}$.

\subsection{AVR}

The Arbeitsgemeinschaft Versuchsreaktor (AVR) is one of the most interesting cases to consider. Although it was a test reactor with only $46 \mathrm{MWt}$ and 13-15 MWe, it operated for over 21 years, most of that time with an outlet gas temperature of $950^{\circ} \mathrm{C}$. Some reports claim it reached a gas temperature of $1000^{\circ} \mathrm{C}^{10,11}$

The AVR first went critical in August 1967. It had only 4 control rods which also served as the shutdown rods. Although the rods were gravity driven, they were inserted into the pebble bed of the reactor from underneath and within graphite noses. This system operated by the use of a rack and pinion drive and a heavier rod from above that acted as a counter-weight. The design required extremely long rods to accommodate the size of the $2.6 \mathrm{~m}$ core: $20 \mathrm{~m}$ for the control rod, with only the portion of the rod that entered the core containing absorber, and $15 \mathrm{~m}$ for the counterweight rod.

To determine the dynamic behavior, expected service life of the drive, and functional capacity, 1:1 scale tests were conducted under "reactor conditions." Once in service, the rods and drive system were inspected annually and the rods were reported to have been operating "faultlessly and without maintenance since commissioning."12

Accident conditions were physically replicated for both depressurized and pressurized loss of coolant in the AVR, and temperatures were measured in various locations within the reactor. Because of safety considerations, and to preserve the integrity of the reactor, a multi-step process was used to produce conditions similar to those found during these accidents. The temperature could not be measured directly on the control rod, but was interpolated between the shutdown rod nose at core mid-height and the bottom reflector. After this experiment, the temperature was found to remain below $700^{\circ} \mathrm{C}$, peaking at about $20 \mathrm{~h}$ of a $120 \mathrm{~h}$ test. This is the only known case of a measured control rod temperature experiment. All other reported temperature tests are the results of various computer models.

The force exerted on the tip of the control rods during insertion into the pebble bed core was measured as varying widely between 1 and $11 \mathrm{~N}$, depending on the penetration depth. ${ }^{12}$ These measurements were not made because of concern about the rods, but because of possible damage to the fuel pebbles.

\subsection{THTR}

The Thorium High-Temperature Reactor (THTR) reactor only operated for four years, because of policy decisions by the German government. It was considered a prototype reactor with $750 \mathrm{MWt}$ and $300 \mathrm{MWe}$ and had an outlet gas temperature of $750^{\circ} \mathrm{C}$. The THTR had two independent shutdown systems: six sets of six rods in the outer reflector and seven groups of six rods with a different design, which were inserted directly into the pebble bed core. Figure 2 shows the manufacture of the in-core rod used in the THTR reactor. 


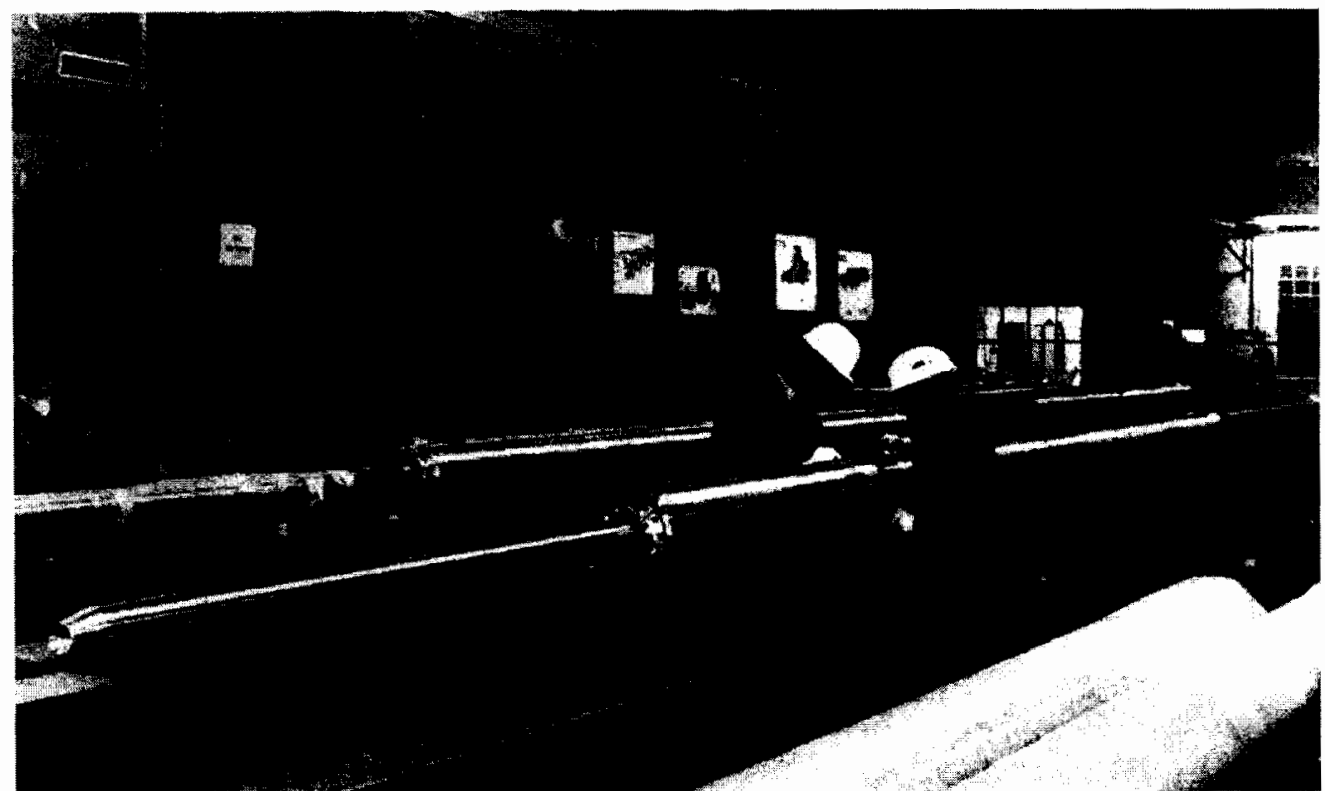

Figure 2. In-core control rod used in the Thorium High-Temperature Reactor (THTR). ${ }^{13}$

Some of the reflector rods were used for reactor control while at least 24 of the 36 reflector rods were in the fully raised position during operation and reserved for scram. If scram was required, all 36 rods fell into their fully inserted position. These rods were composed of 10 annular sections filled with boron carbide and connected by articulated joints. They were suspended from the rod drives by a chain. Mechanical wear, irradiation behavior, and control rod drive efficiency were all considered in the design, as well as scenarios such as chain rupture and air ingress. ${ }^{13}$

The in-core rods served the purpose of maintaining long-term subcriticality and could perform this function without contribution from the reflector rods. They were inserted into the core by a long-drive piston. Inserting the in-core rods resulted in aggressive contact between the pebbles and the rods. Although extensive modeling and testing was done before hand, during commissioning of the plant, ${ }^{13}$ inserting rods directly into the pebble bed core caused a problem with damage to the graphite shell coating the fuel pebbles. However, no problems with the control rods were mentioned as a result of the interaction. It was later determined that the shutdown system was designed very conservatively, and the in-core rods were not needed except for long-term shutdown when four of the groups were partially inserted. ${ }^{14}$ The in-core rods had an estimated insertion force of up to $100 \mathrm{kN} .{ }^{13}$

The control rod sleeves were made of an austenitic alloy developed in Germany specifically for this application. ${ }^{15}$ The austenitic alloy's German and DIN alloy designations are 1.4981 and $\mathrm{X} 8 \mathrm{CrNiMoNb1616}$, and it has nominally $16 \%$ of $\mathrm{Ni}$ and $\mathrm{Cr}, 2 \% \mathrm{Mo}, 0.06 \% \mathrm{C}$, and up to $1.2 \% \mathrm{Nb}$. This alloy was not as susceptible to irradiation embrittlement as alloy $800,{ }^{16}$ displaying superior postirradiation total elongation and creep rupture elongation. ${ }^{17}$

The accident analysis philosophy was outlined for the THTR. Accidents expected to occur at least once during the life-time of the plant $(\mathrm{H} \geq 1 / 30 \mathrm{a})$ require detailed load analysis, and load history of the related components. Accidents which are not anticipated during the life-time of the plant but which cannot be ruled out because of the low probability $\left(3 \times 10^{-2} / \mathrm{a} \geq \mathrm{H} \geq 10^{-6} / \mathrm{a}\right)$ are assessed individually only 
with respect to the safety function. In this case repairs to the plant might be necessary which require new licensing. Finally, accidents with a probability less than $10^{-6} / \mathrm{a}$ are only considered to asses the health hazard of such events. ${ }^{18}$

\subsection{HTTR}

The High-Temperature Engineering Test Reactor (HTTR) in Japan is the most recently built gascooled reactor. It has a prismatic design and annular core, and it operates at an outlet gas temperature of $850^{\circ} \mathrm{C}$, or at $950^{\circ} \mathrm{C}$ during high temperature test operation.

Very detailed control rod design information is available in the open literature (see Figure 3 ). ${ }^{3,4}$ Control rods are positioned in both the outer reflector and core, and they consist of 10 neutron absorber sections contained in a metal sleeve, which are held together by a metal spine and support rings. All metal parts are made from alloy $800 \mathrm{H}$ and mechanically attached without welds. The parts are assembled with gaps among them to reduce thermal stresses and with ventilation, to avoid differential pressure. Each of the 10 annular sections contains $5 \mathrm{~B}_{4} \mathrm{C} / \mathrm{C}$ sintered compacts. During normal operating conditions, the $800 \mathrm{H}$ sleeves reach about $600^{\circ} \mathrm{C}$ maximum. ${ }^{3}$

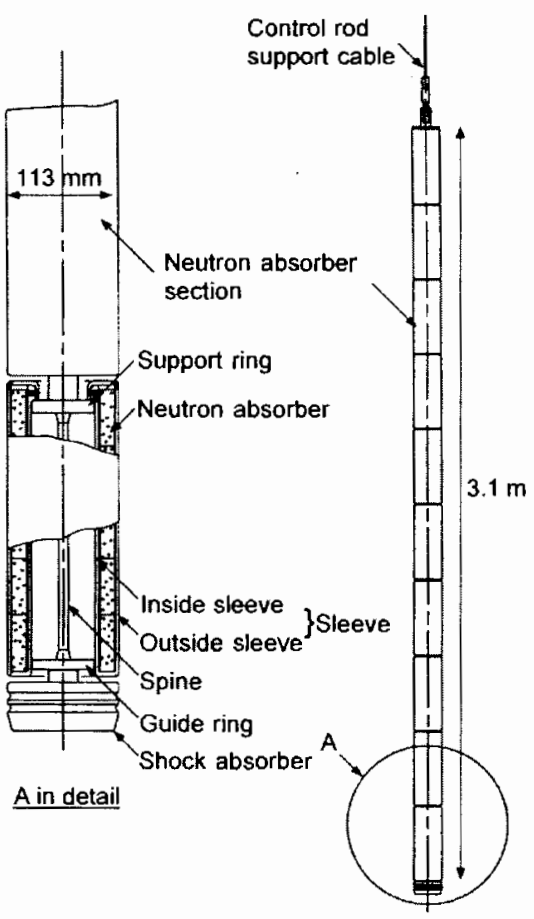

Figure 3. The control rod in the HTTR., ${ }^{3,4}$ 
Since the maximum temperature in the core is about $1100^{\circ} \mathrm{C}$ when the reactor is in hightemperature test operation $\left(950^{\circ} \mathrm{C}\right.$ exit gas), a two-step control rod insertion method is employed for reactor scram. The control rods in the outer reflector are inserted into the core immediately by gravity, and 40 minutes later, when the outlet coolant temperature becomes less than $750^{\circ} \mathrm{C}$, the remaining control rods are inserted into the core. Because of the negative reactivity of the reactor, the inner control rods are only needed once the reactor reaches low temperatures. ${ }^{3,4}$ This two-step scram has been successfully tested during a loss of off-site electric power simulation; subcriticality of the reactor was maintained and temperatures declined. ${ }^{19}$

The reactor and control rods were designed so that the control rods are replaceable. Temperature analysis indicated that for most events requiring scram, the control rods would remain below $900^{\circ} \mathrm{C}$. A maximum exposure temperature of $900^{\circ} \mathrm{C}$ was set, and control rods were required to be replaced if they exceeded this temperature. ${ }^{20}$ This threshold temperature reduces the need for very high temperature data and also extends the lifetime of the control rods. ${ }^{3,4,20}$

Stress analysis was also performed on the HTTR control rod design ${ }^{3,4}$ to confirm that a target life of 5 years could be achieved based on ASME Code Case N-47-21. ${ }^{21}$ In November of 1998 HTTR was the first reactor with an annular core to demonstrate criticality. ${ }^{22}$ It first began producing power in September of 1999, and achieved full thermal power of $30 \mathrm{MW}$ in December of $2001{ }^{19}$ Therefore, the first five years of operation have now elapsed and the control rods have been inspected, but not replaced. ${ }^{23}$

\subsection{HTR}

The $10 \mathrm{MWt}$ High-Temperature Reactor 10 (HTR-10) is a pebble bed test reactor built in China. The original plan called for two operational phases. Phase one would have an outlet gas temperature of $700^{\circ} \mathrm{C}$ and produce $2.6 \mathrm{MWe}$ from a steam turbine, and phase two would increase the outlet gas temperature to $900^{\circ} \mathrm{C}$, in order to produce $2.08 \mathrm{MWe}$ from a steam turbine in addition to $1.36 \mathrm{MWe}$ from a gas turbine. ${ }^{22}$ The HTR-10 first reached criticality in December $2000 .^{24,25}$ The control rods are located in the outer reflector; however, virtually no additional information has been obtained concerning the control rods.

\subsection{FSV}

Fort St. Vrain (FSV) was a HTGR owned and operated by the Public Service Company of Colorado from 1974 to 1989 . It had a lower outlet gas temperature of $785^{\circ} \mathrm{C}$, and the control rods, sheathed with $800 \mathrm{H}$, were located in the core. Although an average core temperature of $800^{\circ} \mathrm{C}$ (and fluence of $8 \times 10^{21} \mathrm{n} / \mathrm{cm}^{2}$ ) was reported, ${ }^{26}$ the control rod was only subjected to $477^{\circ} \mathrm{C}$ during normal operation (reference not available). FSV was similar to the NGNP, as it was a large-scale reactor (842 MWt and $330 \mathrm{MWe}$ with a $4.75 \mathrm{~m}$ high core) and both were/are subject to U.S. regulations and codes, although events such as those at Three Mile Island and Chernobyl have made the licensing process much more rigorous.

FSV was plagued with problems, resulting in low-reliability production efficiency. However, it produced much valuable information for future HTGRs. ${ }^{27-29}$ Some of the problems with the FSV concerned the control rod system. For example, core temperature and power fluctuations resulted due to vertical movement of the control rods within the control rod channels, ${ }^{30}$ and six control rods failed to insert during a reactor scram because of problems with the drive mechanism. ${ }^{27}$ However, the integrity of the control rods themselves was not an issue. ${ }^{31}$ The control rod design and configuration was very similar to the MHTGR, which will be discussed in detail. Figure 4 shows a schematic of the entire control rod and drive assembly used in the FSV reactor. 


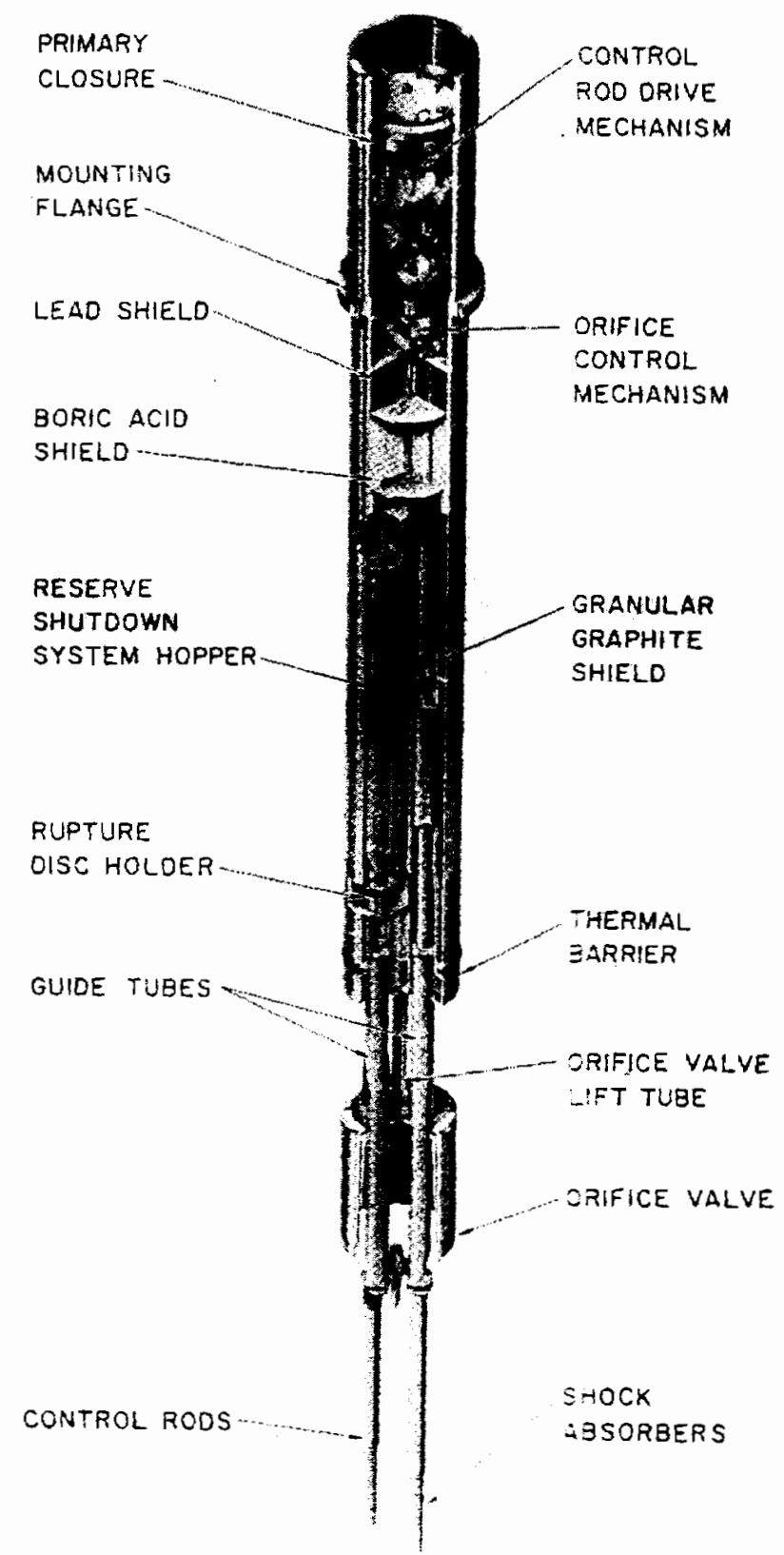

Figure 4. Schematic of Fort St. Vrain (FSV) control rod and drive assembly. ${ }^{32}$ 


\section{GENERAL ATOMIC PRISMATIC DESIGNS}

\subsection{MHTGR}

The Modular High-Temperature Gas Reactor (MHTGR) design uses hexagonal prismatic graphite blocks identical to those used in FSV. The graphite core is surrounded by a steel core barrel and is contained inside an uninsulated reactor vessel. Helium coolant flows down through the core. The active core is composed of columns of blocks arranged in three annular rings which have fuel rods and coolant channels. The central and outer portions of the core are unfueled reflector blocks and control rods are located in the innermost ring of outer reflector blocks and the outermost ring of the central reflector blocks. $^{33}$

The design of the control rod system, both for reactor control and for shutdown, is derived directly from the FSV design, which operated successfully (with exception of the steam-related control rod drive problem). ${ }^{32}$ The MHTGR design has 24 control rods in the outer reflector for normal control and reactor trip, and an additional six rods in the central reflector inserted for cold shutdown and startup only. ${ }^{34,35}$ The location of the control rods in the outer reflector prevents damage due to excessive heat during depressurized or pressurized passive decay heat removal. ${ }^{35,36}$ (Figure 7 in the next section illustrates a similar core.)

The MHTGR design includes a hierarchy of three emergency shutdown mechanisms, the primary shutdown system being the control rods. If the drive mechanism were to fail, for example due to loss of power, the control rods would fall by gravity into the reactor, shutting it down. As a backup, a reserve shutdown system (RSS) with marble-sized boron carbide balls would also fall into channels in the core. ${ }^{32,33}$ If both of these shutdown mechanisms should fail, the reactor is inherently safe and would automatically shut itself down when the core started to overheat because of the large negative temperature coefficient of this system. ${ }^{32}$ Passive cooling would follow without human intervention.

All 30 control rods in the design are interchangeable. Annular compacts composed of $40 \%$ natural boron in the form of $\mathrm{B}_{4} \mathrm{C}$ granules dispersed in a graphite matrix are enclosed in $1.27 \mathrm{~mm}$ thick, alloy $800 \mathrm{H}$ canisters (also referred to as cladding, sheathing, or sleeves) for structural support. The canisters are vented to avoid differential pressure. A string of 18 canisters are mechanically connected by articulated joints so they can traverse any small offsets between graphite elements. ${ }^{37}$ A drawing of one of the canisters with articulation is shown in Figure 5. The total length of the control rod is at least as long as the active core, $7.9 \mathrm{~m}$ in this case. A detailed list of specifications and requirements developed for the Modular High-Temperature Gas Reactor-New Production Reactor (MHTGR-NPR) is listed in Table 2. 
Table 2. Control rod design requirements for the MHTGR-NPR. ${ }^{37}$

\begin{tabular}{|c|c|}
\hline $\begin{array}{l}\text { Control rod } \\
\text { configuration } \\
\text { and essential } \\
\text { features }\end{array}$ & $\begin{array}{l}\text { All control rods must be interchangeable. } \\
\text { Articulated for mechanical flexibility. } \\
\text { Length } \geq \text { length of active core }=7.9 \mathrm{~m} \text {. } \\
\text { Absorber compact: } 40 \mathrm{wt} \% \text { natural } \mathrm{B} \text { in } \mathrm{B}_{4} \mathrm{C} \text { granules dispersed in a graphite matrix } \\
\qquad \mathrm{OD}=82.6 \mathrm{~mm}, \mathrm{ID}=52.8 \mathrm{~mm} \text {. } \\
\text { Canister: } 800 \mathrm{H}, 1.27 \mathrm{~mm} \text { thick. }\end{array}$ \\
\hline Structural & $\begin{array}{l}\text { Flexible insure full insertion by gravity. } \\
\text { Vented to avoid pressure differential. } \\
\text { Maximum horizontal misalignment between penetration centerline and element centerline due to } \\
\text { construction tolerances and normal operation }=43.2 \mathrm{~mm} \text {. } \\
\text { Maximum misalignment during seismic events }<7 \mathrm{~g} \mathrm{~mm} \text {. } \\
\text { Equipped with energy-absorbing device to cushion fall and prevent control rod deformation or } \\
\text { damage to bottom reflector elements which could prevent remote removal of rod with } \\
\text { core service tools in the normal manner. } \\
\text { Acceleration of control rod at start of withdrawal or deceleration at termination of insertion to } \\
\text { limit dynamic loads and prevent any adverse affect on control rods. }\end{array}$ \\
\hline Environmental & $\begin{array}{l}\text { Compatible with coolant, temperature, pressure, and flow conditions. } \\
\text { Capable of withstanding irradiation conditions. }\end{array}$ \\
\hline $\begin{array}{l}\text { Surveillance } \\
\text { and In-Service } \\
\text { Inspection }\end{array}$ & $\begin{array}{l}\text { Samples shall be obtained from metallic portions when they are periodically replaced and tested } \\
\text { for tensile, creep rupture fatigue and impact properties. }\end{array}$ \\
\hline $\begin{array}{l}\text { Availability } \\
\text { assurance }\end{array}$ & No unscheduled unavailability or forced outage allocation for control rods. \\
\hline Maintenance & $\begin{array}{l}\text { No scheduled maintenance for control rods. } \\
\text { Any defective control rod shall be replaced. }\end{array}$ \\
\hline $\begin{array}{l}\text { Codes and } \\
\text { Standards }\end{array}$ & $\begin{array}{l}\text { Control rods shall be designed in compliance with ASME Boiler and Pressure Vessel Code, Case } \\
\text { NH of Section III, Division } 1 .\end{array}$ \\
\hline $\begin{array}{l}\text { Quality } \\
\text { Assurance }\end{array}$ & ANSI/ASME NQA-1 \\
\hline Construction & acilitate the installation and required removal and replacement of the components. \\
\hline
\end{tabular}




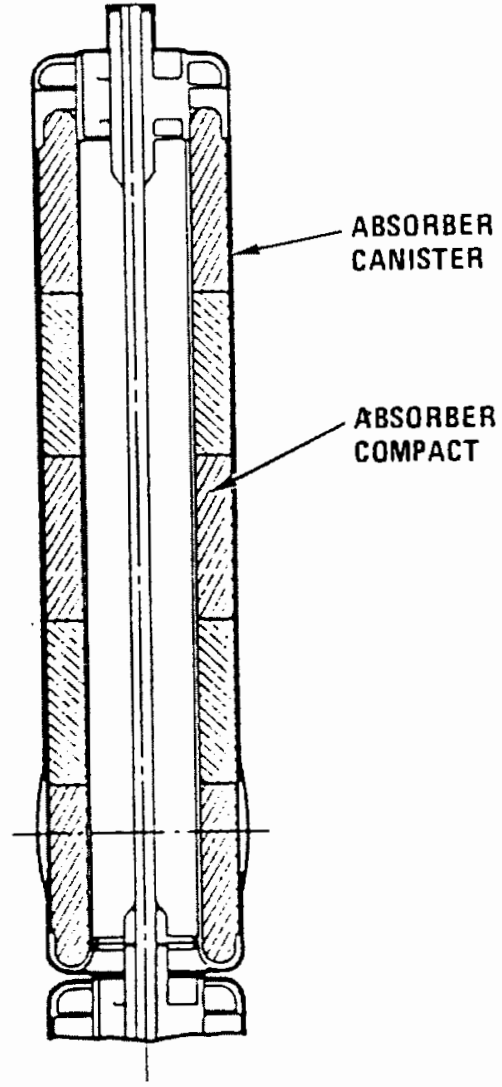

Figure 5. Cross-section of a portion of the MHTGR-NPR control rod showing one of the canisters encasing $\mathrm{B}_{4} \mathrm{C}$ compacts, articulation, and the inner rod. ${ }^{32}$

Maintaining the alignment of the graphite elements within the columns is critical for control rod insertion as well as for coolant flow. ${ }^{35,36}$ The alignment is ensured by dowels and sockets in the graphite blocks. ${ }^{36}$ There has been some suggestion that a liner is used inside the control rod channel to aid graphite block alignment. It is unclear where this idea originated; this feature is not used in modern designs. The guide tubes that extend through the top head of the reactor vessel and upper plenum and guide the control rods to the entrance of the channel may have, at some point, been confused for a tube that resides within the channel.

Fast neutron fluence causes the graphite to shrink and distort, but not to the point where it will interfere with operation or refueling. ${ }^{36}$ Since the refueling schedule results in some graphite blocks within the column having a longer residence time and therefore more shrinkage than others, a slightly tortuous path results within the control rod channel. This is the primary reason that the control rods are articulated, and would make it difficult to implement a liner. Furthermore, a liner would complicate the refueling process itself. The dowel/socket combinations are designed to withstand the highest shear forces generated during seismic conditions, ${ }^{35}$ indicating the dowel/socket system should be adequate to maintain alignment. 
The entire control rod assembly is periodically removed, either to provide access for refueling (see Figure 6), or for maintenance of the equipment. ${ }^{32}$ Control rod replacement is planned after 10 years or more ${ }^{36}$ and will be done at the time of refueling by placing the used control rod into a canister and replacing it with a new one while the assembly is removed ${ }^{31}$ However, if a problem or inspection indicates a control rod needed to be changed, a spare set of control rods is be maintained on site, and could be changed at any time if necessary. ${ }^{38}$ Ideally, this will be be scheduled during refueling as well, which is planned every 20 months. ${ }^{33}$ Various maintenance operations are typically scheduled during refueling. For example, a few reflectors are to be replaced during each refueling to meet the average replacement schedule of every nine years, rather than replacing them all at once. ${ }^{36}$

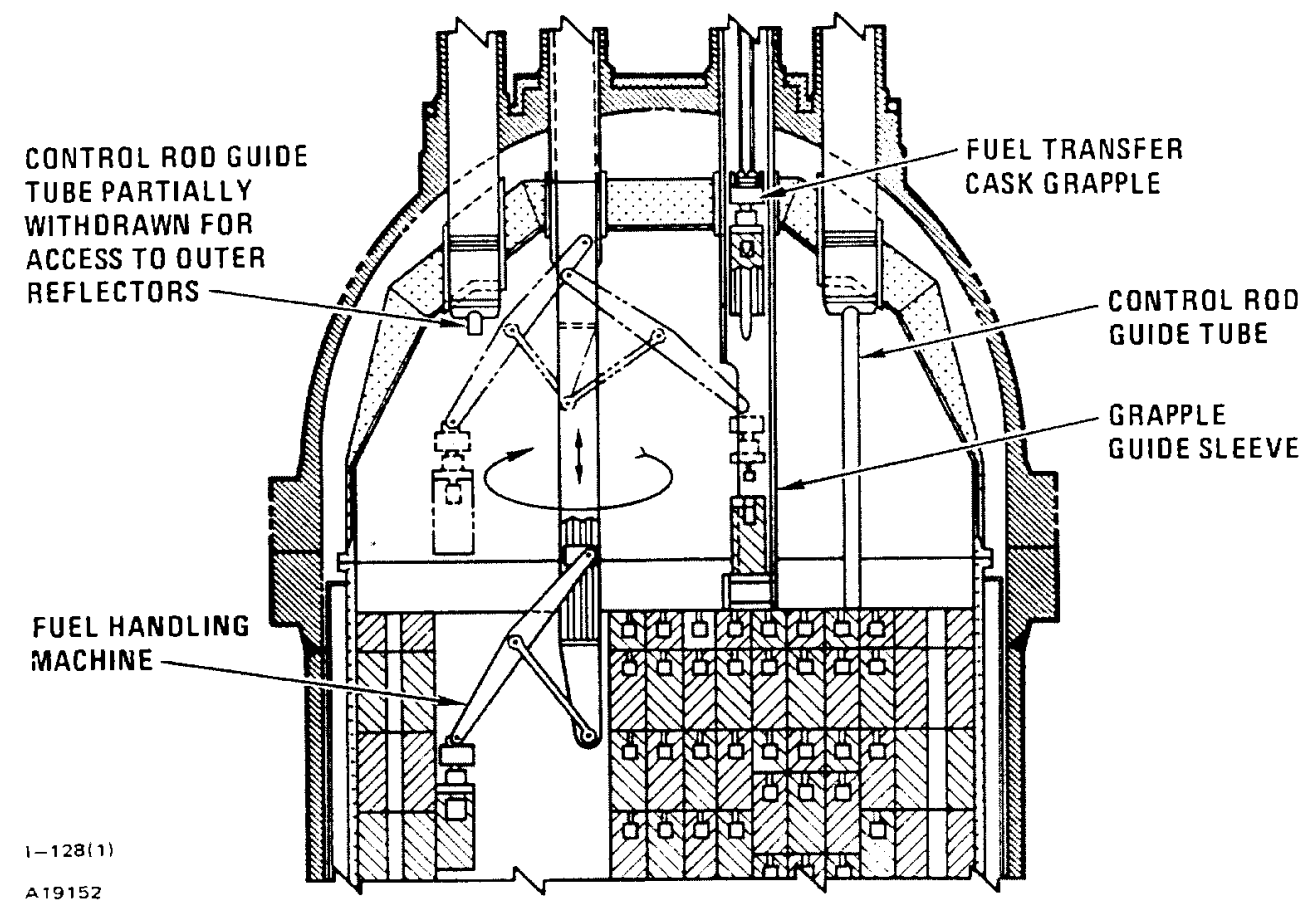

Figure 6. Diagram of the fuel handling equipment illustrating the need to move control rods to make room for refueling. ${ }^{32}$

In addition to the experience base accumulated over several decades, in particular operational experience from FSV, the basic HTGR technology and designs received extensive review by various program participants. According to GA, established designs, standards, codes, and procedures were in place for the MHTGR. There was no need for basic research, and design verification needs had been fully identified and were limited. ${ }^{32}$

The technology for the metallic materials was also well-established and it was determined that a sufficient database existed from the two MHTGRs operated in the U.S. ${ }^{32}$ The major criteria for the MHTGR internals (i.e. pressure, temperature, loading, seismic, radiological) were bounded by operating experience of Peach Bottom and FSV. ${ }^{32}$ All metallic internals in the MHTGR were to be made from alloy $800 \mathrm{H}$. 
One particular component worth mentioning is the hot gas duct. The integrity of this component was demonstrated during seven and one-half years of successful operation in the Peach Bottom Reactor. GA argues, "Since the MHTGR-NPR hot duct is designed from similar but higher grade materials $(800 \mathrm{H})$, and has approximately the same size and operating environment (temperature, gas velocity, acoustics, pressure, etc.), the existing technology base is directly applicable." ${ }^{32}$ The hot gas duct is exposed to the reactor outlet gas, which for Peach Bottom was $725^{\circ} \mathrm{C}$, and for the MHTGR was to be $690^{\circ} \mathrm{C}$. These temperatures are similar to the maximum operating temperatures expected for the NGNP control rods.

The Preliminary Safety Information Document for the MHTGR, published in $1986,{ }^{39}$ listed the control rod must maintain its geometry for positioning and withstand $704^{\circ} \mathrm{C}$ under normal operation and $1338^{\circ} \mathrm{C}$ during accident conditions, with a radiation environment of $1.4 \times 10^{19} \mathrm{n} / \mathrm{cm}^{2}$ in either case. Analysis indicated that during normal operating conditions, the inner reflector achieved a maximum temperature of $477^{\circ} \mathrm{C}$ and the outer reflector $327^{\circ} \mathrm{C} .{ }^{37}$ Considering that the control rods were located in the reflectors and that the outlet gas temperature was only $690^{\circ} \mathrm{C}$, the value of $704^{\circ} \mathrm{C}$ seems high for typical operating conditions, and likely incorporates a safety factor.

Design temperature limits were set for all components of the reactor. A design temperature limit of $1175^{\circ} \mathrm{C}$ was set for the outer control rods. Similarly $1600^{\circ} \mathrm{C}, 760^{\circ} \mathrm{C}$ and $480^{\circ} \mathrm{C}$ were the design temperature limits set for the fuel, core barrel, and reactor pressure vessel, respectively. ${ }^{33} \mathrm{~A}$ temperature of $1175^{\circ} \mathrm{C}$ is high for alloy $800 \mathrm{H}$ unless the exposure is brief, and withstanding $1338^{\circ} \mathrm{C}$ without geometric distortion is not possible since the beginning of the melting range is about $1350^{\circ} \mathrm{C}$. Supporting documents which justify $800 \mathrm{H}$ with these temperatures requirements have not been located.

\subsection{GT - MHR}

The Gas Turbine Modular High-Temperature Reactor (GT-MHR) is a more recent modification of the General Atomics prismatic reactor design. ${ }^{40,41}$ The basics of the core are the same as the MHTGR, with columns of graphite prismatic blocks forming the core and three annular rings of the blocks loaded with fuel to form the active core (see Figure 7). However, the GT-MHR design has a total of 48 rods. The outer reflector contains 36 control rods arranged in 12 groups with 3 control rods in each group, while the core contains 12 control rods arranged in 4 groups of 3 . The dimensions of the control rods and the specifics of the neutron absorber material are identical to those for the MHTGR shown in Table $2{ }^{4 !}$ 


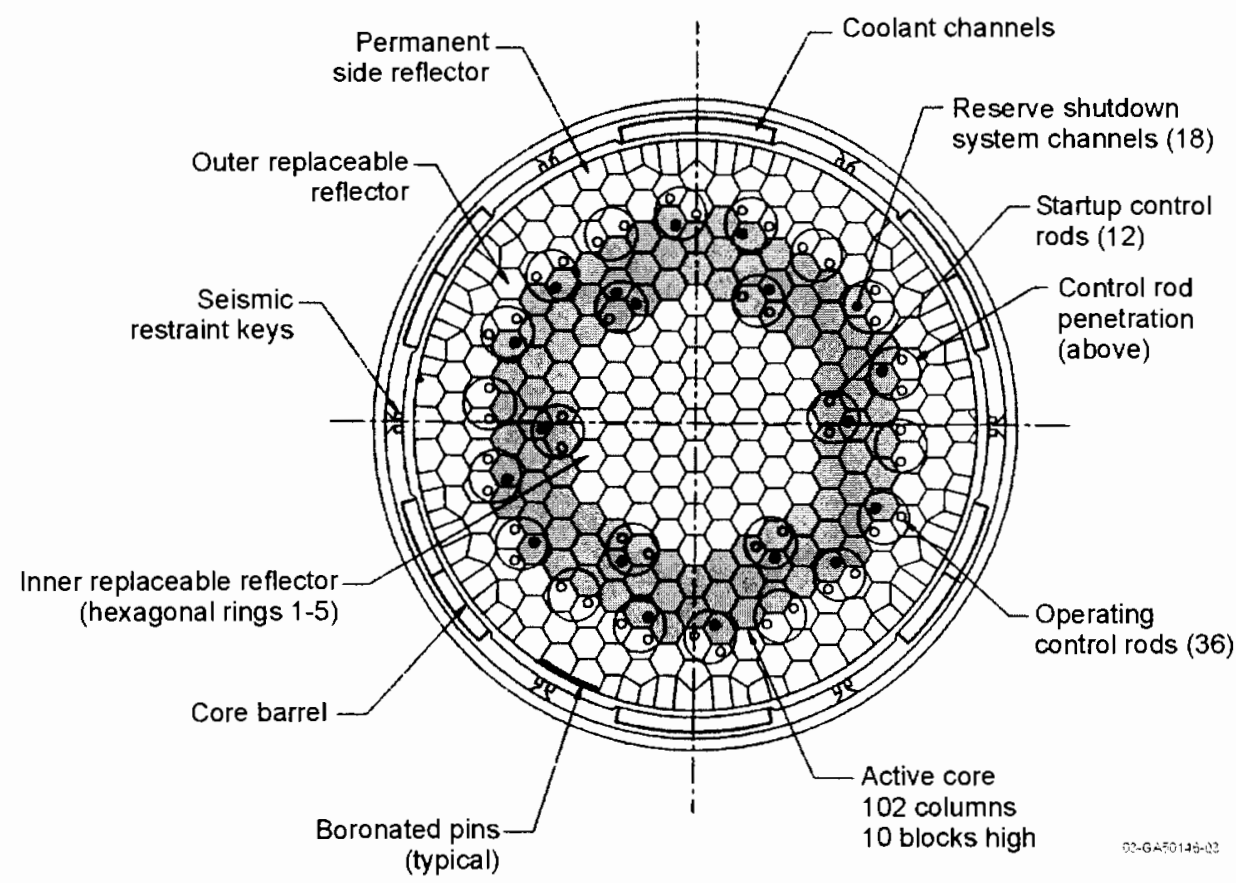

Figure 7. Cross-section of the Gas Turbine Modular High-Temperature Gas Reactor (GT-MHR) core showing the location of the control rods and shutdown (startup) rods. ${ }^{41}$

The baseline design for the GT-MHR calls for control rods with $800 \mathrm{H}$ canisters; however, $\mathrm{C}_{f} \mathrm{C}$ composite canisters are presented as an alternative. ${ }^{40,41}$ (One documents mention $\mathrm{C}_{\mathrm{f}} \mathrm{C}$ composites exclusively as the material selection for control rod sleeves. ${ }^{42}$ ) The obvious motivation for using composite control rods is the improved margin of safety the elevated temperature resistance would provide during normal operation and particularly under accident conditions. General Atomics presents another potential benefit of using high-temperature composite-clad control rods: power peaking (caused by regions of fresh and depleted fuel) could be reduced if the rods in the inner reflector are used as control rods rather than just shutdown rods. Fuel temperatures in the prismatic design could also be reduced by reducing by-pass flow, including in the control rod channels, which would likely require composite control rods as well. ${ }^{40,41}$

Neutron flux levels are monitored by six symmetrically spaced ex-vessel fission chamber thermal neutron detectors. The signals from these detectors interface with the automatic control and protection systems to operate the control rod drives or the reserve shutdown control equipment. Three fission chamber source-range detectors are used to monitor neutron flux during startup and shutdown from vertical channels near the bottom of the core. The in-core flux mapping system contains two independent fission chambers and a thermocouple which vertically move through the central column of the inner reflector and the outer permanent reflectors. ${ }^{41}$ 


\section{PBMR}

The Pebble Bed Modular Reactor (PBMR), to be built in South Africa beginning in 2007 and scheduled to go critical in 2010 , is the most important control rod design to study, because similar decisions are being made with contemporary technology and in the same global economy, although there may be significant differences in national politics, regulations, and public opinion. The decision to use $800 \mathrm{H}$ for the control rods in the PBMR provoked the external review committee to question the exclusive consideration of ceramic composites for this application in the NGNP, and resulted in this study.

At the beginning of the PBMR project, the decision was made to keep the development to an absolute minimum and rely on reported results from previous similar projects to the extent possible. ${ }^{43}$ The focus is on building a demonstration plant as soon as possible to confirm the safety, operations, construction schedule and economics of the design, and then market it globally. ${ }^{44}$

The PBMR builds on the German experience of the AVR and THTR; however, it will use a direct cycle to produce power rather than a steam generator, and it will have an annular core configuration with a solid graphite central reflector. The annular core produces several advantages: it shifts the peak power radially outward, thus enabling significantly higher output; it enhances the fuel safety margin; and, by increasing the neutron flux in the outer graphite reflector, it increases the effectiveness of the control and shutdown systems. ${ }^{22}$ A schematic of the PBMR core is shown in Figure 8.

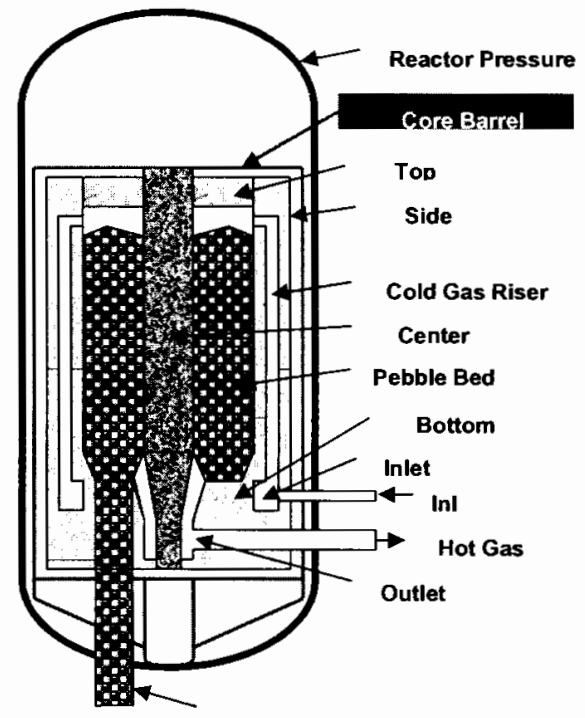

Figure 8. Schematic of the Pebble Bed Modular Reactor (PBMR) annular pebble bed reactor. ${ }^{45}$

The outlet gas temperature will be $900^{\circ} \mathrm{C}$ and will produce $400 \mathrm{MWt}, 164 \mathrm{MWe}$. The core will be $11 \mathrm{~m}$ high and $3.7 \mathrm{~m}$ in diameter, and the annulus will be filled with about $452,00060 \mathrm{~mm}$ diameter fuel pebbles. ${ }^{45}$ Table 3 compares these values and other reactor characteristics to the AVR and THTR. 
Table 3. Comparison of PBMR to previous operating pebble bed reactors (PBRs).

\begin{tabular}{|c|c|c|c|c|}
\hline Parameter & Unit & AVR & THTR & PBMR \\
\hline Service & years & 21 & 4 & 0 \\
\hline Power(t) & $M W t$ & 46 & 750 & 400 \\
\hline Power(e) & MWe & 13 & 300 & 165 \\
\hline Inlet gas $T$ & ${ }^{\circ} \mathrm{C}$ & 270 & 250 & 500 \\
\hline Outlet gas $\mathrm{T}$ & ${ }^{\circ} \mathrm{C}$ & 950 & 750 & 900 \\
\hline He pressure & $\mathrm{MPa}$ & 1.1 & 3.9 & 9.0 \\
\hline Power density & $\mathrm{MW} / \mathrm{m}^{3}$ & 2.6 & 6.0 & 4.8 \\
\hline Mass flow rate & $\mathrm{kg} / \mathrm{s}$ & 13 & 296 & 192 \\
\hline Core height & $\mathrm{m}$ & 2.8 & 6.0 & 8.0 \\
\hline Core diameter & $\mathrm{m}$ & 3.0 & 5.6 & $3.7^{\mathrm{a}}$ \\
\hline \# of pebbles & $\times 1000$ & 100 & 675 & 450 \\
\hline
\end{tabular}

In contrast to a prismatic reactor which is periodically shutdown for refueling, a pebble bed reactor (PBR) is constantly refueled, with pebbles loaded in the top and gradually moving down through the reactor. After exiting the core through a hopper at the bottom of the reactor, the pebbles are assayed, and if insufficient burn-up is achieved, they are returned to the top of the core along with new fuel. Pebbles typically make about six passes through the core. ${ }^{46}$ When the reactor is initially started, a mixture of lower enrichment fuel pebbles and pure graphite pebbles will be used. ${ }^{43}$ The control rods must be fully inserted and will gradually be raised until the proper mixture of fuel is achieved and steady state is reached. At that point, the reactor will always have a mixture of fuel pebbles which are new (fully enriched) and at various stages of depletion. The maximum core temperature for a PBR is significantly lower than for a prism design of the same power, coolant flow rate, and reactor gas outlet temperature. ${ }^{44}$ The cooling in a pebble bed core is much more efficient because the fluid can run between all the pebbles, where in the prism design it can only run through the cooling channels (with the exception of a relatively small amount of bypass flow.)

The Reactor Control and Shutdown System (RCSS) has two components: the Reactivity Control System (RCS) and the Reserve Shutdown System (RSS). The RCS consists of 12 control rods and 12 shutdown rods, located in the outer reflector. ${ }^{43}$ They are evenly spaced around the core and at a radial distance of about $7 \mathrm{~cm}$ from the inner surface of the reflector (see Figure 9) ${ }^{47}$ During normal operation the control rods, which penetrate a maximum distance of $150 \mathrm{~cm}$ into the core, ${ }^{47}$ are used for minor reactivity adjustments to keep the reactor critical, provide reactivity compensation for xenon poisoning effects during load following effects, ${ }^{48}$ and allow for some excess reactivity so the reactor may continue operation for some time if no fuel is being loaded. ${ }^{49}$ They are also used for hot shutdown purposes. ${ }^{43}$ The reactor power is actually adjusted by regulating the mass flow rate of the gas inside the primary circuit rather than by adjusting the control rods. ${ }^{22,43}$ During scram, the additional 12 shutdown rods are lowered to the bottom of the active core. In the event of the loss of electrical power, insertion of the rods is by gravity. The first set of control rods will drop, and later the shutdown rods will drop, should the need arise. 


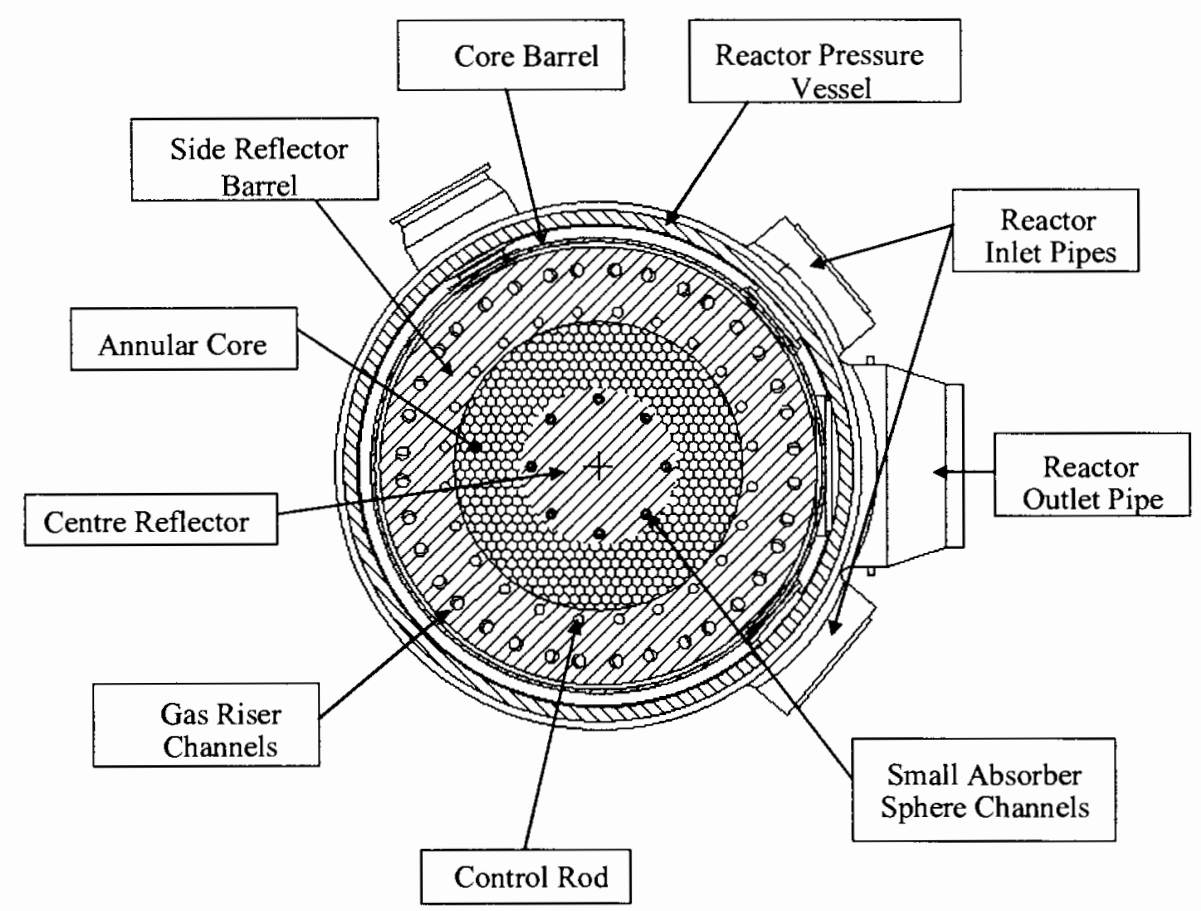

Figure 9. Top view of the core, showing the location of the control rod channels, fuel pebbles, small absorber sphere channels, and other features. ${ }^{50}$

The RSS consists of eight storage containers of $1 \mathrm{~cm}$ diameter Small Absorber Spheres containing $\mathrm{B}_{4} \mathrm{C}$ that can be fed by gravity into eight channels in the central reflector. The RSS serves as both the secondary shutdown system and the cold shutdown system. It must be activated in addition to the RCSS to bring the PBMR to a cold shutdown condition $\left(100^{\circ} \mathrm{C}\right)$.

The control rod design is similar to previous metal control rods. A schematic is shown in Figure 10. A number of annular $\mathrm{B}_{4} \mathrm{C}$ rings are encased between two tubes of $800 \mathrm{H}$, to form a section about a meter long. One unique feature is that the inner tube is much thinner than the outer tube. These sections are mechanically linked to form an articulated control rod several meters long. Another difference from past designs is that the control rod is suspended from the drive mechanism by a chain, rather than a cable. A secondary shock absorber is in place in the channel below the control rod to protect it and the core structure in the event of a chain failure. Additional shock absorbers within the drive mechanism dampen the impact load on the control rod drives during scram. ${ }^{43}$ A control rod guide tube (not shown in Figure 10) connects the control rod drive mechanism to the core structure to guide the control rod into the core as the name implies. ${ }^{51}$ 


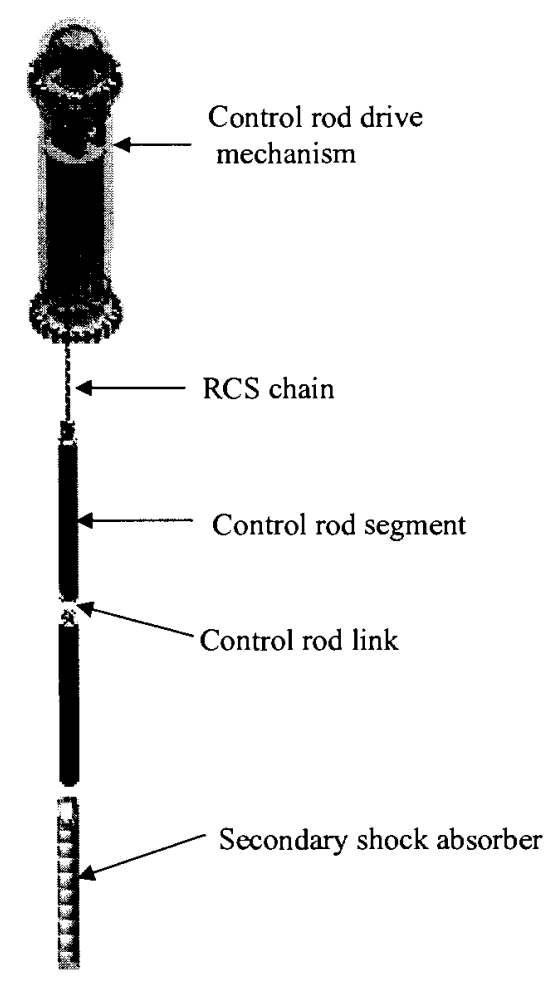

Figure 10. Schematic of the control rod assembly in the PBMR. ${ }^{52}$

There is no design code in place, so the design is by analysis, based on first principles, and will be supported by full component testing in a He testing facility. The design of the control rod considers creep, oxidation, carburization, thermal embrittlement, and neutron embrittlement. Although the control rod application is outside the current ASME allowable limits with respect to temperature, loading and design life, PBMR personnel contend (to the NRC) that material testing is not required because design data is available in non-ASME international standards. ${ }^{45}$

During normal operation, the temperature of the control rods is estimated from about $650^{\circ}$ to $700^{\circ} \mathrm{C},{ }^{4,53}$ and the temperature resulting from DLOC is only $850^{\circ} \mathrm{C}^{53}$ The end of life fast fluence is reported as $2 \times 10^{22}(\mathrm{E}>0.1 \mathrm{MeV}),{ }^{45}$ and the thermal fluence is reported as $5 \times 10^{21} \mathrm{n} / \mathrm{cm}^{2}{ }^{53}$ The secondary shock absorbers have an operating temperature of $900^{\circ} \mathrm{C}$; during DLOC, they can be subjected to temperatures up to $1100^{\circ} \mathrm{C}$ for short periods. Under these conditions the use of $800 \mathrm{H}$ is justified by the PBMR program, which claims ${ }^{53}$ : (a) the high temperature strength and creep resistance are sufficiently qualified for long term normal operation at $700^{\circ} \mathrm{C}$, (b) limited operation at $850^{\circ} \mathrm{C}$ under abnormal events can be tolerated according to available data, (c) the irradiation response has been characterized to high levels of fast fluence, and (d) $800 \mathrm{H}$ control rods have had "extensive qualification" in previous German HTR programs.

The PBMR design includes specialized equipment to remove and replace the control rods, as well as storage for used control rods. The RCSS will be inspected every six years during the scheduled 
maintenance outage, and repaired as necessary. These outages are planned to last 30 to 50 days, depending on the other maintenance scheduled, with the exception of a 180 day shutdown after 24 years to replace the core reflector. ${ }^{47,54}$

The PBMR design does call for the use of carbon/carbon ceramic composites in the application of tie rods to connect the top reflector to the core barrel top plate, and restraint straps to support the outside of the outer reflectors. Plans are to use commercial grade materials to reduce the development and screening required. Both applications have a predicted normal operating temperature of $500^{\circ} \mathrm{C}$ and a fluence of $<2 \times 10^{20} \mathrm{n} / \mathrm{cm}^{2}$ after 24 full-power years. Because of these low temperatures and fluence conditions, irradiation studies are not required at this point. Similarly, the minimal oxidizing impurities in the coolant make oxidation studies on the composites optional.

Eventually, it is hoped that a PBMR design reactor can run with an outlet temperature of $1000^{\circ} \mathrm{C}$ or even higher. In this case, $\mathrm{C}_{\mathrm{f}} / \mathrm{C}$ composites must be considered for more rigorous temperatures of the control rods. ${ }^{53}$ future research requirements would increase substantially to develop the component. While it is not considered a safety application, ${ }^{55}$ it will require qualification for nuclear application. PBMR personnel are participating in composite ASME code development activities under Section III of Boiler and Pressure Vessel (B\&PV) Code. ${ }^{56}$ 


\section{DEFINITION OF REQUIREMENTS}

The requirements for control rods in the NGNP are significantly different than those reported previously. ${ }^{2,57,58}$ Ceramic matrix composites have been the primary candidates for this application because this component was identified as requiring high thermal stability, good fracture toughness, and high irradiation stability. In reality, the requirements are much less severe than originally assumed. This is in part because the target outlet gas temperature has been lowered from $1000^{\circ} \mathrm{C}$ to somewhere between 850 $950^{\circ} \mathrm{C}$, but primarily because the actual conditions the control rods will be subjected to had not been examined in detail and were not properly understood.

\subsection{Temperature}

The temperature the control rods will experience is one of the critical factors in determining the need for composites. Many of the NGNP program documents produced to date routinely cite this temperature as $1250^{\circ} \mathrm{C}$ for normal conditions and as high as $1500^{\circ} \mathrm{C}$ during a loss of coolant accident, also known as depressurized conduction cooling (DCC), low pressure conduction cooling, or loss of pressurized coolant. However, these temperatures are actually the maximum calculated fuel temperatures for the normal operating and DCC condition.

Recent modeling has proven useful in giving a more realistic estimate of the temperature profiles and histories the control rods will experience for both a prismatic and pebble bed designs. These thermalhydraulic calculations were performed with best estimate rather than conservative assumptions. Although the control rods were not explicitly modeled since the intent was to determine the temperatures of the reactor pressure vessel, temperatures at or near the control rod locations can be extracted from these models. ${ }^{59}$

\subsubsection{Prismatic}

Figures 11 and 12 show axial temperature profiles representing the control rods in the outer reflectors of the prismatic design. The profiles are actually determined at a location just outside the active core on the inner surface of the outer reflector. The RELAP5-3D model of Gougar and Davis (2006) was revised to provide a better estimate of the temperature of the outer reflector during normal operation. ${ }^{6061}$ Adjustments were made to the bypass flow paths to more accurately reflect the conditions in the vicinity of the outer control rods. The outer surface of the heat structure representing the outermost fuel ring was also thermally connected to the outer bypass path. The revision to the model had almost no impact on any of the output parameters except for the temperature of the outer reflector at the radial centerline of the coolant channel for the operating control rods. The maximum temperature of the reflector was obtained near the bottom of the core and would be representative of an operating control rod only if it were fully inserted into the core.

The model still does not explicitly represent the control rod geometry or operating conditions. The inside and outside surfaces of the canisters are cooled by the downwards flow of helium during normal operation. An operating control rod could generate significant power due to gamma heating and the scattering/absorption of neutrons when it is partially inserted into the core during normal operation. However, the orifice controlling the flow into the control rod coolant channel could be adjusted to obtain adequate cooling during normal operation.

Results are presented at $0.0 \mathrm{~h}$, corresponding to normal, full-power operation, and at $83.3 \mathrm{~h}$, which is near the time of the peak temperatures during the DCC accident for normal coolant outlet temperatures of 900 and $950{ }^{\circ} \mathrm{C}$. 


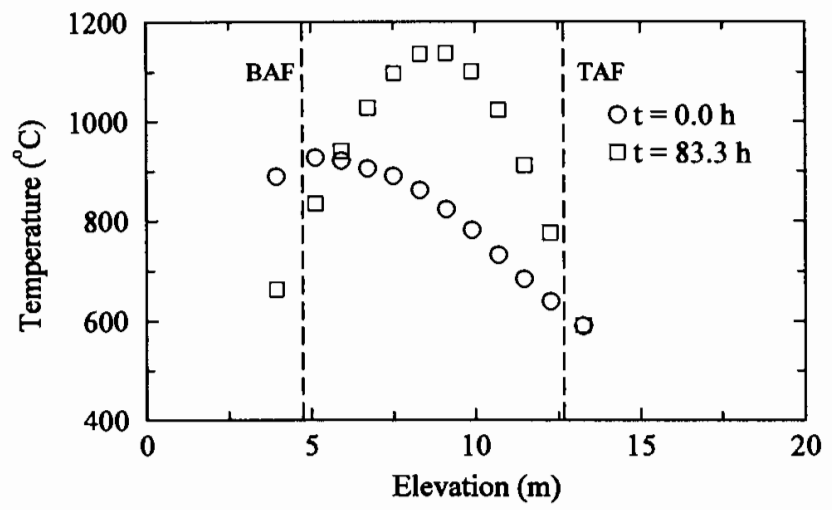

Figure 11. Axial temperature profiles of the outer reflector surface temperature for the prismatic VHTR $\left(\mathrm{T}_{\text {out }}=950^{\circ} \mathrm{C}\right) . \mathrm{BAF}=$ bottom of active fuel, $\mathrm{TAF}=$ top of active fuel.

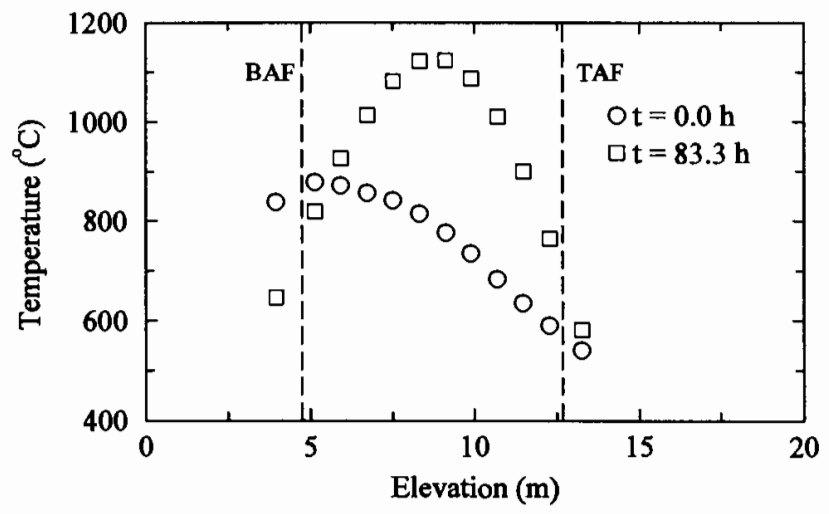

Figure 12. Outer reflector surface temperature for the prismatic VHTR $\left(\mathrm{T}_{\text {out }}=900^{\circ} \mathrm{C}\right)$.

The maximum temperature of the graphite reflector during normal operation $(0 \mathrm{~h})$ is $927^{\circ} \mathrm{C}$, which exceeds the maximum allowable value in the ASME code for Incoloy $800 \mathrm{H}$. However, an operating control rod is not expected to be fully inserted into the core during normal operation. Inserting the operating control rod $30 \%$ into the core yields a maximum temperature of $732^{\circ} \mathrm{C}$, which should be within the capability of metallic control rods. Furthermore, the orifice in the control rod flow channel can be sized to provide the required cooling. Thus, the use of metallic operating control rods appears feasible during normal operation. This conclusion is consistent with General Atomics' most recent design. ${ }^{40}$ The temperature profile is almost monotonic, with the minimum temperature occurring near the top of the active fuel (TAF) and the maximum temperature occurring near the bottom of the active fuel (BAF). The temperature profile shifts during the accident so that the maximum value occurs near the peak power location which is near the axial center of the core. Normal operating temperatures for the prismatic reactor are in the range of $600-900^{\circ} \mathrm{C}$, much less than the previously assumed $1250^{\circ} \mathrm{C}$. Even the estimated maximum accident temperature of $1153^{\circ} \mathrm{C}$ is less than that value, and $\sim 300^{\circ} \mathrm{C}$ less than the 
previous calculations for accident temperature. (Note that while the operating temperature varies with the outlet gas temperature, the maximum accident temperature remains about the same.)

The prismatic design has a set of shutdown rods located in the active core in the inner fuel ring. These rods will be identical to the control rods in both design and material, but they are only required for cold shutdown of the reactor, which is typically defined as less than about $400^{\circ} \mathrm{C}$. Therefore, they are not inserted into the core during normal operation or accident conditions.

The model was used to analyze the temperature profiles for the shutdown rods as determined at the coolant channel surface if they were inserted during normal operation and DCC, or alternatively if a liner resided in the channel. These results, shown in Figures 13 for an outlet temperature of $950^{\circ} \mathrm{C}$, are in the same range as the original temperatures composite researchers have been assuming, and illustrate the basis of those much higher temperature requirements.

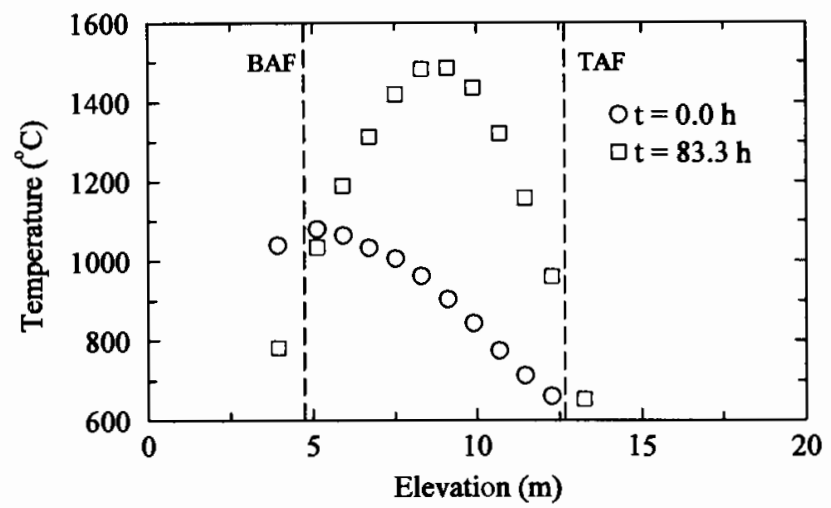

Figure 13. Coolant channel surface temperature for the inner fuel ring in the prismatic VHTR $\left(T_{\text {out }}=\right.$ $\left.950^{\circ} \mathrm{C}\right)$.

Since the shutdown rods are not inserted into the core, portions of the rods are located in the inlet plenum above the core. Figure 14 shows the calculated gas temperature in the inlet plenum of the reactor during the accident. Although not visible in the figure because of the time scale, the gas temperature initially decreases because of the depressurization. The temperature then increases until $85 \mathrm{~h}$, when it reaches a maximum calculated temperature of $590^{\circ} \mathrm{C}$. This relatively low value should preclude concerns about this region for metallic control rods. The maximum temperature could be higher than the calculated value, because the model neglects axial and radial temperature variations in this region. Also, temperatures would probably be higher during a pressurized conduction cooldown accident than a depressurized accident because natural convection at higher pressure would transfer more energy from the center of the core to the inlet plenum. For these reasons, further analysis is probably warranted. Nonetheless, issues relative to the temperature of the rods in the inlet plenum are expected to be much less severe than those described above for the operating control rods. 


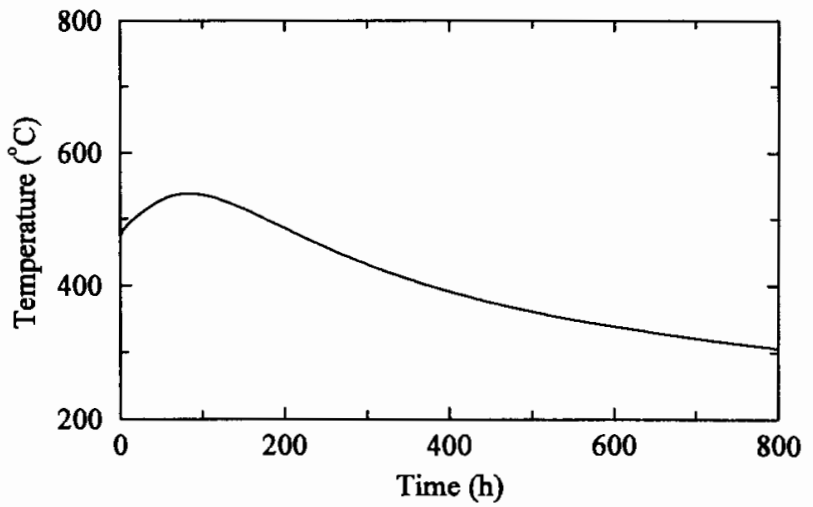

Figure 14. Average gas temperature in the inlet plenum during a DCC accident (Tout $=950^{\circ} \mathrm{C}$ ).

\subsubsection{Pebble Bed}

The control rods in the PBR are located in the outer reflector about 5 to $10 \mathrm{~cm}$ from the outer edge of the core. The axial temperature profiles calculated using RELAP5-3D $\mathrm{D}^{61}$ are plotted at a location about $7.5 \mathrm{~cm}$ from the edge of the core. Figures 15 and 16 present results for outlet temperatures of 950 and $900^{\circ} \mathrm{C}$, respectively, at two times: $0.0 \mathrm{~h}$ which corresponds to normal, full-power operation and $83.3 \mathrm{~h}$, the time of the peak temperature during $\mathrm{DCC}$.

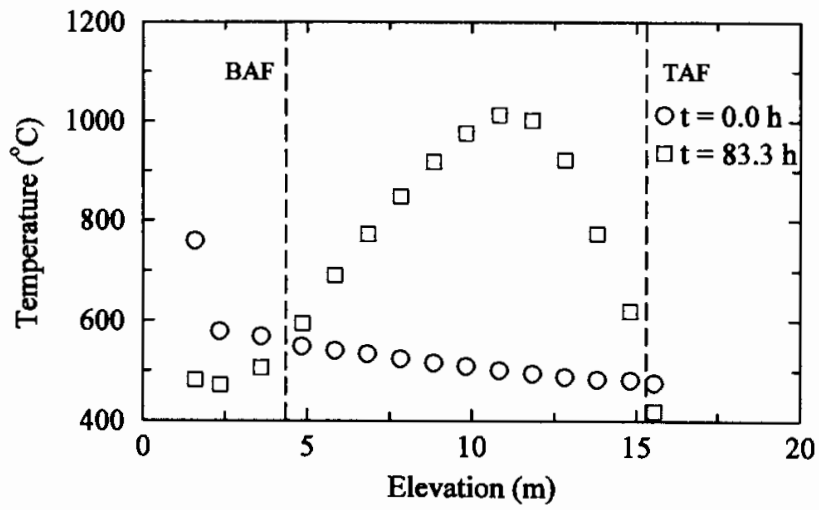

Figure 15. Outer reflector temperature for the pebble-bed VHTR $\left(\mathrm{T}_{\text {out }}=950^{\circ} \mathrm{C}\right)$. 


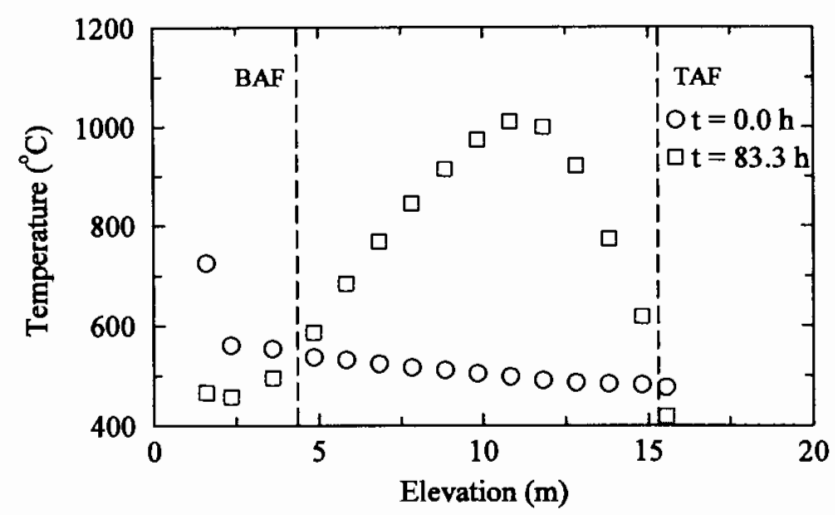

Figure 16. Outer reflector temperature for the pebble-bed VHTR $\left(\mathrm{T}_{\mathrm{out}}=900^{\circ} \mathrm{C}\right)$.

According to the RELAP5-3D results, the operating temperatures for the pebble bed reactor are predicted to be slightly less but similar to the prismatic operating temperatures, less than $600^{\circ} \mathrm{C}$. The maximum accident temperatures are about $150^{\circ} \mathrm{C}$ less than the prismatic accident temperatures, and almost $500^{\circ} \mathrm{C}$ less than previously assumed.

For the PBR, analyses were also performed with the PEBBED-THERMIX computer code. ${ }^{62}$ Although not extensively validated, it was developed specifically for PBR design and analysis. Figure 17 shows the temperature profile for the control rod location calculated by the PEBBED-THERMIX code. Comparing these results to those shown in Figure 15, it is clear that this method predicts higher maximum temperatures for both the operating and accident condition. However, they are still lower than the very high temperatures previously assumed.

The dotted line in Figure 17 shows the position of the control rod, $150 \mathrm{~cm}$ from the top of the core, during normal operation. (Although not shown, this position is the same for pebble bed Figures 15 and 16.) The temperature at this position is nearly $200^{\circ} \mathrm{C}$ less than at the bottom of the active core. Therefore, for the vast majority of the time, the control rod is exposed to temperatures in the range of $500^{\circ} \mathrm{C}$, rather than the maximum operating temperature. 


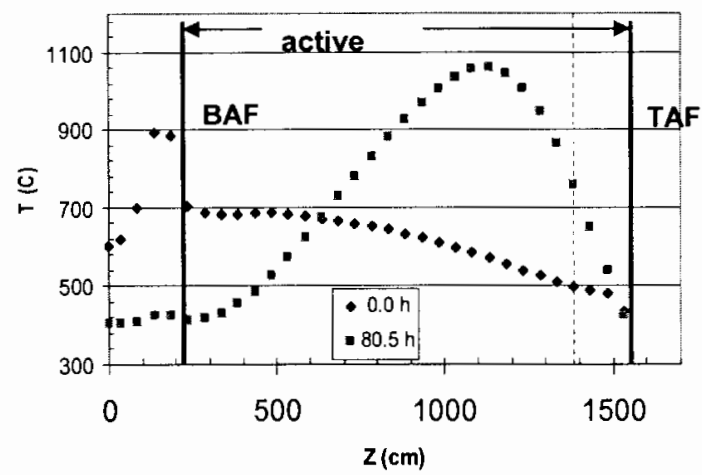

Figure 17. Outer reflector temperature for the pebble-bed VHTR $\left(\mathrm{T}_{\text {out }}=950^{\circ} \mathrm{C}\right)$ calculated using PEBBED-THERMIX. The dotted line shows the position of the control rod during normal operation.

\subsection{Exposure Time for Off-Normal Events}

During scram the control rod is inserted all the way to the bottom of the core (Bottom of Active Fuel Zone [BAF] position in Figures 11 thru 17) so the control rod reaches the maximum normal operating temperature; however, scram begins the process of cooling the core, and for most off-normal events the temperature exposure is limited. There are certain accident scenarios, such as loss of flow, loss of pressure, or loss of coolant, where the passive safety feature of the reactor is relied upon. Of these scenarios, DCC (also known as loss of pressurized coolant) is generally recognized as the most severe in terms of producing maximum temperatures. The high peak temperature results in long exposure time at elevated temperature for the reactor as the huge thermal mass of the core slowly cools.

The DCC temperature profiles were shown in Figures 11 thru 17, along with the normal operating temperature profiles. The maximum temperatures were discussed in the previous section, and that temperature is obtained about 80 hours after the start of the accident and then decreases very slowly. Figure 18 shows an example of the temperature history at the outer reflector control rod location after DCC, calculated for 900 and $950^{\circ} \mathrm{C}$ outlet temperatures using RELAP5-3D. The temperature remains above the current ASME maximum use temperature for 430 hours. Figure 19 presents a similar plot for the pebble bed design, calculated using the PEBBED-THERMIX code. Although this plot only extends to 100 hours; the temperature is above the maximum ASME use temperature for nearly 600 hours and above the normal pebble bed control rod operating temperature $\left(\sim 600^{\circ} \mathrm{C}\right)$ for about 1500 hours. These results indicate that the control rods could remain at elevated temperatures for nearly a month or more, if only the passive decay heat removal system is available; although the operators could probably restore active cooling in much less time. Such extended high-temperature exposure can result in problems that will either eliminate metals as a choice for control rod sheathing, or require component replacement if such an incident occurs. Alternatively, design solutions could be implemented: it is not yet certain that control rods must be inserted immediately for all accident scenarios such as DCC. 


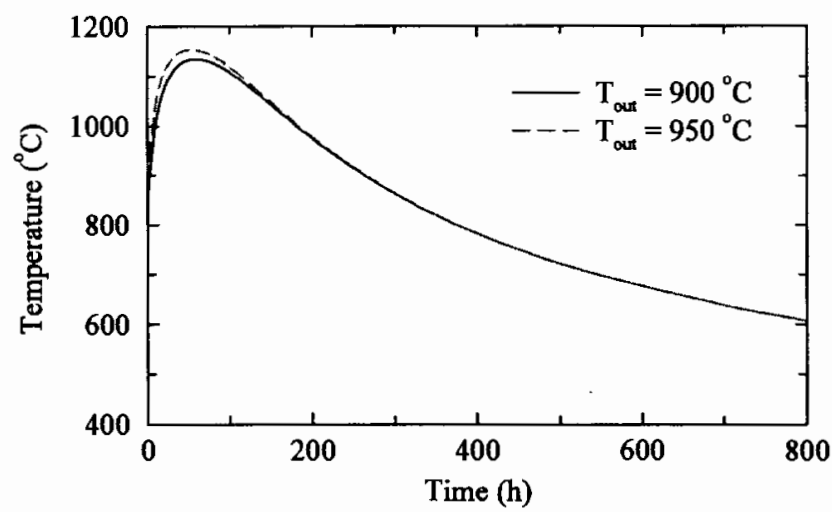

Figure 18. Temperature history of control rods in the prismatic reactor with 900 or $950^{\circ} \mathrm{C}$ outlet temperature during a DCC accident.

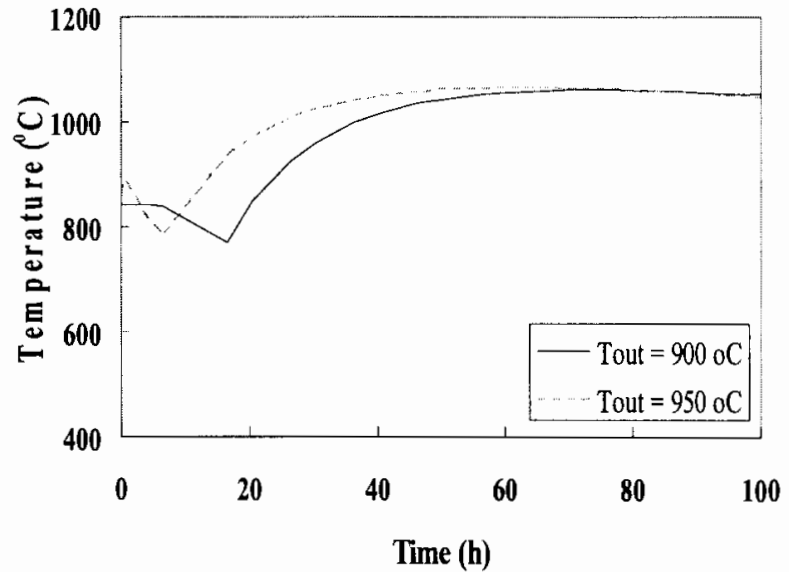

Figure 19. Temperature history of control rods in PBR with 900 or $950^{\circ} \mathrm{C}$ outlet temperature after scram due to DCC accident. 


\subsection{Radiation Dose}

As was the case for the temperature, the radiation exposure the control rods were expected to withstand was estimated from the maximum values within the core. The fast neutron flux of $0.5 \times$ $10^{21} \mathrm{n} / \mathrm{cm}^{2} / \mathrm{yr}$ was assumed, so a component that could last the entire 60 -year target lifetime of the reactor would see a total fluence of $30 \times 10^{21} \mathrm{n} / \mathrm{cm}^{2}$.

\subsubsection{Prismatic}

The dose to which the control rod will be exposed can be calculated from the neutronics analysis performed throughout the prismatic core. ${ }^{63}$ The control rod is in the first ring of replaceable graphite blocks in the outer reflector. The block average values are shown in Table 4 . The fluence per year values are based on a $90 \%$ capacity factor and are for a graphite block average. Since the control rods are closer to the edge of the core, the block average values in Table 4 would probably be slightly lower than the unperturbed flux in the control rod location because it is closer to the active core; however, this will be offset by the neutron absorption of the control rod, which will reduce the local power and subsequently reduce the local neutron fluence to the control rods themselves.

Table 4. Radiation flux profile at the control rod location for the NGNP prismatic reactor design.

\begin{tabular}{|c|c|c|c|c|c|c|}
\hline \multirow{2}{*}{$\begin{array}{l}\text { Energy Range } \\
\mathrm{eV}\end{array}$} & \multirow[t]{2}{*}{ Energy Group } & \multirow{2}{*}{$\begin{array}{c}\text { Peak Flux } \\
\mathrm{n} / \mathrm{cm}^{2} / \mathrm{s} \times 10^{12}\end{array}$} & \multicolumn{4}{|c|}{ Fluence $\mathrm{n} / \mathrm{cm}^{2} \times 10^{21}$} \\
\hline & & & $1 \mathrm{yr}$ & $10 \mathrm{yrs}$ & $20 \mathrm{yrs}$ & $60 \mathrm{yrs}$ \\
\hline$>0.1 \mathrm{MeV}$ & 1 (fast) & 5.0 & 0.14 & 1.4 & 2.8 & 8.4 \\
\hline $1.4 \mathrm{eV}-0.1 \mathrm{MeV}$ & 2 & 18.9 & 0.54 & 5.4 & 11 & 32 \\
\hline$<1.4$ & 3 (thermal) & 84.5 & 2.4 & 24 & 48 & 144 \\
\hline Total & & 108.5 & 3.1 & 31 & 62 & 184 \\
\hline
\end{tabular}

\subsubsection{Pebble Bed}

For a $600 \mathrm{MWt}$ Pebble Bed HTGR, the fluence near the control rods under constant full power are given in Table 5 below. ${ }^{47}$ The control rods are assumed to be in the normal operating position which is partially inserted to a depth of $150 \mathrm{~cm}$ from the top.

Table 5. Radiation flux profile at the control rod location for the NGNP pebble bed reactor design.

\begin{tabular}{llccccc}
\hline Energy Range & Energy Group & \multicolumn{2}{c}{$\begin{array}{c}\text { Peak Flux } \\
\mathrm{eV}\end{array}$} & $\mathrm{n} / \mathrm{cm}^{2} / \mathrm{s} \times 10^{12}$ & \multicolumn{5}{c}{ Fluence $\mathrm{nr}$} & $10 \mathrm{~cm}{ }^{2} \times 10^{21}$ \\
\hline$>0.1 \mathrm{MeV}$ & 1 (fast) & 4.2 & 0.13 & 1.3 & $20 \mathrm{yrs}$ & $60 \mathrm{yrs}$ \\
\hline $1.86 \mathrm{eV}-0.1 \mathrm{MeV}$ & $2-5$ & 14.1 & 0.45 & 4.5 & 8.9 & 26.9 \\
$<1.86$ & 6 (thermal) & 54.0 & 1.7 & 17 & 34 & 100 \\
\cline { 3 - 7 } Total & & 72 & 2.3 & 23 & 46 & 135 \\
\hline
\end{tabular}

It is interesting how close the fast fluence values for the two reactor designs are, though not too surprising since the location of the control rods in the outer reflector is similar. With a 60 -year fast fluence of $7.9-8.8 \times 10^{21} \mathrm{n} / \mathrm{cm}^{2}$, the estimated radiation dose is reduced by about a factor of 3.5 from the value of $30 \times 10^{21} \mathrm{n} / \mathrm{cm}^{2}$ used previously. 


\subsection{Environment}

The He coolant in the primary circuit contains low levels of impurities after steady-state operation that can lead to environmental degradation of high temperature materials used for core internals and heat exchangers. Depending on the coolant impurity concentration and the temperature, high-temperature alloys can undergo oxidation, carburization, or decarburization. $\mathrm{SiC}_{\mathrm{f}} / \mathrm{SiC}$ composites can experience a decrease in strength in mild oxidizing environments, presumably from loss of the interfacial $\mathrm{C}$ layer. ${ }^{64}$

Table 6 shows the impurity levels reported for steady-state operation for several of the Very High Temperature Gas Reactors (VHTRs). ${ }^{5,65-67}$ As shown in the table, at steady-state, all of the reactors for which operating data are available had similar levels of impurities. Some caution should be exercised when comparing the data for different plants, since, in some cases, there are varying values reported in different publications for the same plant. This may be associated with conversion from partial pressure of impurities (the preferred units for corrosion studies) to ppm by volume (the typical units used for comparison of one plant to another).

Table 6. Impurities reported in the He coolant during steady-state operation of VHTRs (in ppm). ${ }^{5,65-67}$

\begin{tabular}{lccccccc}
\hline & $\mathrm{H}_{2} \mathrm{O}$ & $\mathrm{H}_{2}$ & $\mathrm{CO}$ & $\mathrm{CO}_{2}$ & $\mathrm{CH}_{4}$ & $\mathrm{O}_{2}$ & $\mathrm{~N}_{2}$ \\
\hline Dragon & 0.1 & 0.1 & 0.05 & 0.02 & 0.1 & 0.1 & 0.05 \\
Peach Bottom & 0.5 & 10 & 0.5 & $<0.05$ & 1.0 & - & 0.5 \\
Fort St. Vrain & 1 & 7 & 3 & 1 & 0.1 & - & - \\
AVR & 0.15 & 9 & 45 & 0.25 & 1 & & 22 \\
THTR & $<0.01$ & 0.8 & 0.4 & 0.2 & 0.1 & & 0.1 \\
\hline
\end{tabular}

The AVR was used for experiments on the origin of impurity species in the He coolant, kinetics of reactions between impurities and the reactor system, and gas-gas reactions. ${ }^{66,67}$ It was determined that approximately 10 to $20 \%$ of the $\mathrm{H}_{2}$ in the AVR could be accounted for by adsorption on the 50 new pebbles that were added to the core each day. The remaining $\mathrm{H}_{2}$ was thought to arise from diffusion into the reactor from steam in the secondary circuit. $\mathrm{H}_{2}$ is strongly adsorbed by the graphite in the reactor core, which tends to limit the amount circulating with the coolant.

Another major source of impurities has been lubricant from the He circulators back streaming into the coolant during start-up. The FSV plant had very high moisture levels during start-up due to water from the water-lubricated steam-driven He circulators back streaming into the pressure vessel and impregnating the insulation on the interior of the concrete pressure vessel. ${ }^{28,65}$

The generation of dust and particulates in the reactor could also be significant, especially in pebble bed reactors. It appears the generation rate of dust scales with the size of the core. It was shown in the THTR that $65 \mathrm{~kg}$ of graphite from the reflectors was oxidized and presumably removed as particulate during the total period of plant operation of about two years. ${ }^{14}$ The rate of dust production in AVR was estimated to be $3 \mathrm{~kg}$ per year. ${ }^{12}$ The THTR had approximately 675,000 fuel pebbles, but the AVR was a relatively small experimental reactor that contained approximately 100,000 pebbles. The PBMR, undergoing final design in South Africa, calls for approximately 450,000 pebbles in the full core.

Based on operating experience for several of the VHTRs, ${ }^{66,67}$ expected impurity levels for the PBMR have been determined. ${ }^{68}$ The predicted values are shown in Table 7 . The range in impurity level is due to the efficiency allocated to the Helium Purification System (HPS), which could range from 20 to 
$100 \%$, depending on the capacity of HPS and the actual impurity levels entering the HPS. The wide range of $\mathrm{N}_{2}$ levels is based on whether or not a cryogenic trap is placed in the system.

Table 7. Expected levels of impurities in the PBMR. ${ }^{68}$

\begin{tabular}{llll} 
& & \multicolumn{2}{l}{ Impurity Partial Pressure } \\
\cline { 3 - 4 } Gaseous Element & $\begin{array}{l}\text { Concentration } \\
\text { (ppmv) }\end{array}$ & $\begin{array}{l}(\mu \text { bars }) \\
(\text { S } \text { System Pressure of 90bar }\end{array}$ & $($ Pa $)$ System Pressure of 9MPa \\
\hline $\mathrm{H}_{2}$ & $2-11$ & $180-1000$ & $18-100$ \\
$\mathrm{H}_{2} \mathrm{O}$ & $<0.2$ & $<18$ & $<1.8$ \\
$\mathrm{CO}$ & $2-11$ & $180-1000$ & $18-100$ \\
$\mathrm{CO}_{2}$ & $<0.2$ & $<18$ & $<1.8$ \\
$\mathrm{CH}_{4}$ & $<0.1$ & $<10$ & $<1$ \\
$\mathrm{~N}_{2}$ & $3-115$ & $270-10000$ & $27-1000$ \\
$\mathrm{He}$ & Remainder & Remainder & Remainder \\
\hline
\end{tabular}

Several plants have undergone extensive post-mortem analysis of the core internals and heat exchangers. ${ }^{5,65}$ There are reports of some oxidation and at least one report of massive deposition of $\mathrm{C}$ on the internals; however, there have been no problems with failure of components on the primary side associated with environmental effects. However, there are two significant issues that remain to be investigated with respect to possible environmental interactions in the NGNP: environmental interaction at reactor pressure and the influence of very high velocity gas on the environmental interaction. While it is anticipated that the reaction mechanism determined using low-pressure test loops will also be observed at high pressure, there is some concern that the kinetics of reaction will be altered. Although, as noted above, particulate erosion is not expected to be of concern, it is possible that the steady-state gas chemistry at the specimen surface could be considerably different with high-velocity flow.

\subsection{Strength}

It has been determined that the NGNP control rods require only modest strength and fracture toughness. ${ }^{69}$ The static load required has been reported as 3 to $5 \mathrm{MPa}$, and the dynamic load, which is the load that would result from attempting to extract a "stuck" rod, would be 6 to $10 \mathrm{MPa}{ }^{70}$ However, the origin of these calculations or estimates has not been determined. An issue of concern to the PBMR staff is impact properties in the event that the chain suspending the control rod breaks. The shock absorber must limit the force of impact to less than $1.5 \mathrm{~g}$ when stopping a control rod of $180 \mathrm{~kg}$ moving at 0.5 $\mathrm{m} / \mathrm{s}{ }^{43}$ The impact property has not been discussed in NGNP documents to date.

The $\mathrm{C}_{f} \mathrm{C}$ control rod that was being developed for the MHTGR-NPR was required to have an axial strength greater than $400 \mathrm{psi}(2.76 \mathrm{MPa}) .{ }^{70}$ Various strength and ductility requirements were reported for the THTR in-core control rods, but the circumstances of a control rod being forced directly into a pebble bed are so different from anything required in the NGNP that the data is not relevant. Other than that, no data was found in this area. Although not one of the most demanding requirements, analysis of the strength requirements on the control rods is warranted. 


\subsection{Summary of Requirements}

The NGNP control rod material requirements are much more moderate than previously assumed because control rods (and liner/guide tubes) will not be in the active core during normal operation or scram for either the prismatic or pebble bed design. Time at elevated temperature during the worst case accident scenario stili creates an environment that may eliminate metals as a possible control rod sheathing material, or require procedural solutions such as delayed scram. Helium cooling fluid and associated impurities should not pose any significant corrosion issues, unless higher flow rates or gas pressure in this reactor change the corrosion mechanisms. Strength requirements also appear to be minimal, although no analysis appears to have been documented. 


\section{CAPABILITIES OF MATERIALS UNDER CONSIDERATION}

The control rods will be in an elevated high-temperature environment with significant radiation fluxes. All three materials under consideration in this report, $\mathrm{C}_{\mathrm{f}} / \mathrm{C}$ and $\mathrm{SiC}_{\mathrm{f}} / \mathrm{SiC}$ composites and alloy $800 \mathrm{H}$, have different irradiation degradation issues. The mechanisms will be explained and illustrated and a literature review of the properties will be presented to the extent possible. Since the use of ceramic composites in nuclear reactors is only in the research stage, limited data is available, and ironically $800 \mathrm{H}$ was introduced to reactors so long ago that the archival status of data and most of the HTRG documents makes information on $800 \mathrm{H}$ irradiation performance difficult to obtain. The continual decommissioning of most of the nuclear test reactors will make gathering new irradiation data on any material challenging. ${ }^{71}$

\subsection{Irradiation of $\mathrm{C}_{\mathrm{f}} / \mathrm{C}$}

\subsubsection{Graphite Irradiation Damage Mechanism}

6.1.1.1 Atomic Scale On the atomic scale, neutron irradiation causes ballistic displacement of $\mathrm{C}$ atoms from their equilibrium lattice positions to interstitial positions. The displacement results in the formation of vacancies and vacancy clusters within the basal planes. As damage accumulates, clusters grow, basal planes collapse, and shrinkage occurs in the "a" direction (see Figure 20a). Eventually, displaced atoms coalesce to form clusters resulting in new basal planes and forcing the original basal planes apart which causes expansion in the "c" direction (see Figure 20b). ${ }^{70}$ Figure 20, a and b show a schematic of dimensional changes resulting from irradiation induced ballistic displacements of $\mathrm{C}$ atoms. ${ }^{70}$
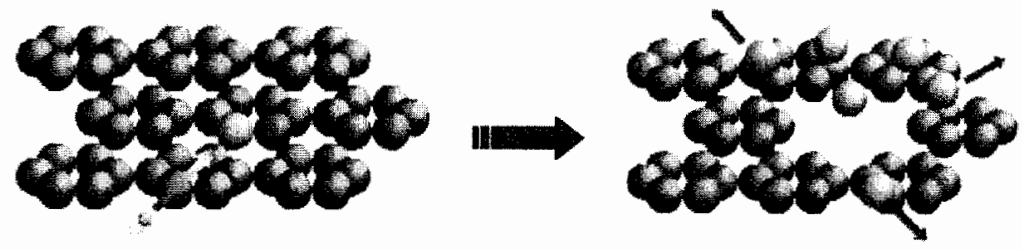

(a)
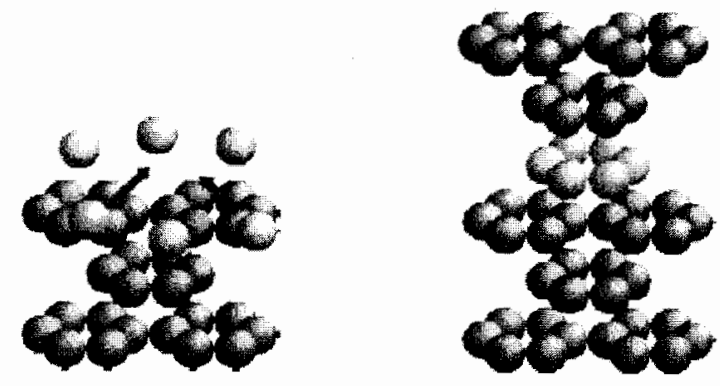

(b) 
Figure 20 (a). Neutron striking a $\mathrm{C}$ atom resulting in ballistic damage to the basal plane in the form of an interstitial which creates vacancy clusters and ultimately shrinkage in the "a" direction. (b). Interstitial atoms diffusing to positions between basal planes, forming a new basal plane in the graphite crystal structure and causing expansion in the " $c$ " direction.

6.1.1.2 Macro-Scale On the macroscopic scale, the material initially shrinks as individual crystallites shrink in the "a" and " $\mathrm{c}$ " direction (see Figure 20). As the irradiation dose increases and the "c" axis of individual crystallites begin to swell, this initial swelling is absorbed by porosity and the intrinsic misalignment of the crystallites as well as microdamage present within the manufactured graphite. As a result, the volumetric shrinkage continues even though crystallites are swelling in one dimension. Eventually the capacity of random orientation, microporosity, and microcracks that accommodate the c-axis swelling is exceeded, and turn-around to volumetric swelling is reached. ${ }^{70,72}$ Once turn-around is reached, strength degradation is observed. The useful lifetime is taken as the point where the swelling returns to zero. ${ }^{72}$ This behavior is illustrated in Figure 21, which plots the volume change for a particular grade of graphite as a function of fluence. ${ }^{73}$

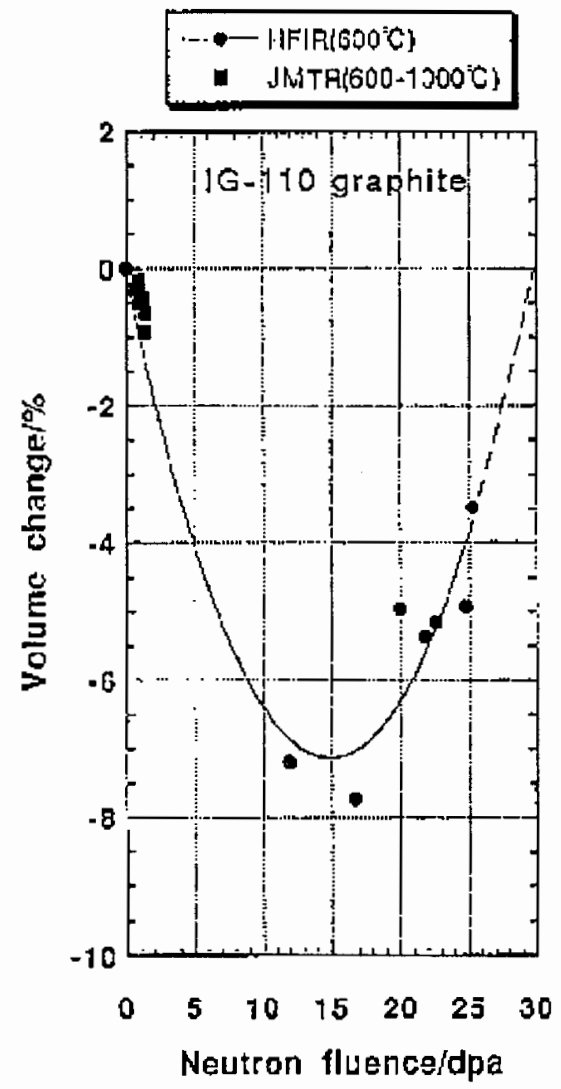

Figure 21. Example of irradiation induced swelling in graphite, illustrating turnaround at about 15 dpa. $^{73}$ 
The dimensional changes resulting from the mechanism described above are primarily a function of the reactor operating temperature; higher temperature results in higher atomic mobility. The turn-around point occurs at lower fluence levels for higher temperatures. ${ }^{72}$ Also the rate of swelling decreases with increasing irradiation temperature. ${ }^{74}$ The degree of crystallinity within the graphite microstructure also plays an important role. Highly ordered graphite structures result in increased recombination efficiency after ballistic events, defects can migrate faster within ordered crystal structures, and the damage accumulation rate within ordered graphitic structures is lower. In quasicrystalline $\mathrm{C}$ structure vacancies are preferentially trapped within the carbonaceous structure and the damage accumulation rate increases substantially. In other words, dimensional changes are greater in materials with less crystallinity. ${ }^{69}$

All $\mathrm{C}_{\mathrm{f}} / \mathrm{C}$ composites behave differently depending on architecture, fiber and impregnation type, and processing history. A higher final heat treatment temperature reduces the total amount of shrinkage for a given fluence and improves the radiation stability because of an increased degree of graphitization or crystallinity. The variation of crystallite orientation and the micro-damage within the graphitic microstructure also influences shrinkage and swelling. ${ }^{69}$

\subsubsection{Complexities of Irradiation Damage to $C_{f} / C$ Composites}

6.1.2.1 Fibers The core of the fiber is nearly amorphous; however, the remainder of the fiber is composed of crystallites that are highly aligned from the fiber drawing process. The crystallites become oriented around the core in the form of shells or sheaths with the "a" basal planes aligned parallel to the drawing direction and the hoop direction while the "c" planes are aligned with the radial direction. The result has been termed the core-sheath microstructure and is illustrated in Figure $22 .^{70,72}$ Considering the core-sheath structure and the behavior of irradiated graphite shown in Figure 21, it is understood that both axial and radial shrinkage occur until tum-around, and then radial swelling and axial shrinkage occur afterward. ${ }^{72}$

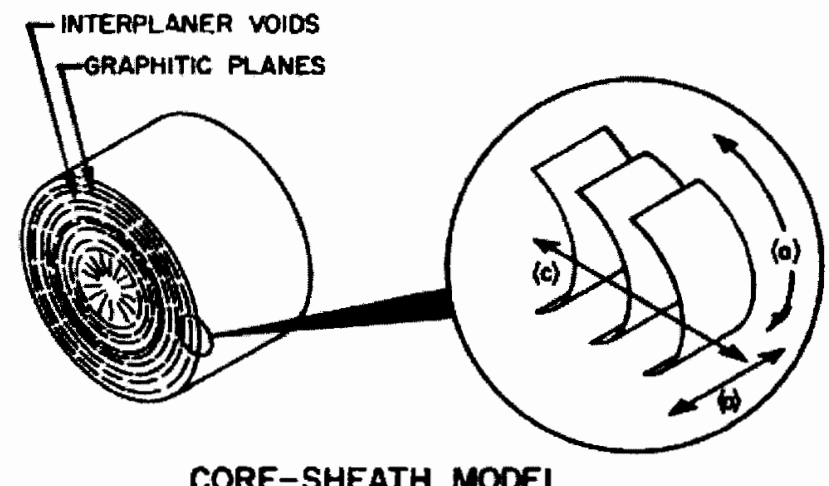

Figure 22. Illustration of the core-sheath microstructure of a fiber used in a $\mathrm{C}_{f} / \mathrm{C}$ composite. ${ }^{72}$

6.1.2.2 Composites The irradiation behavior of composites depends largely on the way the fibers are arranged. A composite with $1 \mathrm{D}$ fibers experiences five to 10 times more shrinkage in the "a" direction than " $c$ ", while a composite with a 2D weave of fibers might have about 4 times more shrinkage in the "a" direction than " $c$ ". Three-dimensional fiber preforms result in the most isotropic, but also the most unpredictable shrinkage. ${ }^{75}$ 
For the type of $\mathrm{C}_{\mathrm{f}} / \mathrm{C}$ composite that would be used for a control rod, the highly anisotropic fibers are woven into cloth and infiltrated with an isotropic matrix to produce a heterogeneous microstructure. The structure results in a stronger, stiffer, and tougher material than homogeneous graphite, but causes problems under irradiation because of differences in radiation-induced swelling between the fiber and the matrix. An example of the damage that occurs in these composites as a result of their heterogeneity is shown in the Scanning Electron Micrographs presented in Figure 23. They show samples of FMI-222, a pitch-fiber, pitch-matrix, 3D-balanced weave $C_{f} / C$ composite, irradiated up to $7.7 \times 10^{21} \mathrm{n} / \mathrm{cm}^{2}$ fast fluence $(\mathrm{E}>0.1 \mathrm{MeV})$ at 500 and $800^{\circ} \mathrm{C}$. In the $800^{\circ} \mathrm{C}$ micrograph, the fiber bundle shrinkage in the axial direction has resulted in gaps at the surface, and the swelling in the radial direction has resulted in internal fracture. At this point, the structural integrity of the composite is clearly compromised. Inadequate adhesion between matrix and fibers due to the difference in rate of dimensional changes can also lead to sample bending and delamination. ${ }^{74}$ Although FMI-222 is a 3D-fiber, balanced weave isotropic composite, the volumetric dimensional change is anisotropic. ${ }^{72}$

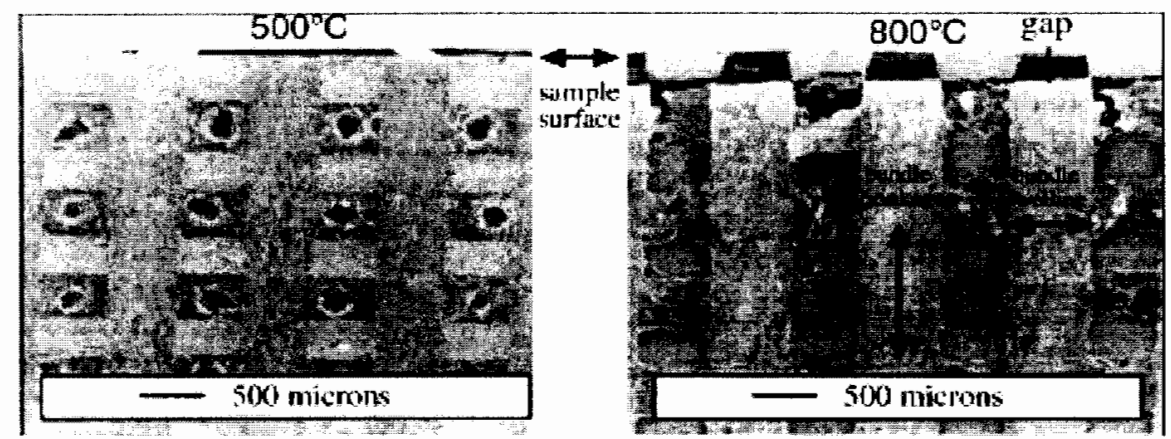

Figure 23. Scanning Electron Micrograph photographs showing the degradation observed at 7 to 8 dpa of the shrinkage and swelling in FMI-222.

Reducing the density of a composite by increasing the fiber content can decrease the shrinkage of the material. Density can range widely and can be controlled by varying the components of the $\mathrm{C}_{f} / \mathrm{C}$ : the fibers, impregnants, and dopants. In addition to composition, the density is a function of the type of matrix infiltration process, and the processing temperature and pressure. ${ }^{74}$

Nominal strength values were determined by four-point-bend flexural loading of small bar samples The samples were $1 / 4$ sub-sized and had a span-to-depth ratio of $15: 4: 1$. This is not an ASTM standard specimen geometry for flexure strength tests, but its use is justified by the claim that it will yield comparative (not absolute) results between various samples. ${ }^{76}$ These smaller samples are used because of the size constraints imposed by the reactor. Neutron irradiation results in increased strength and elastic modulus (see Figure 24), ${ }^{72}$ but the strain depends on the fiber orientation. ${ }^{77}$

Dimensional changes under irradiation determined on small samples are not necessarily representative of bulk response. Changes can be underestimated because of disruption of the reinforcement throughout the sample. ${ }^{74}$ Very recent preliminary results indicated surprisingly large postirradiation swelling, which may be related to small sample size. ${ }^{78}$ Also, a balanced weave, isotropic composite has been reported to undergo anisotropic dimensional changes, because of the sample geometry and constraints, where it is speculated that were the sample cubic and larger, the volume change would be more predictable. ${ }^{72}$ 


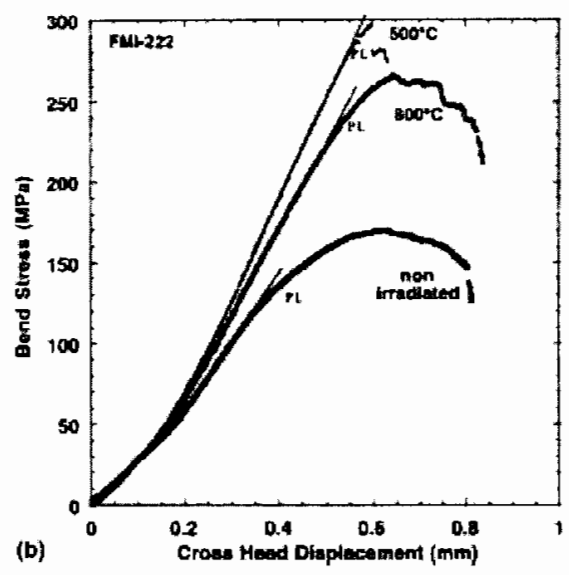

Figure 24. Bend strengths curves illustrating increased strength and elastic modulus (slope of straight-line portion of curve) after irradiation. ${ }^{72}$

6.1.2.3 Processing Issues Details of the processing methods can be found in section 8.2 (Manufacturability). This section will discuss processing only as it relates to irradiation properties.

Pitch and mesophase matrix material has excellent irradiation stability compared to pan- or resinbased matrix material. ${ }^{69,70}$ Pitch-based matrix is not only better because it is highly crystalline, but also because the crystals are arranged randomly. It also has gaps, cracks and microporosity between the crystals, which leave room for expansion of the crystals during irradiation, thus minimizing the overall effect of radiation induced strain. ${ }^{69}$

In an earlier study, the radial fracture load and the amount of deformation was much larger for composites with pan-based fibers. The pitch-based material was less brittle. However, the pan-based material had a large enough fracture strain, and the axial fracture load was similar for the two materials. ${ }^{77}$

In contrast, chemical vapor infiltration (CVI) results in little microporosity in the deposited C structure so the effect of strain is fully translated to the whole system. Swelling of the system leads to earlier degradation of properties. ${ }^{69}$

\subsection{Irradiation of $\mathrm{SiC}_{\mathrm{f}} / \mathrm{SiC}$}

6.1.2.4 SiC/SiC Composite Irradiation Damage Mechanism Monolithic SiC is highly resistant to radiation damage. For example, the swelling of $\mathrm{SiC}$ at $1000^{\circ} \mathrm{C}$ is $\sim 0.2$ percent at $2 \mathrm{dpa}$ and $\sim$ 0.6 percent at $6 \mathrm{dpa}^{79}$ Similarly, the high-purity stoichiometric SiC fibers, Hi-Nicalon Type-S, and Tyranno SA have excellent irradiation properties. ${ }^{80}$ Figure 25 illustrates how the normalized density of Tyranno SA $(\Delta)$ is quite similar to chemical vapor deposition $\mathrm{SiC}(\bullet)$ irradiated under the same conditions. $^{81}$ 


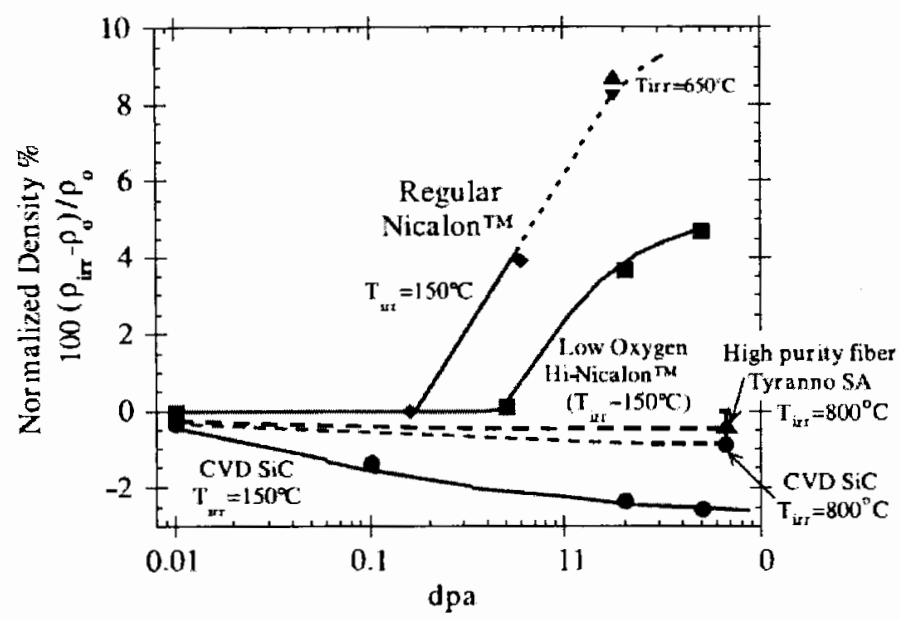

Figure 25. Relative density change of various fibers and CVD SiC material like that are used for the composite matrices resulting from neutron irradiation. ${ }^{81}$

6.2.1.1 Composites As discussed above for $\mathrm{C}_{\mathrm{f}} \mathrm{C}$ composites, mismatch in the irradiation swelling behavior will lead to poor adhesion between the matrix and the fiber. Composites made with a CVD SiC matrix $(\bullet)$ (see Figure 25) and non-high purity fibers exhibiting the most swelling (Nicalon [ $\bullet$ ] and Hi-Nicalon [-]) experienced reduced mechanical properties and fractured with long fiber pullout following irradiation due to debonding of the fiber/matrix interface. Composites reinforced with highpurity stoichiometric fibers with little swelling, nearly matching the CVD SiC matrix (Hi-Nicalon Type-S and Tyranno SA [ $\mathbf{\Delta}]$ ), had very different behavior. They fractured with relatively short fiber pullout and the fracture behavior of the composites following irradiation was similar to that of non-irradiated composites. Post-irradiation mechanical properties were stable, even up to high doses and high irradiation temperature. $^{81}$

This pattern of mechanical behavior is illustrated in Figure 26. Monolithic $\mathrm{SiC}$ and composites fabricated using various $\mathrm{SiC}$ fibers have been irradiated up to $8 \mathrm{dpa}(\mathrm{O})$. While the Hi-Nicalon Type-S fiber composites are slightly less stable than monolithic $\mathrm{SiC}(0)$ they show a threshold behavior where the mechanical properties do not change significantly after about $1 \mathrm{dpa}$. This is in contrast to the curves plotted from composites made with Nicalon ( $\mathbf{\Delta})$ or Hi-Nicalon fibers $(\boldsymbol{})$, which exhibit irradiation induced strength degradation. ${ }^{57}$

$\mathrm{Hi}-\mathrm{Nicalon}{ }^{\mathrm{TM}} \mathrm{Type}-\mathrm{S}$ fibers were chosen for the $\mathrm{SiC}_{\mathrm{f}} / \mathrm{SiC}$ composite research performed to date in the NGNP program, primarily because they had the largest database supporting the excellent neutron irradiation tolerance for these fiber-based composites at the time. ${ }^{82}$ 


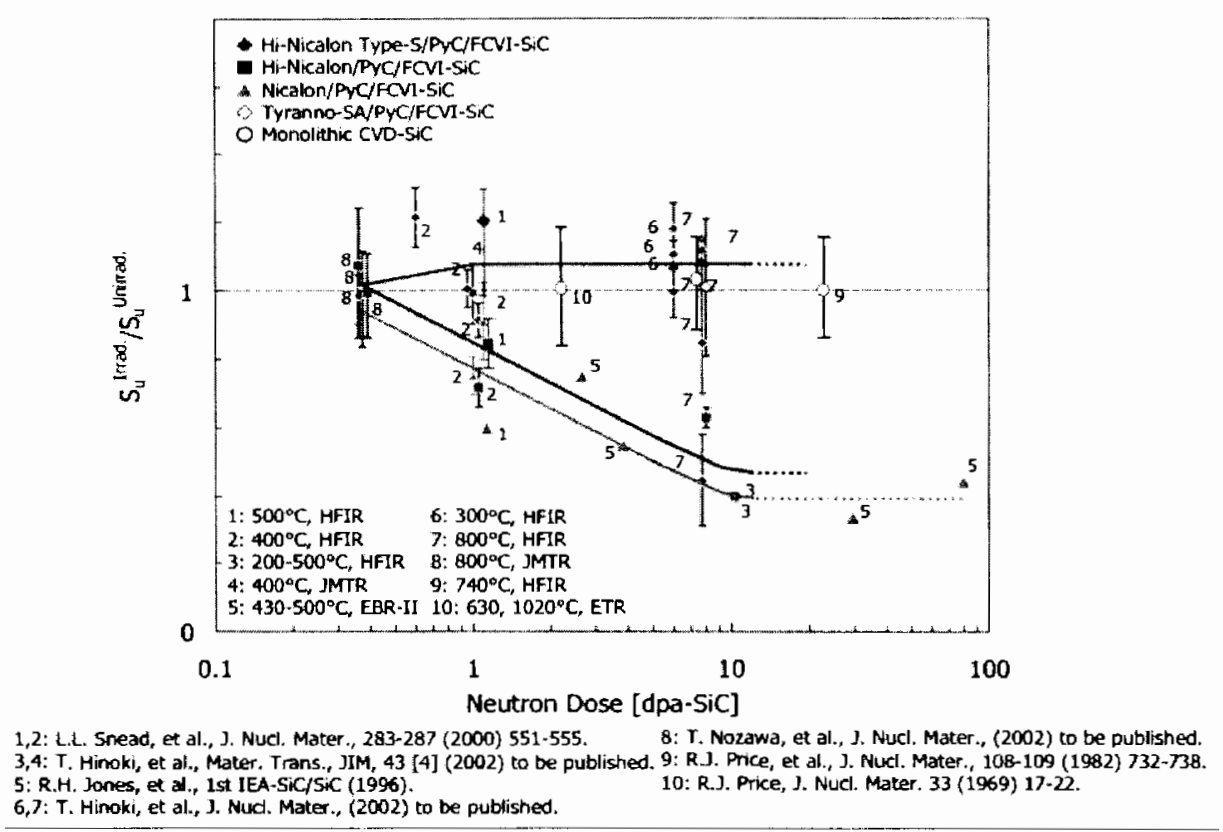

Figure 26. The irradiated-to-non-irradiated ultimate strength ratio $\left(\mathrm{S}_{U}{ }^{\text {Irad }} / \mathrm{S}_{U}{ }^{\text {Unirrad }}\right)$ measured up to $8 \mathrm{dpa}$, demonstrating the irradiation stability of different $\mathrm{SiC}_{\mathrm{f}} \mathrm{SiC}$ composite types compared to monolithic $\mathrm{SiC}^{57}$

6.2.1.2 Effect of Interphase The performance of the interface and the phases that are deposited to improve fiber/matrix adhesion can be critical to the irradiation behavior of $\mathrm{SiC}_{\mathrm{f}} / \mathrm{SiC}$ composites. $\mathrm{A}$ pyrolytic carbon (PyC) fiber coating forms an interphase upon processing which can be sensitive to even low doses of neutron irradiation. While the fiber and matrix did not degrade significantly after neutron irradiation up to $0.4 \mathrm{dpa}$ at $1073 \mathrm{~K}$, the PyC interphase degraded to the point that the interface lost its load transferring function, resulting in decreased composite strength, and especially decreased modulus of elasticity. ${ }^{80}$ However, such irradiation-induced degradation at the interface is not always observed, ${ }^{81}$ as indicated by Figure 26 . However, a $\mathrm{PyC} / \mathrm{SiC}$ multilayered interphase is preferred over a single-layered PyC interphase because of the better irradiation stability. ${ }^{82}$ Samples used for the NGNP composite irradiation studies have a five-layer PyC $(20 \mathrm{~nm}) / \mathrm{SiC}(100 \mathrm{~nm})$ interphase. ${ }^{76}$

\subsubsection{NGNP Test Plan for Composites}

Some of the details of the test plan include irradiation testing composite specimens (or just $\mathrm{SiC}_{\mathrm{f}} / \mathrm{SiC}$ if the $\mathrm{C}_{\mathrm{f}} / \mathrm{C}$ has exceeded its useful limit) to radiation levels of $30 \times 10^{21} \mathrm{n} / \mathrm{cm}^{2}$ and mechanical and environmental testing up to $1600^{\circ} \mathrm{C}$. These test parameters now far exceed what is necessary, even for off-normal events, and need to be modified. Unfortunately, one focus of the composite effort has been to build a high temperature, atmosphere-controlled system for mechanical testing (both creep and monotonic tensile) up to $1600^{\circ} \mathrm{C}$ when it appears only $1200^{\circ} \mathrm{C}$ may be needed. For ceramic composites, high-temperature mechanical properties are nearly unchanged from room temperature properties. However, elevated-tensile and long-duration creep tests for both unirradiated and irradiated samples are planned. 
Room-temperature testing will be used to determine the role of size and geometry effects. Various specimen designs and material architecture will be tested to ensure small-sized specimens eventually selected will adequately represent the response of larger composite tubes. For this type of testing, lowergrade materials can be used where irradiation performance is not being assessed. An ASTM test standard will be developed based on this research, followed by independent laboratory round robin test programs to verify consistency, accuracy, and usability of the draft standard. Following the ASTM balloting process, assuming a positive outcome, the draft will be accepted and published in the ASTM Annual Book of Standards the following year. The standardized test specimen design, dimensions, fabrication issues, and testing methodology need to be developed with national and international input.

\subsubsection{Down-Selection of Composites}

NGNP materials documents discussing the testing plans for composite development state that if $\mathrm{SiC}_{\mathrm{f}} / \mathrm{SiC}$ irradiation stability is not significantly increased from the $\mathrm{C}_{\mathrm{f}} / \mathrm{C}$ composites, they will be eliminated from the testing program and only $\mathrm{C}_{\mathrm{f}} \mathrm{C}$ will be considered. If the irradiation stability of $\mathrm{SiC}_{\mathrm{f}} / \mathrm{SiC}$ is significantly better, then both composite candidates will be tested, but more emphasis will be placed on obtaining $\mathrm{SiC}_{\mathrm{f}} / \mathrm{SiC}$ composite results. In other words, the irradiation testing is a "go/no-go" test for $\mathrm{SiC}_{\mathrm{f}} / \mathrm{SiC}$ composites, since the only advantage $\mathrm{SiC}_{\mathrm{f}} / \mathrm{SiC}$ has over $\mathrm{C}_{f} / \mathrm{C}$ is superior irradiation stability. If the $\mathrm{SiC}_{\mathrm{f}} / \mathrm{SiC}$ samples do not demonstrate sufficient irradiation stability to allow the control rods to become a lifetime component, then $\mathrm{C}_{f} \mathrm{C}$ composites will be selected as the material system for these components. The flow chart for testing is shown in Figure 27.

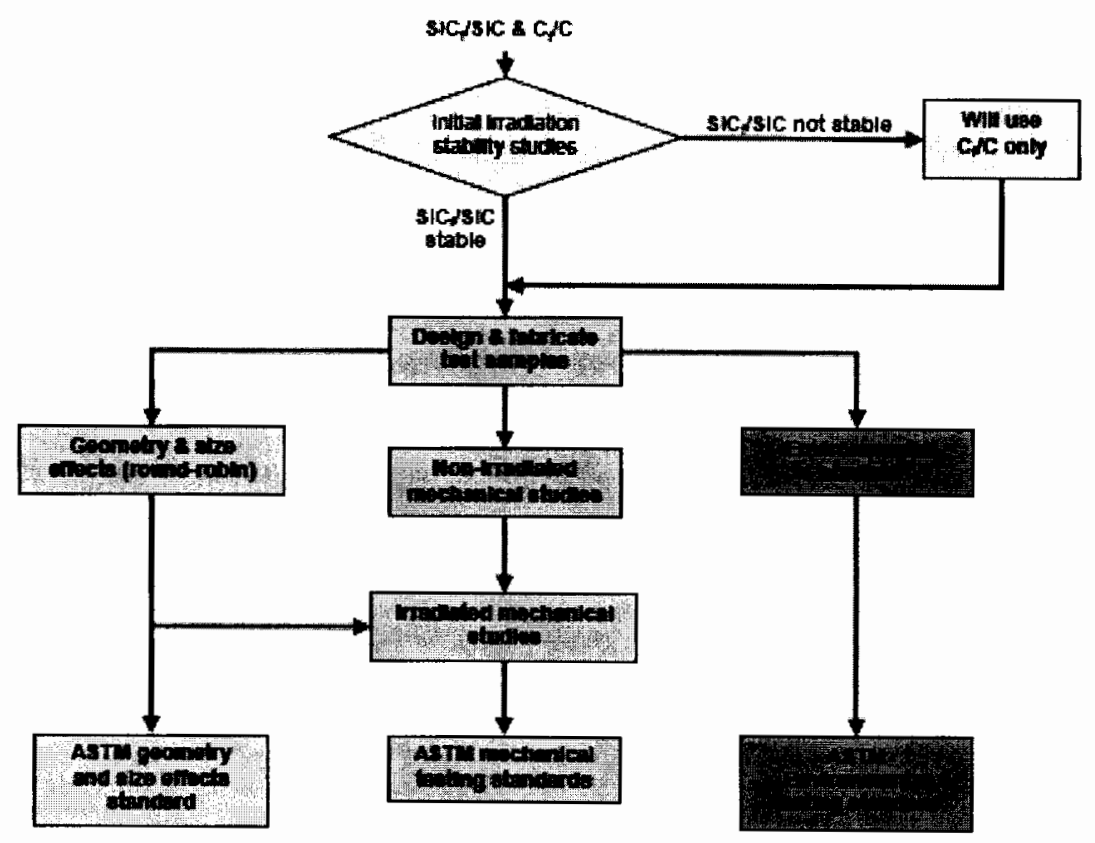

Figure 27. Flow chart illustrating test plan for NGNP control rod composite research. ${ }^{57}$

Using similar logic, with the decreased radiation dose requirement of $\sim 8 \mathrm{dpa}$, one may conclude that the $\mathrm{C}_{\mathrm{f}} \mathrm{C}$ composite will probably allow the control rod to be a lifetime component. Therefore, it is not possible to justify pursuing $\mathrm{SiC}_{\mathrm{f}} / \mathrm{SiC}$ composites if their sole advantage is superior radiation resistance. 


\subsection{Irradiation of 800 and $800 \mathrm{H}$}

Alloy 800 (UNS N08800 and DIN designation X10NiCrAlTi 3220) is a high temperature austenitic iron-based alloy with nominally $32 \% \mathrm{Ni}, 20.5 \% \mathrm{Cr}$ which has good strength and excellent oxidation resistance up to $850^{\circ} \mathrm{C}$. Alloy $800 \mathrm{H}$ (UNS N08810 and DIN designation X10NiCrAlTi $3220 \mathrm{H}$ ) is a higher creep strength variant of alloy 800 with $\mathrm{Al}+\mathrm{Ti} \leq 0.7$, tighter specifications on $\mathrm{C}$, and a minimum grain size of ASTM No. $5(\sim 65 \mu \mathrm{m})$. It is primarily solid solution strengthened, with some carbide precipitate hardening, and at intermediate temperatures, hardening by $\gamma^{2}$-precipitates. ${ }^{71} \mathrm{~A}$ great deal of general mechanical property data for $800 \mathrm{H}$ is available in the literature. An excellent list has been compiled in the High Temperature Metallic Materials Test Plan for Generation IV Nuclear Reactors, ${ }^{83}$ Appendix F. Table 8 gives the chemistry for both 800 and $800 \mathrm{H}^{84}$; the values vary slightly depending on supplier.

Table 8. Nominal chemistry for alloys 800 and $800 \mathrm{H}^{84}$

\begin{tabular}{|c|c|c|c|c|c|c|c|c|c|c|c|}
\hline alloy & $\mathrm{Ni}$ & $\mathrm{Cr}$ & $\mathrm{Fe}$ & Al & $\mathrm{Ti}$ & $\mathrm{Al}+\mathrm{Ti}$ & $\mathrm{C}$ & $\mathrm{Mn}$ & $\mathrm{Cu}$ & $\mathrm{S}$ & $\mathrm{Si}$ \\
\hline 800 & $30.0-35.0$ & $19.0-23.0$ & 39.5 & $0.15-0.60$ & $0.15-0.60$ & $0.30-1.20$ & $\$ 0.10$ & ㄱ. 5 & $\$ 9.75$ & $\$ 0.015$ & 1.0 \\
\hline $800 \mathrm{H}$ & $30.0-35.0$ & $19.0-23.0$ & $\geq 9.5$ & $0.15-0.60$ & $0.15-0.60$ & $0.30-1.20$ & $0.05-0.10$ & $\unlhd .5$ & $\$ 9.75$ & $₫ .015$ & 1.0 \\
\hline
\end{tabular}

The primary technical concern for performance of $800 \mathrm{H}$ in the NGNP control rods is the irradiation behavior (It can be assumed that general comments about the mechanisms and behavior of alloy $800 \mathrm{H}$ generally refer to alloy 800 , which was used in the earliest HTGRs.) There are conflicting reports of the extent of our understanding of the irradiation behavior of $800 \mathrm{H}$. One source stated that the irradiation behavior of $800 \mathrm{H}$ is sufficiently known to consider in the design of control rods, ${ }^{85}$ while others ${ }^{38}$ claimed more information on irradiation effects is needed. ${ }^{86} 800 \mathrm{H}$ has been used in Light Water Reactors ${ }^{87}$ and also in previous HTGRs as mentioned in section 2. (Summary of Previous Reactors). Because of its long history, much of the property data on these alloys is quite old, but should nevertheless be valid; however, retrieving data for review has proven difficult. It seems unlikely $800 \mathrm{H}$ would have been used in reactors without the proper irradiation data on which to base the decision, so it is possible there are corporate or foreign unpublished databases that have not yet been uncovered, and whether such data can be obtained by NGNP is not certain. It now appears $800 \mathrm{H}$ was assumed to behave like any $3 \mathrm{xx}$ stainless steel, having a face centered cubic structure and similar $\mathrm{Ni}$ and $\mathrm{Cr}$ content; this was the case when selecting the material for FSV control rods. ${ }^{38}$

The literature indicates both the Japanese and the Germans have had extensive programs in place to study the irradiation properties of $800 / 800 \mathrm{H}$. Tsuji et al. claimed to be embarking on additional postirradiation testing using creep frames fitted with inert atmosphere chambers and various fluence and temperature exposures. ${ }^{88}$ Also the Japanese Material Test Reactor laboratory was reported to be accumulating much irradiation data for the HTTR and developing post-irradiation examination techniques ${ }^{89}$ but apparently never published more current data. The Thiele et al. results came from a broad irradiation program set up by the Entwicklungsgemeinschaft-HTR Development Company, made up of German nuclear companies and Kemforschungsanlage Jülich to try to determine characteristic end-of-life values for design and safety. ${ }^{71}$ Reference in a PBMR presentation ${ }^{90}$ also indicates the German HTR development program characterized irradiated Incoloy $800 \mathrm{H}$, and specifically mentions hot tensile testing. This may refer to the same study. 


\subsubsection{The Embrittlement Mechanism}

All austenitic alloys, including 800 and $800 \mathrm{H}$ experience irradiation induced ductility loss as a result of exposure to thermal neutrons at elevated temperature. The embrittlement worsens as either the exposure temperature or the fluence increases. ${ }^{91} \mathrm{He}$ is produced by the nuclear transmutation reaction of thermal neutrons with the boron and nickel in the alloy. ${ }^{92}$ The ${ }^{10} \mathrm{~B}(\mathrm{n}, \alpha)^{7} \mathrm{Li}$ reaction occurs for fluence levels up to about $10^{20} \mathrm{n} / \mathrm{cm}^{2}$, and the ${ }^{58} \mathrm{Ni}(\mathrm{n}, \gamma)^{59} \mathrm{Ni}(\mathrm{n}, \alpha)^{56} \mathrm{Fe}$ reaction occurs for fluence levels above $10^{20}$ $\mathrm{n} / \mathrm{cm}^{2}{ }^{71,88}$ In the HTRG, thermal neutrons are abundant. Helium has very low solubility in metals, and therefore clusters to form bubbles, especially at the grain boundaries. The bubbles grow and coalesce under tensile loads, and the result is intergranular cracking and concomitant low ductility. ${ }^{16}$ Because of the role of nickel in the production of $\mathrm{He}$, iron-based alloys experience less embrittlement than nickel-rich alloys, which explains why $800 \mathrm{H}$ performs better than many other high-temperature corrosion-resistant alloys such as alloy $617^{16,92}$

Fast neutrons result in atomic displacement damage, such as vacancies and interstitials. In metals these defects are annealed out, and the effect of fast neutrons on the material properties is negligible at high temperatures. For 800 series alloys this temperature has been identified as $250,{ }^{91} 500-600,{ }^{85}$ and $600^{\circ} \mathrm{C} .^{92}$ However, one study indicates that fast fluence may have some impact, even at test temperatures of $600-850^{\circ} \mathrm{C}$. Tensile strengths were greater for a group of specimens irradiated at $400^{\circ} \mathrm{C}$ with three times the fast fluence, but the at the same thermal fluence; however, ductility was not affected. ${ }^{71}$

\subsubsection{Tensile Properties}

In a classic German study on 800 , irradiation caused a large increase in yield strength and in the ultimate tensile strength when irradiated at $400^{\circ} \mathrm{C}$, but there was no change in strength when irradiated at $600^{\circ} \mathrm{C}$, as shown in Figure 28. Unirradiated control specimens were given the same thermal exposure as irradiated specimens before tests were performed to account for the effects of thermal aging on the mechanical properties. In addition, some irradiated specimens were given simulated service exposure after irradiation. Annealing unirradiated $800 \mathrm{H}$ at temperatures above $500-600^{\circ} \mathrm{C}$ caused carbides to form, which resulted in strengthening. Irradiation also produced carbides and caused strengthening beginning at $400^{\circ} \mathrm{C}$. It is assumed that irradiation caused the formation of carbides at lower temperatures and finer carbides within the grains rather than more precipitates. Finer precipitates impede dislocations more effectively, resulting in improved strengthening. Reduction in ductility is a typical consequence of increased strength. A decrease in ductility was observed at test temperatures above $400^{\circ} \mathrm{C}$ for either irradiation temperature and the values are less than $5 \%$ at test temperatures above $600^{\circ} \mathrm{C}$, but there was no effect at lower test temperatures. ${ }^{71}$ 

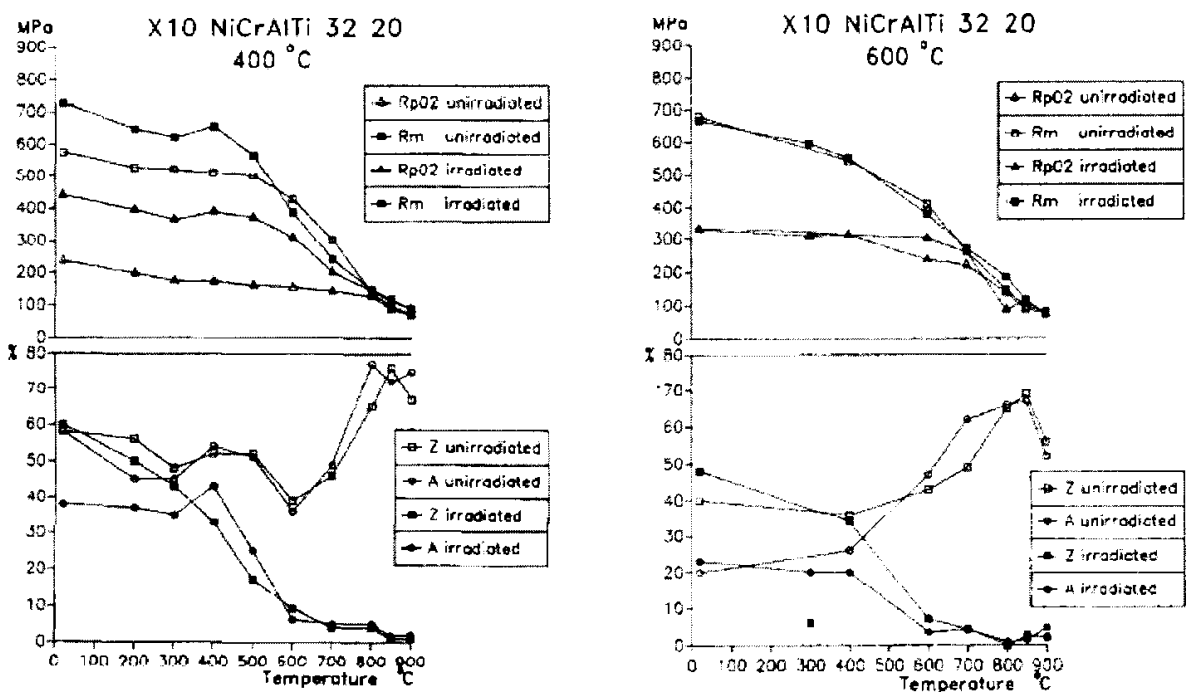

Figure 28. Elevated-temperature tensile test results from specimens irradiated at 400 and $600^{\circ} \mathrm{C} .^{71}$

Tensile testing can be a means of evaluating materials before more complex testing is done, and there have been several tensile studies on irradiated $800 \mathrm{H}$. For example, a German study irradiated eight commercially available alloys at $375^{\circ} \mathrm{C}$ to a fluence of $1.1 \times 10^{21} \mathrm{n} / \mathrm{cm}^{2} .{ }^{16}$ The results pointed to three candidates for further testing, one of which was $800 \mathrm{H}$. The ductility of $800 \mathrm{H}$ decreased after irradiation, but not as much as most of the alloys. Even in the embrittled state it still had $15 \%$ elongation when tested at $700^{\circ} \mathrm{C}$ and about $3 \%$ at $850^{\circ} \mathrm{C}$.

In a Japanese study with a maximum thermal fluence of $1.2 \times 10^{21} \mathrm{n} / \mathrm{cm}^{2}$ at $60^{\circ} \mathrm{C}$ and subsequent tensile testing at $700-1000^{\circ} \mathrm{C}$ and various strain rates, the tensile ductility were reduced by about one order of magnitude for most of the alloys, but only by about half for alloy $800 .^{92}$

These studies have indicated some other general trends. The tensile ductility decreases as the deformation temperature is increased. ${ }^{1692}$ Precipitation hardened alloys such as Inconel 625 showed more embrittlement than austenitic solid solution strengthened alloys like Incoloy $800 \mathrm{H}$, and the alloys with the greatest ductility before irradiation also had the greatest tensile ductility after irradiation exposure, although the ductility was reduced more in these materials. ${ }^{16}$

\subsubsection{Creep Properties}

The creep properties of 800 are also seriously degraded by irradiation-induced He embrittlement but again, 800 outperformed other alloys under consideration. ${ }^{88,92-94}$ Conclusions based entirely on either post-irradiation tensile ductility or creep-rupture can be misleading. Rather, the two should be evaluated together for the most meaningful interpretation. ${ }^{94}$ The post-irradiation creep behavior is dependent on the chemistry (e.g. $0.1 \%$ Ti appears optimum ${ }^{94-96}$ ) and also on the grain size, with finer grained material having better properties as expected. ${ }^{95.96}$ This indicates $800 \mathrm{H}$ may have inferior creep properties to 800 , since it has a larger grain size specification. 
Figure 29 shows an example comparing the stress rupture of alloy 800 to Hasteloy X tested at $900^{\circ} \mathrm{C}^{88,92}$ In an older study, creep rupture strengths of alloy 800 appear to merge for longer rupture times. ${ }^{97,98}$

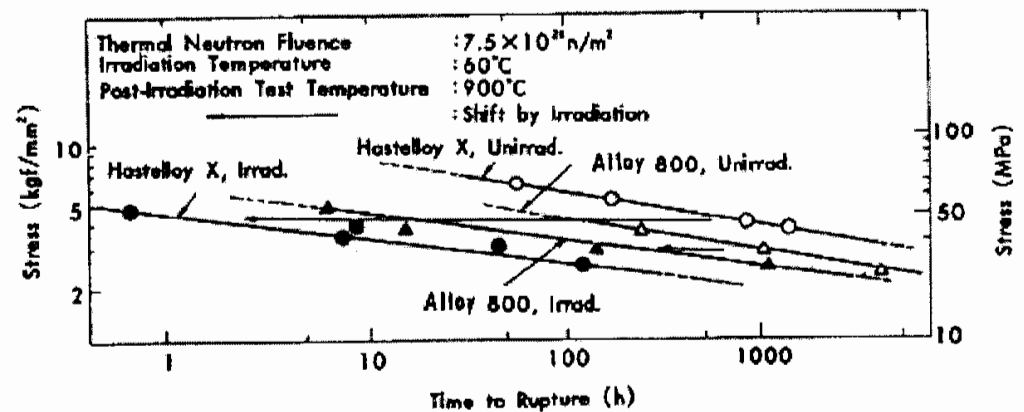

Figure 29. Creep rupture data of irradiated and unirradiated samples for 800 and Hasteloy $X^{88}$

The most relevant creep deformation curves are for specimens tested at $900^{\circ} \mathrm{C}$ and $29 \mathrm{MPa}$ in the unirradiated condition and after irradiation at $700^{\circ} \mathrm{C}$ and a fluence of $2.3 \times 10^{20} \mathrm{n} / \mathrm{cm}^{2} .{ }^{89}$ These exposure and test conditions are close to what is anticipated in the NGNP. The study revealed the creep-rupture time of irradiated $800 \mathrm{H}$ is $10-30 \%$ of the unirradiated value. The design of the HTTR control rod accounted for this loss of creep rupture life by multiplying the total duration of a specific loading by a factor of 10 , and using this time to determine the allowable stress values, $\mathrm{S}_{\mathrm{R}}$ and $\mathrm{S}_{\mathrm{T}}{ }^{3}$.

Short-term creep tests of 100 to 300 hours were performed, reasoning that only relatively shortterm loads are experienced by in-core control rods. Even these short terms are long enough to permit He to diffuse to the grain boundaries and agglomerate into bubbles, and irradiation results in lower creep rupture strength and a large reduction in time to rupture. With increasing irradiation temperature (400 to $600^{\circ} \mathrm{C}$ ), times to rupture are reduced by a factor of up to 100 or more. Creep ductility was also greatly reduced. Irradiating at higher temperatures resulted in the lowest creep rupture strength. ${ }^{11}$

To date, no in-pile creep results for 800 or $800 \mathrm{H}$ have been found. The argument can be made that this is not needed because the primary concern is He embrittlement resulting from thermal neutrons, and this damage can be evaluated by post-irradiation tests. The contribution of fast fluence that can be observed by in-pile creep testing will be negligible for the high temperature, primarily thermal fluence environment seen by a control rod in a HTRG. This question is currently under evaluation.

\subsubsection{Fatigue Properties}

Fatigue properties are not likely to be an issue for control rods; however, two studies have been published for alloy 800 reporting opposite results. One found that irradiation had no discernable effect in the fatigue cracking behavior after irradiations of $2.5-6.0 \times 10^{22} \mathrm{n} / \mathrm{cm}^{29},{ }^{97}$ while the other reported a decrease by a factor of 35 in fatigue life after irradiations of $0.4-5 \times 10^{22} \mathrm{n} / \mathrm{cm}^{2} .99$

\subsubsection{Fracture Toughness}

Incoloy 800 has inherently high fracture toughness, comparable to those of austenitic stainless steels. As a result, elastic-plastic $J_{c}$ methodology was used to characterize the ductile fracture behavior of the material at room temperature, $427^{\circ} \mathrm{C}$, and $538^{\circ} \mathrm{C}$. The $\mathrm{J}_{\mathrm{c}}$ for unirradiated 800 decreases with increasing temperature. ${ }^{100}$ 
Irradiation at temperatures of 400 to $427^{\circ} \mathrm{C}$ to neutron exposures of 7 and 12 dpa causes an order of magnitude reduction in $\mathrm{J}_{c}$, as shown in Figure 30. The fracture properties after 7 and 12 dpa were very similar, so data for these exposures were plotted on a single curve. As a result, fracture toughness at higher neutron exposures is not expected to be worse. Note that 7 to $12 \mathrm{dpa}$ corresponds to a total fluence range of 2.2-3.4 $\times 10^{22} \mathrm{n} / \mathrm{cm}^{2}$. Fracture specimens were irradiated in EBR-II, but no energy range was reported. This fluence range is several times greater than the fast fluence predicted for the total 60 year lifetime of the control rod, or roughly equivalent to the total fluence accumulated in 15 years of exposure (see section 5.3, Definition of Requirements). Nevertheless, the degradation in fracture toughness leads to flaw sensitivity, which should be considered in any plans for nondestructive examination (NDE) inspections. ${ }^{100}$

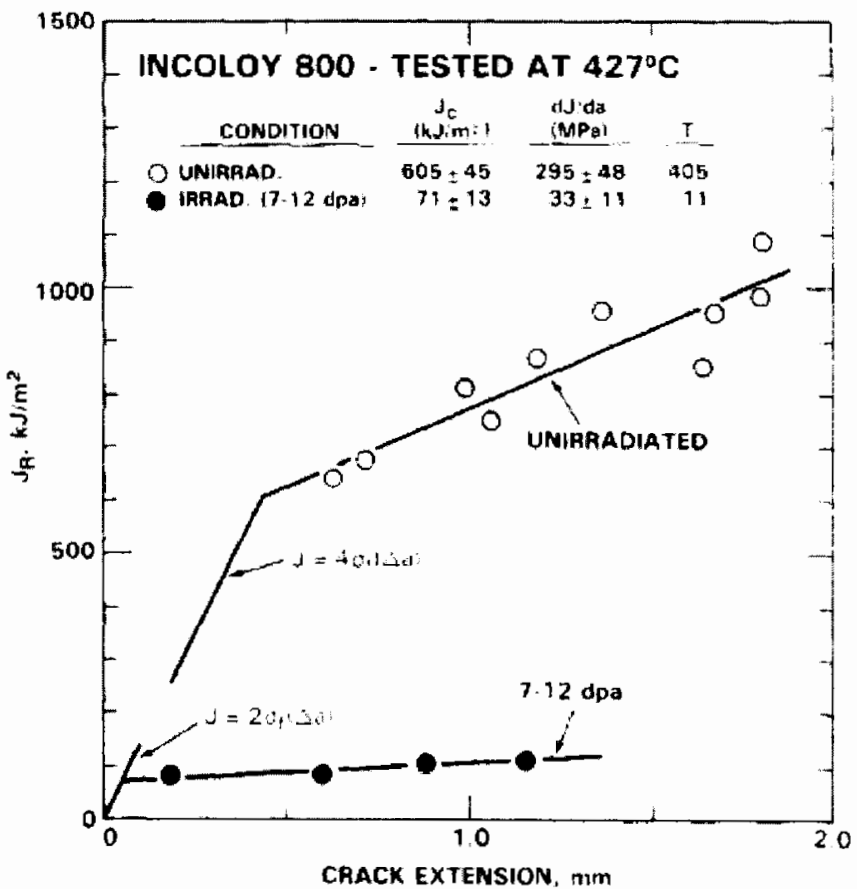

Figure 30. Ductile fracture behavior of INCOLOY 800 at $427^{\circ} \mathrm{C} .^{100}$

\subsubsection{Swelling}

Irradiation induced swelling in alloy 800 is similar to other austenitic stainless steels and high $\mathrm{Ni}$ alloys, becoming large at high doses. ${ }^{101-103}$ The peak swelling rate in this alloy appears to occur at around $500^{\circ} \mathrm{C}$ and decreases at higher temperatures; it is low for doses of 1-10 dpa. 


\subsection{Summary of Materials Capabilities}

While the creep and tensile ductility of $800 \mathrm{H}$ are dramatically diminished by exposure to radiation, the alloy does maintain more ductility than many other alloys ${ }^{16}$ and is more predictable than Hasteloy. ${ }^{97}$ It has the additional advantages of already appearing in ASME Section III code for use up to $760^{\circ} \mathrm{C}$, with extension to higher temperatures being a top NGNP program priority (see section 7.4.2, Regulatory Acceptability), and it has a track record of being used as control rod sheathing material in a number of HTRG reactors (see Table 1 from section 2.1, Summary of Previous Reactors). However, its implementation in this application may push the limits of the material. The prospects for using $800 \mathrm{H}$ as control rod sheathing also depend on what safety factors are required and what off-normal events it must endure. Clearly the maximum core temperatures calculated for severe accident scenarios such as DCC are beyond its limit and would require procedural solutions, such as delayed scram. However, these occurrences are also the least probable. Testing and perhaps modeling would be needed to measure at what temperature the material would deform significantly under its own weight. Thermal models performed for the HTTR design showed that the control rods maintained geometric form to continue functioning with short-term exposure to $1100^{\circ} \mathrm{C}^{20}$ 


\section{REGULATORY ACCEPTABILITY}

Any material or engineered material system to be used in the NGNP reactor design will require acceptance by the NRC prior to implementation in a commercially constructed facility and, to some extent, in a prototype system. Final NRC acceptance may involve a range of activities such as extending allowable operating temperatures for a particular material in existing ASME code material (in the simplest case) and completing qualification of a new material system or class of materials that have no performance or design basis at the present time. These activities would entail development of ASTM International testing standards, ASME performance specifications, ASME design rules, and ASME inspection requirements. These items would provide acceptable evidence of the material's suitability for the application to the NRC. Such an application may involve many years of development activities before submittal of a topical report to NRC for consideration.

\subsection{Nuclear Regulatory Commission Acceptance}

For material qualification and acceptance in the past, NRC would expect to be provided with the proposed material, along with justification for its proposed use. Additionally, the material would be expected to have achieved approval by the relevant ASME committee and to have been accepted into the appropriate section of the ASME B\&PV Code or in an ASME Code Case. The justification for use would historically be based upon analysis and interpretation of extensive test data. It is also worthy to note that the NRC's experience and perspective on materials development, acceptance, and licensing is almost exclusively related to light water reactor (LWR) designs and that there are many fundamental differences between LWRs and HTGRs.

The control rods in the NGNP are of significantly lower safety significance than those in an LWR due to the passively safe design of the system. The fuel will not melt even if the control rods are completely removed from the core, thus they are not a true reactor safety-critical component in the NGNP designs being considered. However, they are an engineered safety system, required for controlled reactor shutdown and power moderation. Conversely, LWR control rods are an essential component in maintaining safe reactor power levels (temperature). It will be of primary importance in the control rod material acceptance process to ensure the NRC understands this fundamental difference, as it is inappropriate to assign the same safety performance criteria to an NGNP control rod as it would be for LWR control rods.

The precise criteria for NRC acceptance of a new material class, or criteria not already included in the relevant ASME codes, is not well defined, especially with respect to HTGR applications. In this circumstance, the potential user or material developer will need to estimate the qualification criteria and type and level of justification, at least in the initial submittal to the NRC. The result of this acceptance review system historically tends to create an approval (or disapproval) process that extends over long time-periods with a series of increasingly detailed Requests for Additional Information made by the NRC. Presently there is a movement by the NRC towards the creation of a unified design criteria document for NGNP reactor designs. This process is assisted by the ASME Board on Nuclear Codes and Standards. It is uncertain whether or not such a document will be developed soon enough to be of use in the first NGNP prototype design and acceptance program. 


\subsection{ASTM International Standards Development}

ASTM provides a variety of Standards for material specifications ${ }^{a}$ and test methods to determine material properties specified in the standards. These test methods include characterization of physical, mechanical, and electro-chemical properties. By testing a given material according to ASTM Standards (for the properties of interest) and comparing the results to the specification for that material, one can be assured the material will perform as intended. Having an approved method to reliably measure material properties and performance characteristics is an integral part of the overall NRC approval/acceptance process. NRC acceptability of materials is partly based on reliable performance measures of a candidate material for its intended use.

The composite materials being considered for use in control rod structures require test methods to measure their properties, due to non-homogeneity and anisotropic characteristics. Where test methods do exist for these material types, the tests are most often restricted to room temperature evaluation. While such tests may be somewhat useful for certain comparative purposes, tests at the temperatures of use are necessary for absolute performance assessment. There are also material behavior issues that are unique to composite material classes, commonly referred to as damage mechanisms or damage accumulation. This behavior is somewhat analogous to plastic deformation in a ductile metal, although in a composite it may manifest as a lower remaining strength or higher compliance without any noticeable permanent deformation. Deformation may be the result of fiber/matrix debonding, matrix cracking, fiber degradation or other physical phenomena that may be caused by environment, stress, or irradiation. A damage accumulation model is usually required along with appropriate damage coefficients that relate to the material, environment, and type of degradation occurring. However, it is something that is unique to composite material systems that must be evaluated. Again, some methods and techniques exist for these evaluations, but are typically limited to near-room temperature.

Standardized test methods to measure all properties of interest of new high-performance materials (ceramic composite systems) at substantially high temperatures, do not exist or are still in development. Test methods to evaluate these composite materials at elevated temperature, including irradiation effects, will need to be developed and formalized using ASTM International standards development procedures (Form and Style for ASTM Standards, ASTM International, 2006; Regulations Governing ASTM Technical Committees, ASTM International, 2005; ASTM Technical Committee Officer Handbook, ASTM International, 2000; Strategic Planning Manual, ASTM International, 1998; other guidance articles from various ASTM publications). This can be a lengthy process, depending on the complexity of the test method proposed, and the difficulty in obtaining the trial test data. Such a trial is usually provided by at least six interested laboratories on a volunteer basis, which is necessary in assessing the viability and reliability of the method. This would be the first step in the NRC acceptance process.

Following development of standardized test methods, the material(s) of interest would have to go through the ASME codification process to achieve a standard performance specification. This step also has the potential to be a lengthy process. There are no ASME specifications for composite materials to be used in nuclear applications. The nature of the behavior and performance of the composite material systems are substantially different from homogeneous metals that are in current codes. Because of this, entirely different design and performance philosophies must be adopted for their use.

Because of the atypical behavior of most composites compared to homogeneous materials, there is a fundamental need to determine what types of properties or performance criteria are to be measured.

"In most instances, ASME has equivalent material specification standards, with designations that are essentially the same as the
ASTM Standards. ASME usually prefaces the equivalent ASTM designation with an "S" to differentiate the source of the specification 
Then appropriate methods must be devised to make the measurements in a repeatable way. A subcommittee of interested parties within an appropriate ASTM Section/Division will typically develop a draft standard. Once approved at various committee levels, a round-robin test program will typically be organized to assess the standard. If analysis of results obtained in the round-robin test proves acceptability of the standard, it will be presented to the membership for a vote. If approved by general vote, it will be incorporated into the following year's edition of the ASTM Standards. It is important that there are enough members interested in developing such a standard and to have the subcommittee actively pursue its development.

\subsection{ASME Performance Specification and Design Methodologies}

ASME oversees the B\&PV Code. Section III of this Code provides internationally-accepted design criteria for all types of pressurized or stressed mechanical systems, including the containment vessels, reactor pressure vessels (RPVs), piping, and related components for nuclear reactors. The ASME Code includes properties and performance data for a wide variety of materials commonly used in fabrication and construction of the various types of systems that the code addresses. The code also includes methodology for component and system design and safety assessment of such structures once they are put into service.

The ASME Board on Nuclear Codes \& Standards is chartered to "manage all ASME activities related to codes, standards, and accreditation programs applicable to nuclear facilities and technology." The ASME Board is actively working with NRC towards development of a risk-informed regulatory structure (probabilistic risk assessment-based structure) for future reactors. This approach for future approval of designs and materials should provide a shorter path from material identification or specification to final approval. However, the time when such an approach is developed and implemented for actual use is uncertain.

Inclusion of new information in the ASME Code follows a formal development, review, and approval process, similar to that described in the previous section on ASTM Standards Development.

\subsection{Qualification and Acceptance Issues}

Because of the potentially lengthy process for final NRC approval of an entirely new class of material for a new reactor design (or one of its components), use of materials with some existing performance basis would be an expedient route. Extension of performance and design criteria to higher temperatures (if possible) would eliminate the need for at least some of the test method development. The real question is whether or not existing metallic materials can perform at the required temperatures. However, the actual time/temperature/irradiation conditions the candidate material will need to survive is not precisely known. Current estimates are reported in section 6.1 (Irradiation of $800 \mathrm{H}$ ), and work is underway to establish more accurate estimates that will help with the material selection process, but these data are not available at present.

High nickel content alloys with acceptable high-temperature mechanical properties may be suitable for application in areas of relatively high irradiation and up to moderately high temperatures. The same nickel alloys may be suitable for other areas exposed to high temperatures but with relatively low irradiation. Ni-Fe-Cr Alloy $800 \mathrm{H}$ (UNS N08810) is the candidate metallic material most in favor for use in the reactor control rods subjected to relatively high levels of irradiation over long time-periods. However, these same components will be near the limit of current ASME design-allowable temperatures for Alloy $800 \mathrm{H}$ during normal operating conditions, and they would exceed the limit during off-normal temperature excursions. Performance, at least over shorter time-periods with these higher temperatures, 
will have to be measured and then proven to be satisfactory at required statistical confidence levels before the NRC will allow its use in the design and construction. Alternatively, procedures would have to be proposed and accepted by the NRC to avoid the high-temperature exposure in the event of such an excursion; examples include taking advantage of the passive safety features of the reactor and removing the control rods above a certain temperature or preparing a plan to replace control rods if they are exposed to temperatures above some maximum limit.

$\mathrm{C}_{\mathrm{f}} / \mathrm{C}$ matrix composite materials have been in use for high-temperature applications in the military and aerospace sectors for many years. The material's high-temperature performance is well established. There is a substantial database on general performance of $C_{f} / C$ materials. However, there is very limited data concerning irradiation effects on its performance. A more substantial obstacle from the regulatory approval perspective is that there are no composite materials of any type approved for structural reactor internal components within the ASME Section III Code. There is, at least, the perception that the NRC is adopting a more progressive approach to its approval methodologies and processes. The federal government has mandated cooperative development of new licensing-strategy documents that utilize modern approaches to reactor design and operational risk assessment. This should assist in shortening the approval process for a new type of material, but it will still be a long process. However, the new documents should make a more well-defined path.

\subsubsection{Alloy $800 \mathrm{H}$}

Alloy $800 \mathrm{H}$ seems the most likely metallic material for possible use in control rods. Current estimates for the normal operating temperature for the pebble bed design are about $250^{\circ} \mathrm{C}$ lower than the $760^{\circ} \mathrm{C}$ maximum allowed by existing ASME specifications for Alloy $800 \mathrm{H}$ for nuclear applications per Section III of the Code. ${ }^{56}$ The prismatic control rods may experience a maximum temperature in the vicinity of $760^{\circ} \mathrm{C}$, depending on their position due to fuel depletion levels, and on the coolant flow around and through the control rods. In either case, a substantial effort will be required to complete the broad range of testing required to support use at higher temperatures ${ }^{104}$ (contrary to the approach of PBMR, [see section 4.]) Without a reasonably accurate specification of time/temperature history, it is difficult to determine the probability of acceptable performance, and hence regulatory approval. The likelihood of success probably decreases exponentially with increasing temperature and time at temperature. Alloy $800 \mathrm{H}$ begins melting at about $1360^{\circ} \mathrm{C}^{105}$ Any use or exposure beyond about $1100^{\circ} \mathrm{C}$ would probably eliminate the material from consideration for control rod structures.

Preliminary thermal analysis of a possible prismatic reactor design suggests structural temperatures (coolant channel surfaces) in the outer reflector block (nominal control rod insertion location) are between $590^{\circ} \mathrm{C}$ and $625^{\circ} \mathrm{C}$ for normal operation at the $\mathrm{BAF}$ within the core, and between $1120^{\circ} \mathrm{C}$ and $1140^{\circ} \mathrm{C}$ for a DCC where the maximum-temperature shifts vertically to near mid-core (see Figure 13 from section 5.1, Definition of Requirements). ${ }^{106}$ The inner fuel ring gas channel reaches about $1490^{\circ} \mathrm{C}$ during a depressurized conduction cool-down (DCC) at core mid-height (see Figure 14 from section 5.1).

The inner fuel ring gas channel surface sees temperatures of about $1020^{\circ} \mathrm{C}$ to $1090^{\circ} \mathrm{C}$ under normal full-power operation (at BAF); however, the rods at these locations are for shutdown only and will not be in the core during normal operation. Insertion of the shutdown control rods in the inner fuel ring under normal full-power operation (scram condition) would expose the rod material to temperatures of at least $1000^{\circ} \mathrm{C}$. Even though core heat generation would subside almost immediately, the great thermal mass of the reactor dictates a slow cooling rate, even with pressurized gas flow. To avoid control rods exposed to $1000^{\circ} \mathrm{C}$ temperatures, a two-stage shutdown procedure could be employed. The control rods are inserted first, but then insertion of the shutdown rods is delayed until temperatures are acceptably low; this approach is employed in the Japanese HTTR operational procedures. HTTR procedures are designed such that the maximum CR temperature is kept below $900^{\circ} \mathrm{C}$. Thermal models performed for the HTTR design 
showed that the control rods maintained geometric form to continue functioning with short-term exposure to $1100^{\circ} \mathrm{C}^{20}$

Whether or not the outer control rods would be inserted and exposed to these off-normal temperatures above $625^{\circ} \mathrm{C}$ is also a function of the reactor operating procedures that have not been established. The actual NGNP design and operating procedures will dictate the control rod channel locations, as well as the control rod positions during certain operating scenarios. $625^{\circ} \mathrm{C}$ is within current ASME Section IlI code-allowable range for $800 \mathrm{H}$. However, $1020^{\circ} \mathrm{C}$ and $1140^{\circ} \mathrm{C}$ are well above any approved operating temperature for $800 \mathrm{H}$ in any application, including non-nuclear applications, and probably would preclude its use in those temperature regimes.

There may also be considerations for control rod (and related component) temperatures in the upper plenum region of the reactor vessel when they are not inserted into the core. The temperatures in this region could possibly exceed the ASME-allowable $760^{\circ} \mathrm{C}$ level during certain scenarios where forced coolant flow stops and the upper plenum is heated by convection from the core region. ${ }^{42}$ Although preliminary results indicate this region will remain reasonably cool (see section 5.1.1, Definition of Requirements), accurate temperatures in the upper plenum during various off-normal events (Class B or C) are not available. Some type of active cooling, insulation, or other engineered solution may be needed to keep the metal control rods below an acceptable temperature during such events.

Figure 31 shows an allowable time during a service life of only $20 \mathrm{hrs}$ at a temperature of $650^{\circ} \mathrm{C}$ before creep behavior must be considered. In essence this means creep behavior must be considered in the application of $800 \mathrm{H}$ for control rod components. The existing ASME design-allowable stress $\left(\mathrm{S}_{\mathrm{mt}}\right)$ for $800 \mathrm{H}$ at $750^{\circ} \mathrm{C}$ for long-term performance where creep behavior is a consideration is the order of $20 \mathrm{MPa}$ or less for $100,000 \mathrm{hr}$ exposure (from Table 5.2c, p. $61^{107}$ ). The design ultimate (Su) and yield (Sy) strength values are found in Tables 2.2 and 3.2, p. 13. ${ }^{107}$ Note that Alloy $800 \mathrm{H}$ in tubular form is qualified for use up to $982^{\circ} \mathrm{C}$ in non-nuclear applications. ${ }^{108,109}$ While there is a basis, including a reasonable database of tensile properties, for qualification to higher temperature use (above $760^{\circ} \mathrm{C}$ ) in nuclear applications, there is a lack of both data and design methodology related to creep and fatigue at the higher temperatures. ${ }^{104}$ The Japanese Energy Research Institute has developed design curves on alloy $800 \mathrm{H}$ for temperatures up to $1000^{\circ} \mathrm{C}$ during work on HTTR. ${ }^{3}$ 


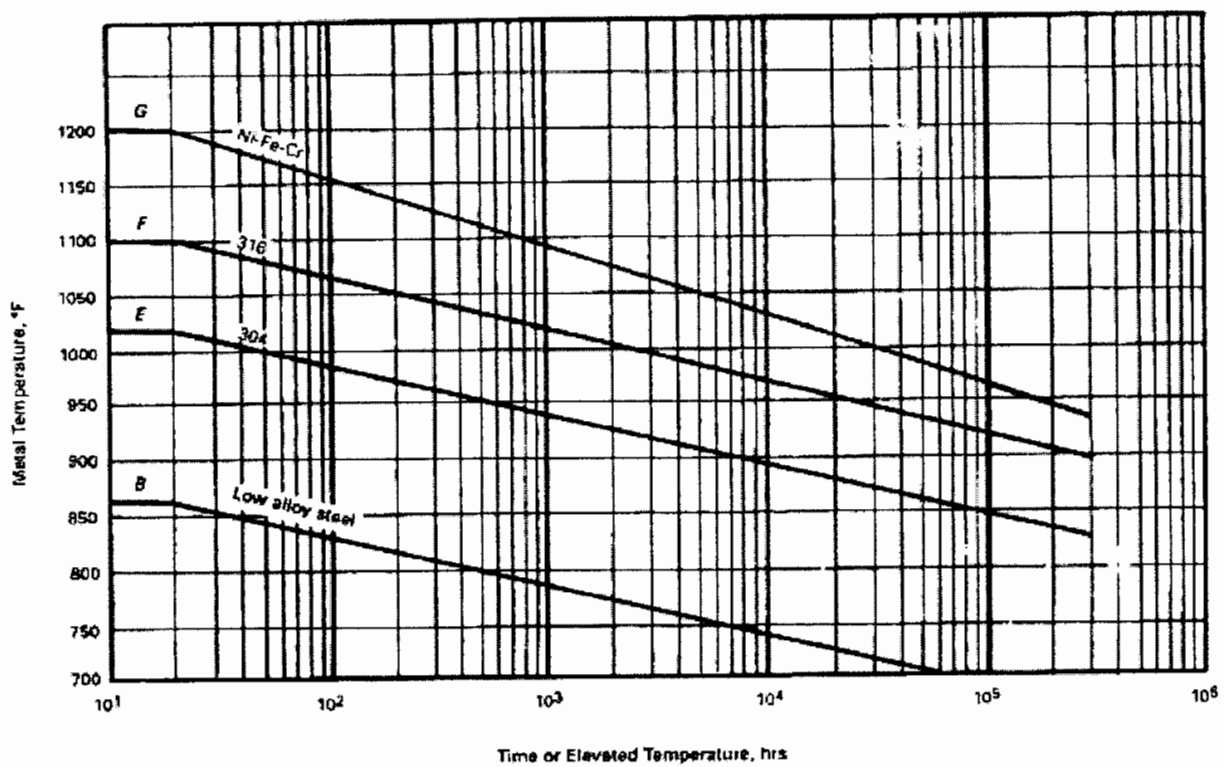

Figure 31. Allowable time during service life at temperature for $800 \mathrm{H}^{107}$

Shah, et al. reviewed Codes and Procedures applicable to HTGR components and stated:

"... an evaluation of the applicability of the codes, standards, and procedures to the materials that have been used or recommended for HTGRs, taking into account the HTGR operating temperature and environments. Seven codes and procedures, including five ASME Codes and Code Cases, one French Code (RCC-MR), and one British Procedure, were reviewed and evaluated. The ASME Codes and Code Cases included Section III, Subsection NB and Subsection NH; Code Cases N-499-1, N-201-4; and the draft Code Case for Alloy 617. Major findings of the evaluation are as follows. (1) Most of the materials needed for HTGR are not included in the code cases. New code cases are needed for these materials. (2) The maximum temperature permitted by the codes and code cases for the materials acceptable for HTGR components is lower $\left(760^{\circ} \mathrm{C}\right)$ than the maximum temperature $\left(850^{\circ} \mathrm{C}\right.$ or higher $)$ that these components may experience in reactor service. The scope of the code and code cases needs to be expanded to include materials with allowable temperatures greater than $850^{\circ} \mathrm{C}$. (3) The codes and code cases do not provide specific guidelines for environmental effects, especially the effect of impure He on the high-temperature behavior (e.g., creep and creep-fatigue) of the materials considered. "110

At that time (2003), the anticipated temperature for NGNP outlet gas was higher than $850^{\circ} \mathrm{C}$.

However, current code-allowable temperatures for $800 \mathrm{H}$ are still set at $760^{\circ} \mathrm{C}$ in nuclear applications, and with somewhat restrictive limits placed on allowable stresses where creep and other potential environmental effects may be present. The highest priority item of the five on the DOE-ASME 3-year development plan funded in FY 2006 is to extend Section III qualified use temperature for Alloy $800 \mathrm{H}$. 
ASME Nuclear Code Case N-499-2 addresses use of SA-533 and SA-508 steels at elevated temperatures (but only $371^{\circ} \mathrm{C}$ to $538^{\circ} \mathrm{C}$ ) for limited times. ${ }^{111}$ This Code Case demonstrates the general type of data that will be required for extending the allowable temperatures for Alloy $800 \mathrm{H}$. However, additional creep and creep-fatigue data, and possibly other information, will be required in the $1000^{\circ} \mathrm{C}$ or higher temperature range.

\subsubsection{Ceramic Composites}

Performance of $\mathrm{C}_{\mathrm{f}} \mathrm{C}$ composites above any anticipated control rod maximum temperature is well established for various environments (notably air) without irradiation considerations. Considering only strength at temperature, $\mathrm{C}_{\mathrm{f}} / \mathrm{C}$ material systems would most likely have acceptable performance for the reactor control rod structures, but there are the important considerations of irradiation and operating environment (the core atmosphere).

An effort was initiated some years ago to develop ASME Code sections related to design and specification of $\mathrm{C}_{\mathrm{f}} \mathrm{C}$ composites (non-nuclear) for structural applications. The work proceeded for about two years, but due to lack of funding, the effort was terminated. ${ }^{112}$

Long-term irradiation degradation to levels greater than several $\mathrm{dpa}$ of $\mathrm{C}_{\mathrm{f}} \mathrm{C}$ materials has not been fully characterized. Early test data suggests a limited irradiation lifetime, probably less than $8 \mathrm{dpa} .^{70}$ Recent estimates of accumulated control rod dose for the reactor lifetime have been reduced from $30 \mathrm{dpa}$ to about $8 \mathrm{dpa}$, thus $\mathrm{C}_{\mathrm{f}} / \mathrm{C}$ irradiation lifetime may not be a significant selection factor. Other than component and time expense, there are no probable technical obstacles to replacement of the control rods, if deemed necessary.

Another complicating factor for $\mathrm{C}_{\mathrm{f}} / \mathrm{C}$ material is that it is an engineered material system, meaning the composite structure and processing are designed to meet particular performance criteria. Existing ASME design and assessment rationale within Section III are guided by homogeneous material characteristics typical of use in LWRs. The system of design and assessment, as well as specification, will have to be revised to properly account for the differing performance modalities presented by fiber composite systems. It can be argued that test specimens must be cut from prototype components subjected to appropriate thermal and irradiation conditions. ${ }^{42}$ One way to shorten the assessment of such materials is to test actual structures, or at least test specimens produced with the same internal structure and nominal form as the component of interest. This may provide useful design information for the particular component of interest but very little detail for comparative purposes, or a different material system. This also creates substantial costs, both time and fiscal, as a test method and procedure developed according to this approach may only be suited for a narrow range of articles and material thickness.

There is also the issue of a composite material system qualification. Not only must the individual constituents of the final material be qualified and approved, but also the method of assembly. All of these will combine to create the final material system, which will have to meet the various performance criteria as well.

ASME B\&PV Code Section X, "Fiber-Reinforced Plastic Pressure Vessels" 113 is representative of the basic requirements for materials, design, and qualification of composite material systems (for pressure vessel applications). A composite material system specification will necessarily be more complex than a homogeneous metal specification. Attention to appropriate performance-affecting properties and processes will be required to develop a specification that allows sufficient flexibility in the material selection and composite architecture to meet design requirements, while simultaneously assuring acceptable performance for the resulting structure. 


\subsection{Acceptability Summary}

It is certain that development of standards and codes to qualify composite materials of any type for nuclear reactor internal structural components will take longer to achieve than for a homogeneous metallic material, especially one that already has some ASME Code basis. Whether operating temperature requirements will dictate use of advanced materials is still uncertain.

If composite structures/materials are not developed and ultimately selected for the NGNP program, they may be developed by the French, South Africans, or Japanese who also want high-temperature composites in the ASME code and to be NRC-approved, so they can operate at higher temperatures and market their reactor designs in the U.S. It may be advisable to develop these composites even if they cannot make the initial NGNP materials deadline because of codification delays. NGNP reactor target life is 60 years. The initial NGNP is a demonstration reactor sponsored by the government, and there may be a driving force to put a composite control rod in the NGNP to build confidence and prove concepts. This is related to the NGNP mission to develop a state-of-the-art reactor system capable of $\mathrm{H}_{2}$ co-generation. 


\section{MANUFACTURABILITY}

\section{$8.1800 \mathrm{H}$}

Alloy 800 was developed in 1949 when $\mathrm{Ni}$ and other strategic metals were being stockpiled by the U.S. government and an alloy was needed that could be used in applications such as home appliances. ${ }^{114}$ Its value as a material for high temperature, corrosive applications was soon discovered. Higher $\mathrm{C}$ contents and larger grain sizes (ASTM 5 or coarser) resulted in better creep rupture properties, and alloy $800 \mathrm{H}$ was introduced. It became part of the ASME B\&PV Code, Section III (nuclear) in November $19644^{115}$

Incoloy $800 \mathrm{H}$ is available from the manufacturer in all standard mill forms including rod, bar, plate, sheet, strip, shapes, and tubular products. Seamless pipe, the form required for control rods, can be manufactured to ASTM nuclear code specifications by the vendor. The alloy can be readily hot- and coldworked and machined. ${ }^{105,116}$ Welding procedures have been established; however, the welds would present a potential weak link in the aggressive reactor core environment, so only mechanical joints are anticipated in the control rod as for past control rod designs. No unique metalworking processes are required and no significant problems are foreseen in the manufacturing of metallic control rods.

\section{$8.2 \quad C_{f} / C$ Composites}

The production of $\mathrm{C}_{\mathrm{f}} / \mathrm{C}$ composites is a mature technology, with a wide variety of fabrication techniques, capable of producing complex geometry components, resulting in more design flexibility and lower cost compared to $\mathrm{SiC}_{f} / \mathrm{SiC}$ composites. ${ }^{42,57,76}$ A number of domestic companies currently manufacture $C_{f} / C$ composites using various processes. As a result, necessary equipment such as preform weaving set-ups and high-temperature furnaces are available to make $1-2 \mathrm{~m}, 10 \mathrm{~cm}$ diameter sections required, and machining capabilities, NDE expertise, and quality assurance programs are available. ${ }^{69}$

$\mathrm{C}_{\mathrm{f}} \mathrm{C}$ composites were first developed in the 1950's. The $\mathrm{C}_{\mathrm{f}} / \mathrm{C}$ composites on the space shuttle are late 1970's technology and $C_{f} / C$ aircraft brake pads saw widespread application in the 1980's. The progression from initial development to large volume application of $\mathrm{C}_{\mathrm{f}} / \mathrm{C}$ composites has taken 20 to 30 years. The highest volume $\mathrm{C}_{f} / \mathrm{C}$ composite products produced today are brake pads for both military and passenger aircraft. An example is shown in Figure 32. The majority of these are processed with CVI because of the lower cost; however, $\mathrm{CVI} \mathrm{C}_{\mathrm{f}} / \mathrm{C}$ composites have inferior irradiation properties as discussed below.

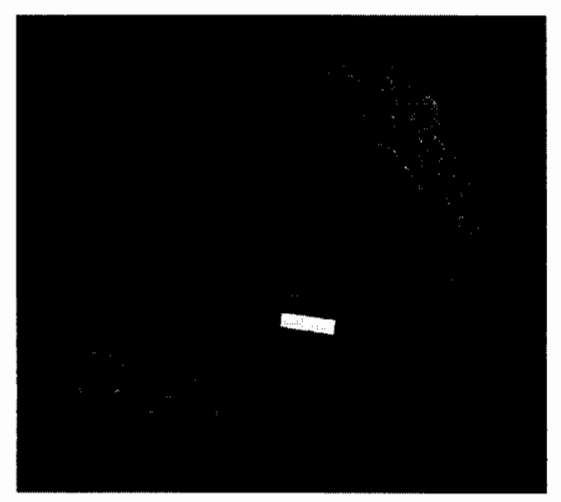

Figure 32. Typical aircraft brake parts made from $\mathrm{C}_{f} / \mathrm{C}$ composite. 


\subsubsection{Fibers}

Carbon fibers fall into two general categories: PAN and pitch. PAN fibers are made from polyacrylonitrile. This substance cannot be melted, so the pre-cursor fibers must be formed by a wet spinning process. The copolymer is dissolved in a solvent and then extruded through a spinneret, a die head containing small capillary holes. The extruded fibers are polymerized inside a coagulating bath and then stabilized by heating in air at about $250^{\circ} \mathrm{C}$ under tension in order to fix the molecular orientation. Finally, the fibers are carbonized $(\leq 1700 \mathrm{C})$ or graphitized $(\sim 3000 \mathrm{C})$ in an inert atmosphere. The thermal processing eliminates the majority of non-carbon elements from the fiber allowing $\mathrm{C}-\mathrm{C}$ bonding. ${ }^{69}$

Pitch fibers are comprised of a complex material containing mainly polyaromatic hydrocarbons and their heterocyclic analogs. The precursor can be tar, petroleum, or synthetic hydrocarbons. Fibers are formed by melt-spinning, then thermoset and carbonized at higher temperatures $(\sim 1000 \mathrm{C})$ in an inert atmosphere to develop their final properties. No tensile load is required to orient basal planes of graphite crystallites parallel to the fiber axis. By heating to the graphitizing temperatures, the pitch develops 3D order.

The performance of $\mathrm{C}$ fibers is quite consistent, ${ }^{117}$ and $\mathrm{C}$ fibers have a mature and stable supplier base and are mass produced by a number of suppliers, both foreign and domestic ${ }^{118}$; however, the industry is currently capacity constrained and some types of $\mathrm{C}$ fiber are more difficult to acquire than the SiC fibers discussed in section 8.3 of this report. ${ }^{177}$

\subsubsection{Fiber Preforms}

The $\mathrm{C}$ fibers are arranged into multi-filament bundles, or tows, and made into preforms. ${ }^{70}$ The tube geometry required for a control rod can be achieved by a variety of preform methods, including the jelly roll, the T-form, and tube braiding. In the jelly-roll method (see Figure 33a), a 2D-woven fabric is rolled around a mandrel and then impregnated with the matrix. The jelly-roll architecture is simple to produce and low cost, ${ }^{82}$ but jelly-roll preforms have limited shear strength. To increase shear strength, stitching is added to the jelly roll to produce $T$-forms (see Figure 33b). Tube braiding (see Figure 33c) uses a specialized machine (shown in Figure 34) to braid the fibers over one-another down the length of tube rather than forming a flat woven sheet into a tube. The weave pattern looks like a Chinese finger puzzle and results in good infiltration, good shear strength, and high axial strength. Variations include tube braiding over the last layer of a jelly-roll to improve the outer shell and inserting axial fibers into the braid (also shown in Figure 2c) to increase the axial strength. ${ }^{69}$ 

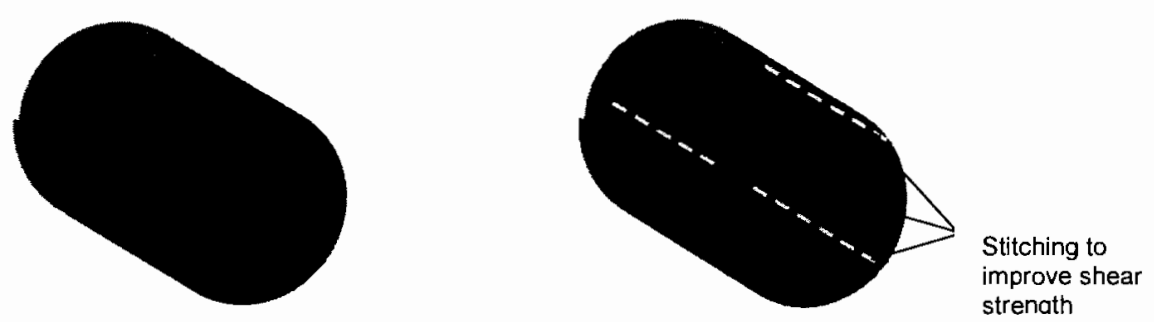

a. Jelly-Roll

b. T-Form

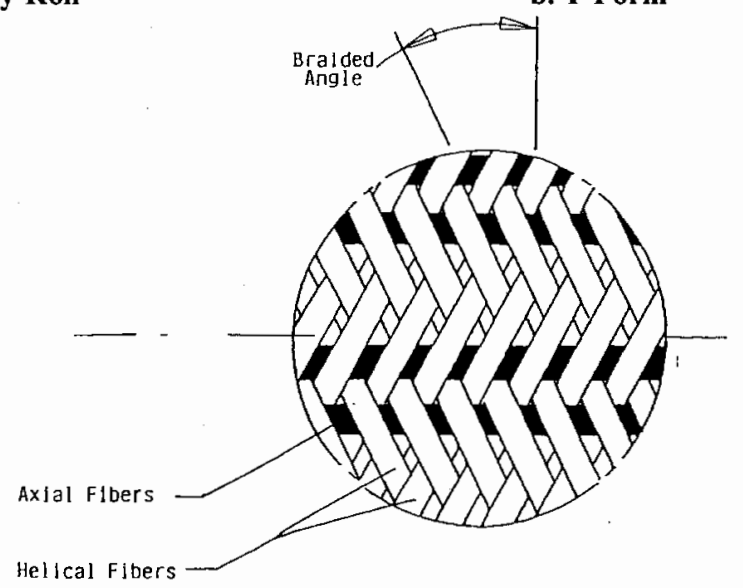

c. Braided Tube

Figure 33. Types of preforms for making $C_{f} / C$ composite tubes: (a) jelly-roll, (b) $T$-form, and (c) braided tube. $^{69}$

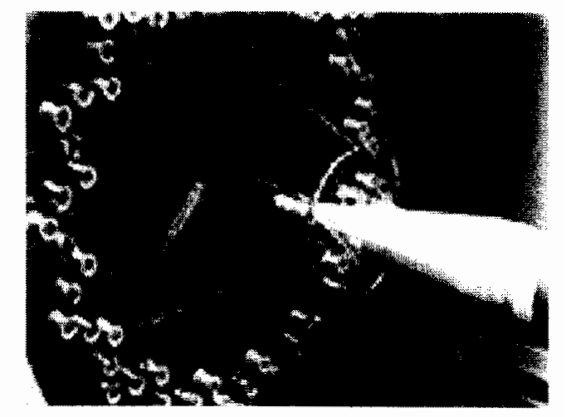

Figure 34. Tube braiding equipment. ${ }^{69}$ 


\subsubsection{Carbon Matrix}

The $\mathrm{C}$ fiber preforms must be infiltrated with a carbonaceous precursor, either a liquid or a gas that will ultimately form the matrix of the composite. In liquid impregnation, resin- or pitch-based liquids are pressed between the fibers, followed by carbonization at elevated temperatures and high pressures. Several multi-week cycles may be required before the final graphitization step at very high temperatures. The $C_{f} / C$ composite must be densified and converted to graphite in order to create a structurally viable and irradiation resistant product. Liquid impregnation can produce composites up to $93 \%$ dense. The entire process, shown in Figure 35, can take 9 to 12 months.

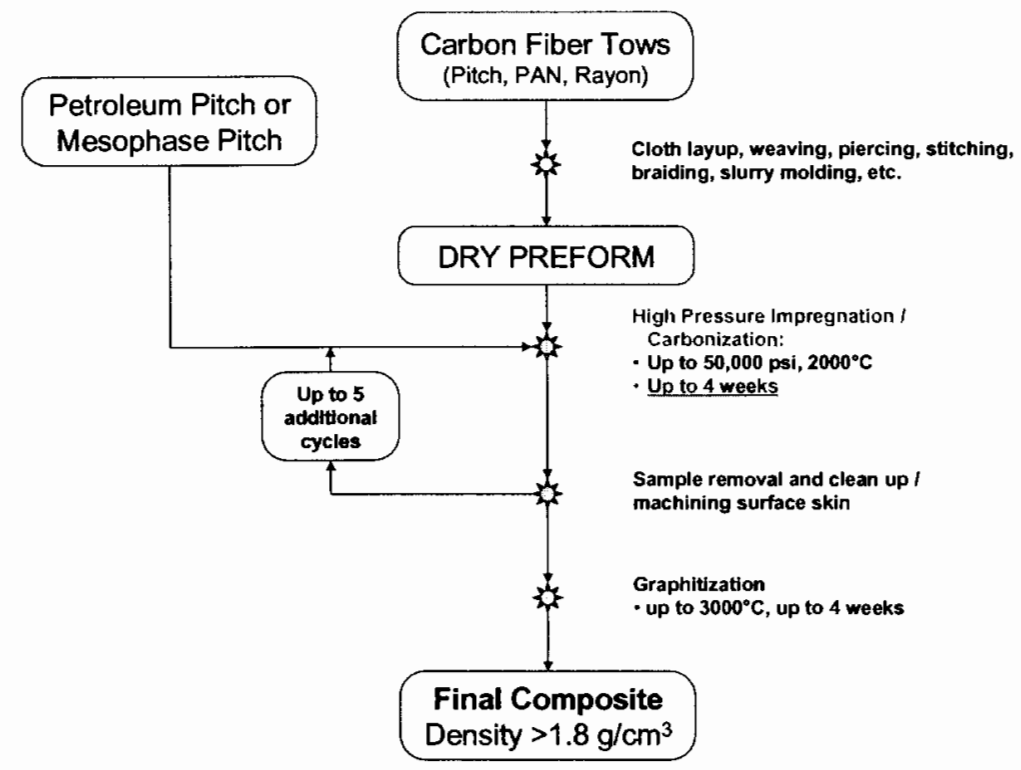

Figure 35. Flow chart of processing methods for $C_{\mathrm{f}} / \mathrm{C}$ composites. ${ }^{69}$

Another type of liquid impregnation is synthetic naphthalene conversion. Naphthalene is the precursor and a super acid catalyst is used to initiate a conversion to mesophase pitch. Naphthalene saturates the fiber preform readily and can be impregnated without high pressure furnaces. It is then converted directly into the $\mathrm{C} /$ graphite matrix. ${ }^{69}$

$\mathrm{CVI}$ is a process where heated hydrocarbon gases flow through the preform and $\mathrm{C}$ is deposited upon the fibers and in the pores of the preform. CVI is a well characterized process that can produce a highly graphitic matrix with very few microcracks and pores, resulting in a composite with up to $95 \%$ total density. After each infiltration the composite is carbonized to eliminate volatile elements, similar to the process used for the fibers, and produce quasicrystalline $\mathrm{C}$ structures. A great deal of shrinkage occurs, generating pores and cracks; however, subsequent infiltrating fills in these flaws until the desired density is obtained. The material is fired at temperatures up to $3000^{\circ} \mathrm{C}$, which forms a bond across the matrix and the fiber and generates an ordered graphitic microstructure. It can take more than a month to complete one cycle of the CVI process. ${ }^{69}$ 


\subsubsection{Machining}

When designing any fiber-reeinforced continuous composite, care must be taken that fibers will be aligned to create higher strength in the desired directions. Threading in the articulated joints, which is a design element of at least one composite control rod concept, is a particular concern, because the fibers may not be aligned appropriately for strength in both the tube and the threads. Very coarse threads may alleviate this concern, but qualification could also be an issue due to the load complexity and the amount of testing required, including full scale tests. ${ }^{117}$ It is also generally undesirable to cut the fibers during a machining process, because doing so degrades the material performance in that area. Edge effects, environmental attack, and other factors may contribute to performance degradation.

\subsubsection{Additional Details}

It has been determined that simple 2D braided fiber architecture with a liquid precursor impregnation technique is best for initial test samples. A 3D weave will have much larger cost and lower infiltration efficiency, and although the strength is increased by adding a third set of fibers, there is no need for increased strength for this application. The control rod need not be gas-tight; therefore, full density is not required, so reduced infiltration cycles can be used, particularly for preliminary samples. ${ }^{69}$ Pitch matrix and fibers are desired because of the high crystallinity that results.

Eventually, specifications for final C/graphite purity (trace elements) will need to be established for a nuclear grade composite. A very high temperature heat treatment in a halide gas will be needed to remove metallic impurities such as $\mathrm{Al}$ and $\mathrm{Fe}$, in order to use the composites in a radiation environment. ${ }^{69}$ Figure 36 shows two conceptual designs of ceramic composite control rods. 


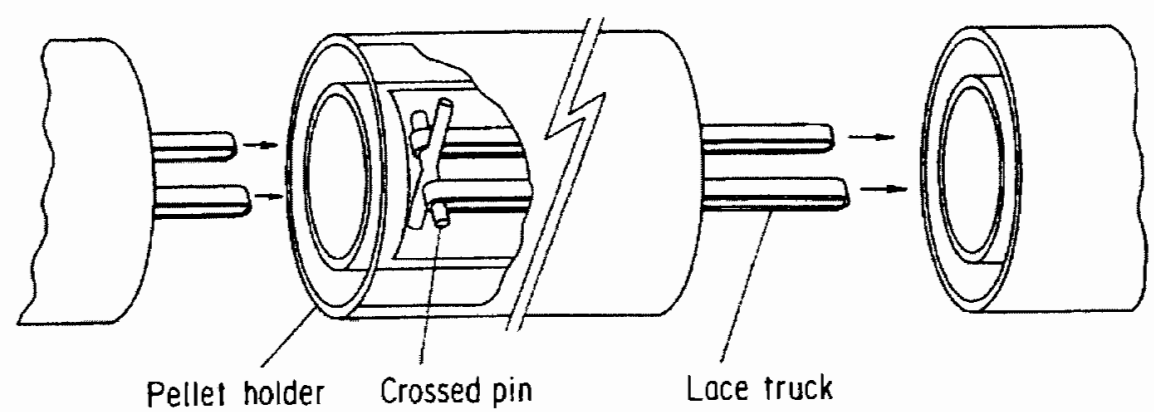

(a).

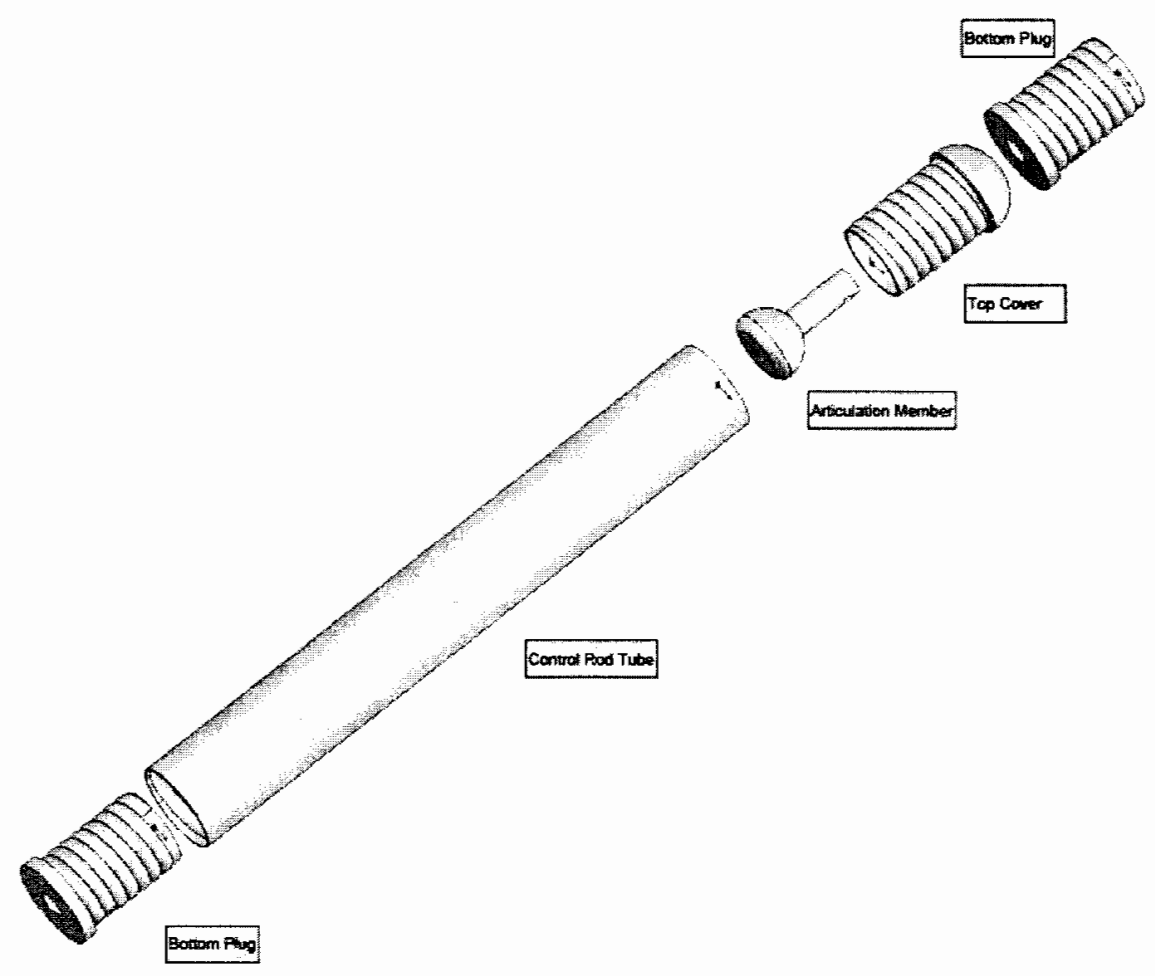

(b)

Figure 36. (a) A schematic of an annular, articulated composite control rod design presented by the Japanese. ${ }^{77}$ (b) schematic of a potential NGNP composite control rod design. ${ }^{119}$ 


\section{3 $\quad \mathrm{SiC}_{\mathrm{f}} / \mathrm{SiC}$ Composites}

$\mathrm{SiC}_{\phi} / \mathrm{SiC}$ composites are an emerging technology first developed about 15 years ago. Production of fibers, composite material, and finished components has been limited, although much research and development is being done. Figure 37 shows a $\mathrm{SiC}_{\mathrm{f}} \mathrm{SiC}$ thrust chamber for liquid rocket propulsion systems. ${ }^{120}$ Assuming $\mathrm{SiC}_{\mathrm{f}} \mathrm{SiC}$ composites follow a similar 20 to 30 year development time frame as $\mathrm{C}_{\mathrm{f}} / \mathrm{C}$ composites, large volume production can be anticipated about 2015-2025. ${ }^{117}$

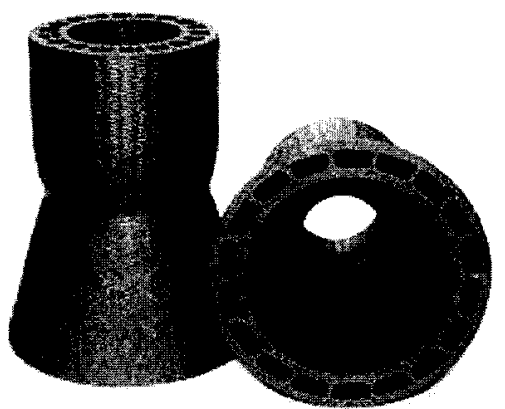

Figure 37. $\mathrm{SiC}_{\mathrm{f}} \mathrm{SiC}$ thrust chamber for liquid rocket propulsion systems. ${ }^{120}$

\subsubsection{Fibers}

Several commercially available SiC fibers have been considered. Any that use boron as a sintering aid must be eliminated because of the nuclear reactions that would occur with trace amounts of $B$ left in the composite. Hi-Nicalon ${ }^{\mathrm{TM}}$ Type-S (Nippon Carbon co., Tokyo, Japan) and Tyranno ${ }^{\mathrm{TM}}$-SA3 (Ube Industries, Ltd., Ube, Japan) are two SiC fibers which have proven superior for nuclear applications. (Because of the high cost of Type-S fiber, some Hi-Nicalon ${ }^{\mathrm{fM}}$ was also used in this program for testing standard development where irradiation properties were not an issue. ${ }^{82}$ )

Hi-Nicalon Type-S is only produced at the laboratory scale and has not been increased to pilotplant scale yet. As a result, it is currently very expensive and has limited availability; however, it has superior mechanical and irradiation properties. ${ }^{117}$ Polycarbosilane is melt-spun into a fiber, followed by an electron-beam curing process and pyrolysis. ${ }^{121}$

Tyranno SA fibers are prepared by melt spinning polyaluminocarbosilane, curing in air, and then continuously firing in inert gas up to $1300^{\circ} \mathrm{C}$ to obtain an amorphous Si-Al-C-O fiber. It is then sintered at temperatures above $1800^{\circ} \mathrm{C}$, releasing $\mathrm{CO}$ gas from 1500 to $1700^{\circ} \mathrm{C}$. Aluminum acts as a sintering aid, but must be kept below $1 \mathrm{wt} \%$ to obtain the desired properties. ${ }^{121}$ 


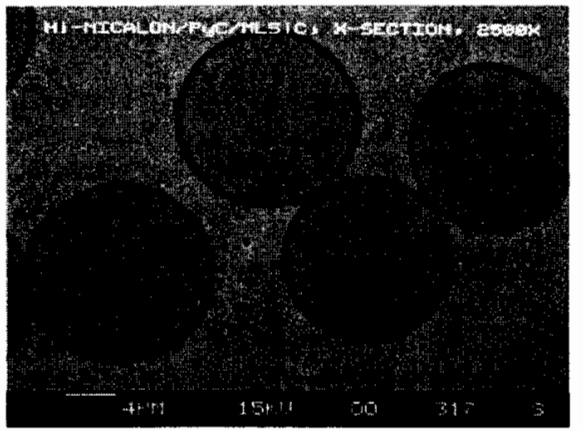

Figure 38. Micrograph showing cross-section of some SiC fibers.

lnitially there was some difficulty braiding with $\mathrm{SiC}$ fibers, but the issue has been resolved. ${ }^{117}$ The same types of preforms can be made as described above in the $\mathrm{C}_{f} / \mathrm{C}$ composite section, and, as for the $\mathrm{C}_{\mathrm{f}} / \mathrm{C}, 2 \mathrm{D}$ braiding has been chosen for preliminary development work. ${ }^{57}$

\subsubsection{Interphase}

The interphase transfers the load between the matrix and the fibers, deflects the matrix cracks, enables fiber pull-out once the composite begins to fracture, and alleviates thermal residual stresses. To form an interphase for $\mathrm{SiC}_{\mathrm{f}} \mathrm{SiC}$ composites, the fibers are coated with thin layers of boron nitride, PyC, or multiple layers of $\mathrm{PyC}$ and $\mathrm{SiC}$. As mentioned above in section 8.3.1 (fibers), boron cannot be used, and the $\mathrm{PyC} / \mathrm{SiC}$ multilayer has the best irradiation and oxidation behavior. ${ }^{82}$ The single $\mathrm{C}$ layer can be removed by oxidation or degraded by radiation, and the multilayer can cause a tortuous fracture path which results in better toughness. ${ }^{122}$

Alternate layers of $\mathrm{SiC}$ and $\mathrm{C}$ are deposited onto the fibers using a $\mathrm{CVl}$ process. ${ }^{122,123} \mathrm{~A}$ picture of the multilayer interphase is shown in Figure 39.

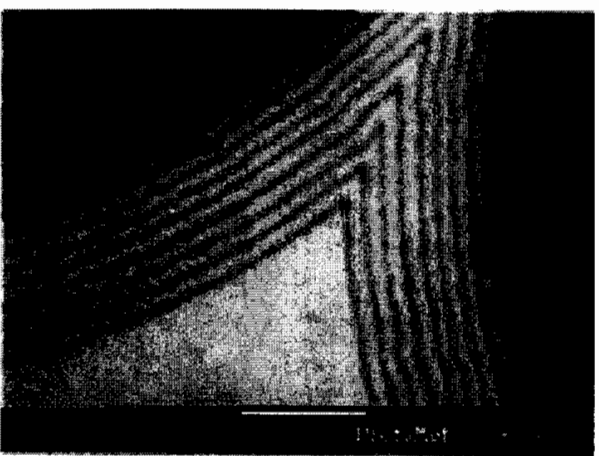

Figure 39. Multilayer PyC/SiC interphase layer. Dark areas are fibers and light area is matrix. 


\subsubsection{Matrix}

A number of processes have been used to create the matrix of $\mathrm{C}_{\mathrm{f}} / \mathrm{C}$ composites, such as meltinfiltration, polymer impregnation and pyrolysis, and nano-infiltration and transient eutectic-phase process; however, these require process optimization and/or irradiation studies before they can be considered viable candidates. $\mathrm{CVI}$ is the only process that is being considered for the $\mathrm{SiC}_{\mathrm{f}} / \mathrm{SiC}$ composite matrix. ${ }^{82} \mathrm{CVI}$ produces a high purity, highly crystalline, stoichiometric and homogeneous $\beta$-SiC matrix with $\sim 85 \%$ total density and less damage to fibers than other processes. ${ }^{64,8157,124}$

During CVI, process reactant gases (methyltrichlorosilane or ethyltrichlorosilane with a $\mathrm{H}_{2}$ carrier gas) are allowed to flow around the preform at temperatures of about $1200^{\circ} \mathrm{C}$ under atmospheric pressure and diffuse into the pores. ${ }^{123,125,126}$ Multiple cycles are required with a high temperature anneal between cycles, and occasional surface machining is needed to open the gas pathways that have become sealed. ${ }^{127}$

The CVI process discussed above is isothermal and isobaric, and can efficiently produce thinwalled, complex geometries; however, sections greater than $3 \mathrm{~mm}$ can require weeks to months of processing time. Forced flow thermal-gradient CVI (FCVI) can produce an equivalent section in a single step requiring only tens of hours. ${ }^{127}$ The process also offers low porosity, uniform pore distribution, and uniform C interphase thickness. ${ }^{123,126}$ In FCVI, the reactant stream is forced to flow through the preform. The thermal gradient prevents the surface from sealing, so periodic surface machining is not required. ${ }^{127}$

$\mathrm{SiC}_{\mathrm{f}} / \mathrm{SiC}$ composites are limited to a maximum cross-section of less than $20 \mathrm{~mm}$, a restriction not faced by $C_{f} / C$ composites, but this should not be a limitation for control rods. ${ }^{117}$

\subsubsection{Machining}

The issue with machining $\mathrm{SiC}_{f} / \mathrm{SiC}$ composites is not whether it can be done, but whether it should be done. $\mathrm{SiC}$ fibers are too expensive to machine geometries from a billet, including test specimens, creating large amounts of waste. This issue is not as important for the less expensive $C_{f} / C$ composites. Further, machining can degrade the properties that a composite material system was designed to achieve and is a concern for both types of composites. More clever designs are needed to fabricate near-net-shape parts and minimize machining. $\mathrm{SiC}_{f} / \mathrm{SiC}$ is also harder than $\mathrm{C}_{f} / \mathrm{C}$ and must be rough machined more slowly; but this issue would be minimal if near net shapes can be produced.

\subsection{Summary of Manufacturability}

Producing the basic shapes required to make the control rod sheathing poses no particular problem for any of the materials. SiCf/SiC is still produced in small quantities, although that may change by the time the actual control rods are required. The necessary equipment, capacity, and expertise are available for $800 \mathrm{H}$ and $\mathrm{Cf} / \mathrm{C}$ composites. Machining is not particularly difficult, but each material poses its own design challenges. $800 \mathrm{H}$ will be operating in a temperature regime where creep could be significant, so care must be taken with stress concentrations. Composites must be designed so that threads are either avoided or properly supported by fibers, with consideration not only towards the integrity of the part, but the difficulty in qualifying the component design. $\mathrm{SiCf} / \mathrm{SiC}$ requires additional effort to design near net shape parts because of the very high cost of the high quality $\mathrm{SiC}$ fibers required for irradiation resistance Both processing time and material availability could be issues if composites are chosen. Only two companies currently produce $\mathrm{SiC}$ fibers; both are Japanese and production is at the laboratory scale. Carbon fibers are mass produced by both domestic and foreign suppliers, but the industry is currently capacity constrained and certain types of fiber are very difficult to obtain. This may not be the case when material is needed for production of control rods, but would affect development. 


\section{SUPPLY AND COST}

\subsection{Material Cost}

\subsubsection{Raw Materials}

Currently, raw stoichiometric SiC fibers (Hi Nicalon ${ }^{\mathrm{TM}}$ Type S, Tyranno ${ }^{\mathrm{TM}} \mathrm{SA}$ ) cost 15 to 30 times more than C fibers. ${ }^{118}$ Tyranno SA \& Hi-Nicalon Type $S$ are about $\$ 5000 / \mathrm{kg}$ and $\$ 10,000 / \mathrm{kg}$, respectively, the Tyranno SA being consistently much less than the Hi-Nicalon Type $S,{ }^{118}$ while the current price of C fiber is about $\$ 200$ to $\$ 400 / \mathrm{kg}$. ${ }^{117}$ For example, T300 $\mathrm{lk}$ Carbon tow is about $\$ 350 / \mathrm{kg} .118$

Carbon fiber has a more mature and stable production/supplier base, versus stoichiometric SiC fiber for which there are only two suppliers at this time - UBE and Nippon Carbon both in Japan. The cost of $\mathrm{SiC}$ fibers would be expected to decrease as the manufacturing process is scaled up from lab, to pilot plant, to commercial production. CG-Nicalon costs $\$ 1,400 / \mathrm{kg}$ and uses the same precursor as Hi-Nicalon; it is presently at the low-volume end of manufacturing. Nippon Carbon has projected a decreasing price of CG-Nicalon with increasing volume. ${ }^{117}$

The raw material cost for a $\mathrm{kg}$ of $\mathrm{SiC}$ matrix precursor is less than $\$ 150$. This is a commodity material that could decrease in cost by $10-30 \%$ with volume buying for manufacturing. Therefore, significantly greater cost savings in materials would be realized with $\mathrm{SiC}_{\mathrm{f}} \mathrm{SiC}$ with increasing volumes, but the $\mathrm{SiC}_{\mathrm{f}} \mathrm{SiC}$ raw materials would still be more expensive than $\mathrm{C}_{\mathrm{f}} / \mathrm{C}$ raw materials. ${ }^{117}$ Domesticallyproduced radiation-resistant $\mathrm{SiC}$ fibers may be available from $\mathrm{COI}$ Ceramics in the near-future (though made from Tyranno fiber pre-cursors).

$\mathrm{C}_{\mathrm{f}} / \mathrm{C}$ composites are mass produced in high volumes both domestically and off-shore; however, the world industry is currently capacity-constrained and some carbon fibers are more difficult to acquire than $\mathrm{SiC}$ fibers. ${ }^{117} \mathrm{Hi}-\mathrm{Nicalon}$ Type $\mathrm{S}$ is only available in lab scale production, with capacity of about $100-200$ $\mathrm{kg} /$ year/supplier. ${ }^{118}$ Depending on the timing of an order, Hi-Nicalon Type S is either in stock or a two to three month delivery (for small volumes), due to limited production capability. The availability of Tyranno SA fiber in smaller quantities has not been a recent problem. ${ }^{17}$

$\mathrm{C}_{\mathrm{f}} / \mathrm{C}$ composite has two-thirds the density of $\mathrm{SiC}_{f} / \mathrm{SiC}$ composite and thus more volume of $\mathrm{C}_{\mathrm{f}} \mathrm{C}$ is obtained per $\mathrm{kg}$ of material, but the lower specific strength of the $\mathrm{C}$ materials may dictate a heavier component to withstand the design stresses. However, the substantially lower cost of the $C$ fibers makes this difference irrelevant to the overall component cost.

\subsubsection{Billet and Part Fabrication}

Currently, Hi-Nicalon Type S material components cost about $\$ 22,000 / \mathrm{kg}$ and the Tyranno SA components cost about $\$ 15,000 / \mathrm{kg}$. This cost difference between the $\mathrm{SiC}_{\mathrm{f}} \mathrm{SiC}$ materials is due almost entirely to fiber cost. The cost of fabrication-related material rejection as the result of the less manure $\mathrm{SiC}_{f} / \mathrm{SiC}$ technology would likely be minor in comparison. The fiber manufacturer (Nippon Carbon) has historically predicted decreasing prices with increasing volumes. "Typical" $\mathrm{C}_{f}^{\prime} \mathrm{C}$ parts (items in current production from various manufacturers) may sell for $\$ 1400-\$ 2200 / \mathrm{kg}$ in $2006 .{ }^{117}$ Precise values for FMI222 material, a C fiber under consideration for NGNP composites, are not readily available. Even considering current economies of scale for production $\mathrm{SiC}_{f} / \mathrm{SiC}$ components, they will be substantially more expensive than $\mathrm{C}_{f} / \mathrm{C}$ composite pieces and likely will remain so. 
One control rod tube segment (about $1 \mathrm{~m}$ in length $\times 100 \mathrm{~mm}$ diameter $\times 3 \mathrm{~mm}$ wall thickness) requires approximately $\mathrm{I} \mathrm{kg}$ of fiber. The mass may be a bit more for $\mathrm{C}_{\mathrm{f}}$ due to its lower specific strength. Current fabrication capabilities limit tube segment lengths to about $2 \mathrm{~m}$.

Woven mats are generally less expensive than braided tube pre-forms. Braiding cost for the SiC fiber composite preforms have been estimated to be on the order of $\$ 10 \mathrm{~K}$ per tube segment and infiltration costs about $\$ 10 \mathrm{~K}$ per tube segment when 4 tubes are infiltrated together at Hyper-Therm. ${ }^{128}$ It is likely that this cost would decrease substantially if higher quantities were processed at one time. The potential vendor would need to be consulted to make this assumption reliable.

Studies by GE/Ceramic Composite Products show that in production quantities, CVI and liquid infiltration processes for matrix formation are comparable in price. Although at present, CVI for small scale production is substantially more expensive. ${ }^{118}$ Therefore, the matrix formation cost will be similar regardless of the material system chosen; $\mathrm{SiC}_{\mathrm{f}} / \mathrm{SiC}$, which requires $\mathrm{CVI}$, may be a bit more costly per unit volume in small quantities for research purposes. $\mathrm{C}_{\mathrm{f}} / \mathrm{C}$ manufacturing, which may be $\mathrm{CVI}$ or liquid impregnation, is typically faster relative to $\mathrm{SiC}_{\mathrm{f}} / \mathrm{SiC}$, but is more labor intensive. The cost of implementing quality control measures would increase costs as well. A segment of a $C_{f} / C$ control rod tube might cost approximately $\$ 30 \mathrm{~K}$ if purchased in substantial quantities. The cost could be significantly higher if only a few parts are ordered.

While these costs (preforms, matrix, QA) may prove to be substantial, none of them appear to differ considerably between the two types of composites. The primary cost factor for production-scale acquisition is the huge difference in fiber cost. For small quantity orders for research, the cost per unit may be essentially the same for SiC fiber- or $\mathrm{C}$ fiber-based composites.

\subsection{Material Testing}

\subsubsection{Test Specimens}

Some testing on representative tubular components will be required in the initial testing. The properties determined from these test results will be compared to equivalent results obtained from simpler structural geometries such as flat plate specimens. Tubular test specimens, especially if made individually to near net shape (or requiring extensive machining or finishing), will likely be many times more costly than multiple flat specimens cut and machined from a single large plate. These test results will be required before a determination can be made about suitability of small, flat specimens for material characterization testing relative to tube form performance.

Requests for quotes for producing a small lot of $\mathrm{C}_{\mathrm{f}} / \mathrm{C}$ tubes for preliminary testing was issued in the 2004-2005 time period. Proposing vendors could not supply the requested parts within the $\$ 160 \mathrm{~K}$ budget provided for the acquisition. ${ }^{69}$ To proceed with some effort at initial characterization, Oak Ridge National Laboratory ordered five $300 \times 300 \times 3 \mathrm{~mm}$ flat plate samples from ATK/Thiokol Corporation for initial test specimens at a cost of $\$ 73 \mathrm{~K}$. This amounts to about $3.5 \mathrm{~kg}$ of material. The exceptionally high cost, approaching that of a $\mathrm{SiC}_{\mathrm{f}} / \mathrm{SiC}$ component, compared to a typical production $\mathrm{C}_{\mathrm{f}} / \mathrm{C}$ material (about $\$ 2000 / \mathrm{kg}$ ) is attributable to the uniqueness of the order; it was a one-time, small volume special order. The plates have been received at Oak Ridge National Laboratory and are being cut and machined into test specimens for material characterization tests.

\subsubsection{Machining}

$\mathrm{SiC}_{f} / \mathrm{SiC}$ composite material is hard and requires machining with diamond-tipped tools or electric discharge machining. Machining $\mathrm{C}_{f} / \mathrm{C}$ composite is not much different from machining graphite. Because 
of the high SiC fiber cost, the approach of "billet machining" is very costly from a fiber waste perspective. There is also a strength reduction issue associated with cutting through engineered fiber architecture. Near-net-shape fabrication is the only realistic approach to consider for $\mathrm{SiC}_{\mathrm{f}} \mathrm{SiC}$ composites and is probably a better choice for $\mathrm{C}_{P} \mathrm{C}$ materials as well.

\subsubsection{Mechanical Testing Needs}

A moderate amount of room temperature testing for flexural strength has been performed on at least two of the three material systems. This type of test is simple to perform and the specimens are easy to fabricate, but the reliability and repeatability of the results are less than optimal for anisotropic composites. Maximum stress is localized at a small area at one surface (no volumetric sampling), and there will be geometric effects at the outer edge corners due to anisotropic response and porosity. Reliability of results in this type of test requires a large number of replicate specimens be tested for a statistical basis. The results are useful for preliminary scoping studies but will be of limited use for material specification or design purposes. Some of this testing is already completed.

Other types of planned testing include direct tension at room and elevated temperatures on both flat and tubular sample geometries. These tests will include both tensile strength tests, tensile creep tests, and remaining-strength tests following long term exposure under load (creep assessment). Irradiationenhanced creep tests are planned as well. These are tests that will be run in a reactor, subjected to both elevated temperature and applied stress.

Other tests to examine geometric effects (round versus flat, small versus large) are also required. These tests will allow future testing to be performed on smaller samples, providing data that can be used for design and qualification of larger components. Success in this area should help lower future costs by reducing specimen sizes and complexity and eliminating the need for full-scale component tests.

Regardless of which material is being tested, these tests will be expensive to perform, and the cost will be similar.

\subsubsection{Testing Needed to Meet Codification Requirements}

A substantial effort will be required to generate enough data to support ASME specification and design methods, eventually leading to NRC acceptance for in-reactor use. To begin with, an assessment to determine what properties/performance measures will likely be required to obtain ASME and NRC approval of these ceramic composite material systems will be needed. It will certainly include some basic mechanical and thermal properties. Because of the anisotropic nature of the composite material systems, there will be orientation effects on strength and elastic properties. There may be orientation effects on other properties, too. Properties which are significant to design methodology for these materials will need to be identified and tested for anisotropy.

Much of the needed test methodology development for nuclear composite applications can be conducted on $\mathrm{C}_{\mathrm{f}} / \mathrm{C}$ material, reducing the material/specimen cost (compared to using $\mathrm{SiC}_{\mathrm{f}} \mathrm{SiC}$ materials), while building a database for the $\mathrm{C}_{f}{ }^{\mathrm{C}} \mathrm{C}$ material. This is applicable since the general fiber architecture is similar for all material systems being considered for control rod fabrication. The test methodology is really developed for "high-temperature composites" and will not be material-specific, but somewhat "fiber architecture-specific." Therefore, the developed methodology for evaluating and qualifying materials for nuclear applications can then be applied to any candidate composite material, and most of this testing framework can be applied to $\mathrm{SiC}_{\mathrm{f}} \mathrm{SiC}$ later. 
However, the validity of standards and test methodologies must be critically examined with respect to the material being examined, i.e. the effect of off-axis loading must be understood, as well as coupon width for a particular architecture. For example, testing $100 \mathrm{~mm}$ diameter tubes is likely not viable (nor even possible) for all tests, and validity of size and geometry effects must be considered. Additionally, elevated temperature properties of tubes (compared to flat plate specimens or parts) must be established. This may best be done using tubes directly. However, some tests cannot be performed on full scale parts, so the correlation between sub-scale and full-scale specimens must be shown. Even more importantly, can some existing flat composite test standards be utilized to represent behavior of a tube form? Can curved cross-section samples be utilized for the axial tube properties machined from a full-scale tube? There remains a lot of work to be done and a lot of questions to be answered in these areas. However, the combination of necessity, economics, and scheduling will dictate the requirement for making these investigations.

As has been mentioned previously, alloy $800 \mathrm{H}$ is already in the ASME section III code up to $760^{\circ} \mathrm{C}$. Additional testing will be required specifically for the purposes of codification at higher temperatures if it is determined that the temperature limit in the code must be increased for this application either for safety factors or to incorporate off-normal event temperatures.

\subsubsection{Cost of Testing}

For a cost reference, a single tensile test on a typical un-irradiated metal sample at room temperature will cost about $\$ 50-\$ 100$ for the test specimen, $\$ 50$ for specimen preparation (measuring and labeling), $\$ 75$ for testing time, and about $\$ 100-\$ 150$ for data analysis and recording/reporting, and quality assurance functions. Raw material costs for the specimen may vary widely, from less than $\$ 1$ to over $\$ 50$ for an exotic material, or even higher for a single small piece of research-produced material.

Fixtures, instrumentation, and specimen preparation for composite materials are all typically more complex. Composite specimen preparation for room temperature could take 1 to 4 times longer than a homogeneous metal specimen. Composites typically require different test fixture types, at least for composite-specific tests. Some may require special instrumentation to be set up on each specimen (extensometer targets, strain gages, and end tabs.)

Composites will have higher variability than a homogeneous material in their properties, requiring more tests for equivalent reliability in results. Double or triple the number of tests of each type should be planned. Typical metals test standards require 3 to 5 replicates. Ten to 15 (or more) composite samples may be required for equivalent data confidence.

Composites have more properties to measure, such as strength in different directions; tensile, compressive, and shear strengths on multiple directions; damage accumulation parameters; and others. Depending on what is being assessed, there may be two to six times as many parameters to establish.

Tests for fracture resistance properties increase specimen preparation costs and take longer to set up and perform. Data analysis is frequently more complex.

Fatigue and creep properties tests last considerably longer than basic strength tests. Although they do not require continuous human monitoring, additional costs associated with equipment time and other factors will be incurred.

Elevated temperatures over $1000^{\circ} \mathrm{C}$ or so require special furnaces, instrumentation, and fixtures. INL has spent well over $\$ 100 \mathrm{~K}$ on setting up two test systems for very high temperature creep studies on the composites, and the systems are still not completed. These are custom made, purpose-built systems 
capable of creep and tensile testing at $1500^{\circ} \mathrm{C}$ or higher, with controlled atmosphere, and direct tension loading on tubular samples with precision strain measurement and long-term data acquisition. However with the revised temperature requirements contained in this report, the need for such extreme high temperature testing will be much less than originally thought.

Any type of testing involving irradiated samples will greatly increase cost and time, due to: - Reactor time/space for irradiation (expensive per unit volume and specific irradiation levels)

- Hot cell time (preparation and testing)

- Dedicated equipment (test machines, transducers, fixtures, etc.)

- Administrative requirements (IHRs, permitting, waste management).

Certain radiation effects experiments can be performed using ion-beam facilities; but the depth of penetration is typically not sufficient to assess bulk mechanical properties. However, charged particle experiments can provide a low-cost method for conducting research on radiation effects. ${ }^{129}$

The one advantage of the composite materials under consideration is their low residual activity following irradiation. Neither the $\mathrm{SiC}_{\mathrm{f}} / \mathrm{SiC}$ nor $\mathrm{C}_{\mathrm{f}} / \mathrm{C}$ composites (in high-purity form) will have much residual activity. Both materials can be contact-handled shortly after irradiation (days to months), substantially reducing testing, storage, and disposal costs compared to nickel-alloy metal specimens. All of the composite materials would be classed as a low-level radioactive waste for disposal purposes.

It is easy to see that elevated temperature testing of irradiated materials can easily cost many $\$ 1000$ s per specimen, and $\$ 100 \mathrm{~K}+$ for a single test series for measuring a single property. It is probable that this level of effort will be required for all parameters or properties of interest in achieving NRC acceptance for reactor component usage.

In addition to being isotropic, and ASME codified, alloy $800 \mathrm{H}$ is well established and well understood in most areas. However there is a question of whether irradiation creep data is needed, and if so, must it be in-pile creep testing. It may also be determined that there are other "holes" in the data that should be filled in. Even so, the testing will be substantially less than that required for the composites.

\subsubsection{Cost of Joining Method Development and Qualification}

Depending on the actual control rod designs being considered, joining and attachments will require various forms of testing and qualification. One initial design for the composite control rod shows a threaded-on/in cap. Final qualification of such a design would involve a substantial effort to test the thread systems for function, performance, and durability. Other tube designs that do not use threaded connections will probably prove more reliable and easier to qualify. Threads on composite materials are notoriously weak since the thread strength cannot be reasonably enhanced by fiber architecture. Full scale testing would likely be needed to qualify this aspect of the design. ${ }^{117}$ Metals can be easily machined or forged into any configuration to accommodate the articulated joint. In either case, finite element modeling would be needed to ensure too much static load (the weight of the control rod) is not placed on either an unsupported composite thread or a thin metallic section of the joint. Without actual designs to consider, a reliable estimate of joining qualification costs cannot be made.

Until a full qualification and testing program is specified, including a complete testing matrix, it will not be possible to make a reasonable estimate at the overall test program cost. 


\subsection{Cost of Final Components}

The cost of the control rod structures for the first reactors will likely be lower, maybe substantially lower, than the cost of material qualification to get approval for use. This applies to any of the candidate materials: composites or metals.

There will be additional cost associated with design, fabrication, and qualification (QA and NDE) of a composite control rod, compared to one made of metal. Composite material systems design for particular performance is a reasonably mature technical field. Most of the expense for composite control rods will fall in the testing and qualification efforts, not in actually designing and fabricating control rod sections which have fairly simple shapes.

Making a metal alloy tube, threaded connections, etc., will be substantially less expensive than an equivalent structure made of $\mathrm{C}_{\mathrm{f}} / \mathrm{C}$ or other composite system. Hot working, cold working, heat treating and machining procedures for alloy $800 \mathrm{H}$ are all well-established and straight-forward and seamless tube is a commercially available product, so the product form presents no issues. Since the $800 \mathrm{H}$ has been in nuclear reactors for years the suppliers have experience working to the stringent NQA-1 quality requirements. ${ }^{305}$ Multiple suppliers should make bidding competitive, and availability is a non-issue.

\subsubsection{Cost vs. Lifetime}

The total control rod cost over the reactor lifetime is very difficult to estimate without detailed design data. In the overall reactor construction and lifetime operating expense, differences in total lifetime cost between the control rod materials chosen (not considering development and qualification before construction) is probably not significant. Material performance will likely be a more significant deciding factor, if the deciding factor is not the overall development expense.

\subsubsection{Reactor ShutDown/Control Rod Change-Out Cost}

Additional down-time is not expected for control rod change-out, if it is required. Control rods or rod segments could be changed as part of normal maintenance cycles. In prismatic designs, change-out can be done during re-fueling outages which are anticipated every 18 months. In the PBMR pebble bed design, maintenance is scheduled every six years. PBMR thinks their control rods may need to be changed once or twice (or possibly not at all) in 40 years. ${ }^{130}$

\subsection{Other Potential Cost-Affecting Considerations}

$\mathrm{C}_{\mathrm{f}} / \mathrm{C}$ material shows degradation over time at temperature and irradiation. Data obtained so far indicate mechanical property stability of the $\mathrm{SiC}_{\mathrm{f}} / \mathrm{SiC}$ materials after irradiation. Thus $\mathrm{C}_{\mathrm{f}} / \mathrm{C}$ composite useful lifetime will be shorter than $\mathrm{SiC}_{\mathrm{f}} / \mathrm{SiC}$ given similar design and environment (replacement expense could be an issue). Based on a 20 to $30 \mathrm{dpa} 60$-year lifetime dose, irradiation data predicts that $\mathrm{C}_{f} / \mathrm{C}$ control rods would need to be replaced four or five times over the reactor life, while available data indicates that $\mathrm{SiC}_{\mathrm{f}} / \mathrm{SiC}$ control rods may last for the entire reactor lifetime (although preliminary data is only available to about $8 \mathrm{dpa}$ accumulated dose). More recent estimates substantially reduce the lifetime control rod dose to the order of $8 \mathrm{dpa}$, so irradiation performance of $\mathrm{C}_{F} / \mathrm{C}$ material may be adequate to survive the 60 year lifetime as well. Metal control rods would certainly need to be replaced; however, it appears that the cost of changing a control rod is not that significant, particularly since a large portion of the cost of the control rod is in the material development and codification, and this appears far less for the metal. 
The Hi-Nicalon Type S fiber has demonstrated better irradiation and structural properties than the early Tyranno-based materials. More recent data suggest less difference between Hi-Nicalon Type S and newer lots of the Tyranno SA. ${ }^{128}$

$\mathrm{Hi}$-Nicalon Type $\mathrm{S} \mathrm{SiC}_{\sharp} / \mathrm{SiC}$ composites have superior as-fabricated mechanical properties for a given fiber architecture compared to $\mathrm{C}_{\AA} / \mathrm{C}$ composites. For example, Hi-Nicalon Type $\mathrm{S} \mathrm{SiC}_{f} / \mathrm{SiC}$ composites have a flexural strength of about $400 \mathrm{MPa},{ }^{123}$ while $\mathrm{C} / \mathrm{C}$ composites have a flexural strength of about $150 \mathrm{MPa}$. Therefore, the wall thickness of the $\mathrm{C}_{f} / \mathrm{C}$ might need to be thicker to reduce stresses.

Consider that there may be a substantial material performance/properties database that already exists for $\mathrm{C}_{f} / \mathrm{C}$ composite materials within the aircraft industry or U.S. Department of Defense similar to that envisioned for control rods. Possibly, all but the irradiation data exists and access could be purchased. This approach would be less costly (and much faster) than buying materials and doing the tests. This approach, at least for preliminary comparison between $\mathrm{C}_{\mathrm{f}} / \mathrm{C}$ and other candidate materials, may be a faster, economical alternative and should be explored.

The more mature state of $\mathrm{C}_{\mathrm{f}} / \mathrm{C}$ technology may make it more expensive (or at least more difficult or time-consuming) to get sample material. Suppliers are busy supplying parts at large scale production for their large customers such as U.S. Department of Defense and the aerospace industry. There is little incentive to work with researchers to make small batches of special materials, especially considering the relatively limited potential market for eventual control rod fabrication. ${ }^{131}$

\subsection{Cost of Hazardous Waste}

There will be some irradiated material waste resulting from the composite material qualification testing program. The overall volume / mass will not be excessive - maybe $10 \mathrm{~kg}$ or so for the entire program. The MHTGR-NPR project, which planned to have $800 \mathrm{H}$ control rods, predicted $377 \mathrm{ft}^{3}$ of waste generated from the control rods. This waste would be packaged in casks and transported by truck, estimated at 4 shipments/year. ${ }^{36}$ That version of the design had 8 reactor modules virtually identical to the prismatic design being considered for the NGNP, so perhaps one shipment every other year (on average) resulting from metal control rods would be a reasonable estimate. In actuality, several shipments after 10 years would be more likely. At any rate, the volume will be very small relative to fuel and graphite reflectors that must be disposed of.

As mentioned in section 9.2 (Cost of Testing), neither the $\mathrm{SiC}_{f} / \mathrm{SiC}$ nor $\mathrm{C}_{f} / \mathrm{C}$ composites (in highpurity form) will have much residual activity following irradiation. Either material would be classed as a low-level waste following irradiation and testing. Metal control rods would be highly activated (Ni especially) and be at high activity levels for months to many years following irradiation. Shielded storage would be required, probably followed by high-level waste disposal procedures.

Past reactors and PBMR have on-site storage to keep old (metal) control rods until decommissioning. The general goal for the NGNP design seems to be to minimize waste generation. Fuel burn-up is high, so spent fuel is minimized. There is no available information about planned disposition of old control rods and other replacement parts that cannot be decontaminated (or that have too much residual radiation to dispose of in other ways or recycle). 


\subsection{Cost Summary}

A 2003 materials survey estimated the costs of developing materials for core internals for the GTMHR and of a VHTR (outlet temperature of $1000^{\circ} \mathrm{C}$ ) as shown in Table 8 . The analysis is in agreement with this report, that the cost of developing $\mathrm{C}_{\beta} \mathrm{C}$ composites for core internals is expected to be significantly greater than the cost of developing an alloy such as $800 \mathrm{H}$ for control rods. ${ }^{42}$

Table 9. Cost of developing materials for core internals. ${ }^{42}$

\begin{tabular}{lcc}
\hline Component & GT-MHR Costs & VHTR Costs $^{\mathrm{a}}$ \\
\hline Metallic internals materials & 10 & 12 \\
C-C composite materials & 17 & 31 \\
a. Costs in 2003 \$million. & & \\
\hline
\end{tabular}

Raw material costs are trivial except for the composite fibers and the $\mathrm{SiC}$ fibers are 15 to 30 times more expensive than carbon fibers. Processing for all the composites is expensive compared to the metal because of the long times and high temperatures involved, material and component testing is the largest cost, and that is also larger for composites because of the extra testing that would be required to standardize and qualify a new class of material. Availability of the composites could also be a difficulty. Compared to the development costs, the individual part cost of a component should be low, particularly if it is from one of the more mature industries with competitive bidding. Therefore, the lifetime of the component is of minimal significance, providing is reasonable and can be changed during scheduled maintenance shutdowns. 


\section{RECOMMENDATIONS AND CONCLUSIONS}

The information presented leads to the following recommendations regarding materials for the NGNP control rods.

1. Alloy $800 \mathrm{H}$ is certainly worthy of consideration. The reactivity control rods for both the prismatic and pebble bed design could arguably operate under the ASME code for $800 \mathrm{H}$ as it currently stands, with a maximum use temperature of $760^{\circ} \mathrm{C}$. Like all austenitic alloys, $800 \mathrm{H}$ experiences radiation embrittlement, but the alloy has been and is being used in HTGRs, and the behavior can be accounted for in the component design. The primary problem with using $800 \mathrm{H}$ control rods is planning for high-temperature off-normal events such as DCC. Either procedural solutions, such as delayed scram or high-temperature testing, will be required. The testing would determine if the part would deform to the point that it could not be extracted from the outer reflector after exposure at $1150^{\circ} \mathrm{C}$ for more than 1500 hours. $800 \mathrm{H}$ may also require additional testing, including irradiation testing to fill out the database and perhaps elevated temperature testing to extend the use temperature specified in the ASME code, but these needs appear to be less than what will be required to codify composites.

2. The development of ceramic composite control rods should continue, even though they may not make the NGNP program deadlines because of the challenges involved with achieving codification. Although the primary heat exchanger is currently limiting the outlet gas temperature to a maximum of $950^{\circ} \mathrm{C}$, a composite control rod would also be required to push the reactor operating temperature, and thus the efficiency, higher. At this point it would be premature to narrow the control rod material choices to one metal with significant issues to resolve; continuing composites research will help to mitigate technical risk. Continuing the composites development may also allow the NGNP program to leverage work being carried on by the French, South Africans and Japanese. These nations have expressed interest in the NGNP composites work and may collaborate in the effort to get the composites into the ASME code and NRC approved, in part so they can market reactors in the U.S.

In addition, it seems reasonable to continue some advanced materials development since this reactor is promoted as an advanced next generation design intended to build confidence in the nuclear industry by successfully licensing, building, and running a commercial scale HTGR and using it to produce $\mathrm{H}_{2}$. Even though composite control rods may not be ready for the startup of the NGNP, there may be a driving force to test advanced materials, such as composite control rods, in the NGNP at some point in the expected 60 -year lifetime.

3. In light of the revised design requirements of $\sim 8 \times 10^{21} \mathrm{n} / \mathrm{cm}^{2}$ for the 60 -year reactor lifetime, $\mathrm{C}_{\mathrm{f}} / \mathrm{C}$ composite material has sufficient radiation properties up to about $\sim 8 \mathrm{dpa}$, for the NGNP control rod. The properties of $\mathrm{SiC}_{\mathrm{f}} \mathrm{SiC}$ composites far exceed the needs of this application. In light of the expense, limited availability, less mature technology relative to $\mathrm{C}_{\mathrm{f}} / \mathrm{C}$ composites, and the expense of developing two composites, continued research on $\mathrm{SiC}_{\mathrm{f}} / \mathrm{SiC}$ composites is difficult to justify.

In addition to these recommendations, the evaluation has yielded a number of secondary conclusions and observations.

1. The control rod requirements are much less demanding than previously thought. In part, this is because the outlet temperature has been lowered from $1000^{\circ} \mathrm{C}$ to $850-950^{\circ} \mathrm{C}$, but primarily because of a misunderstanding that the material must be capable of withstanding the core environment. The shutdown rods in the prismatic design were mistakenly thought to be inserted in the core during normal operation and off-normal events, rather than suspended above the core. Also, control rod liners were mistakenly thought to be required inside the channels in order to maintain alignment of the graphite reflector blocks. As a result of becoming aware of these misunderstandings, temperature requirements for normal 
operation of control rods are about half as much, and radiation dose requirements are less than one-third as much as the original assumptions based on modeling results for the control rods residing in the outer reflectors (see Table 9). Consequently, metals were never considered as a candidate for the NGNP control rod application and testing was conducted or planned at very high temperatures and radiation levels.

Table 10. Comparison of operating requirements for the NGNP control rod.

\begin{tabular}{lccc}
\hline & $\begin{array}{c}\text { Est. operating T } \\
{ }^{\circ} \mathrm{C}\end{array}$ & $\begin{array}{c}\text { Max. DCC T } \\
{ }^{\circ} \mathrm{C}\end{array}$ & $\begin{array}{c}\text { Radiation dose } \\
\times 10^{21} \mathrm{n} / \mathrm{cm}^{2}\end{array}$ \\
\hline Old - prismatic & 1250 & 1500 & 30 \\
New - prismatic & $\sim 750^{\mathrm{a}}$ & 1150 & 8.4 \\
New - pebble bed & $500^{\mathrm{b}}$ & 1050 & 7.9 \\
a. Assumes control rods are not inserted to BAF for normal operation. \\
b. Temperature at 150 cm, typical position for control rods inserted in outer reflector of pebble bed.
\end{tabular}

2. Most of the requirements are similar for the conceptual prismatic and PBR designs, as shown in Table 10. Although the pebble bed has a somewhat lower fluence value, this would not impact material selection. However the prismatic design has potentially higher operating temperatures under certain conditions and also a higher maximum depressurized conduction cool down (DCC) temperature, which could be significant if $800 \mathrm{H}$ is selected for the control rod sheathing.

3. This evaluation has illustrated the need for material researchers and nuclear engineers to work closely. Requirements were overestimated because the reactor design was not fully understood by the material researchers. Likewise, the reactor experts did not question why such high temperatures and fluence levels were deemed a necessary requirement for the control rod materials. Material researchers sometimes tend to be too focused on the details of their material to see the big picture, while the nuclear systems developers may be totally unaware of material issues other than those related to fuels and graphite. Bridging the gap between these two parties is necessary. 


\section{References}

1. INL, Idaho National Laboratory, Next Generation Nuclear Plant Prototype Preliminary Project Management Plan; INL/INT-05-XXXXX DRAFT; November 2005.

2. INEEL, Idaho National Engineering and Environmental Laboratory, Next Generation Nuclear Plant Materials Research and Development Program Plan; INEEL/EXT-03-001 128; November 7, 2003.

3. Tachibana, Y., Sawahata, H., Iyoku, T., et al., "Reactivity Control System of the High Temperature Engineering Test Reactor," Nuclear Engineering and Design, Vol. 233, 2004, pp. 89-101.

4. Tachibana, Y., Shiozawa, S., Fukajura, J., et al., "Integrity Assessment of the High Temperature Engineering Test Reactor (HTTR) Control Rod at Very High Temperatures," Nuclear Engineering and Design, Vol. 172, 1997, pp. 93-102.

5. Simon, R. A., Capp, P. D., "Operating Experience with the Dragon High Temperature Reactor Experiment," Proceedings of the Conference on High Temperature Reactors, Petten, NL, 22-24 April 2002pp. 1-6.

6. Organisation for European Economic Co-Operation, Agency, E. N. E., O.E.E.D. Dragon High Temperature Reactor Project First Annual Report 1959-1960; 1 April 1959 - 31 March 1960.

7. Rennie, C. A., "Achievements of the Dragon Project," Annals of Nuclear Energy, Vol. 5, 1978, pp. 305-320.

8. Organisation for Economic Co-Operation and Development, Agency, E. N. E., O.E.C.D. Dragon High Temperature Reactor Project Eighth Annual Report 1966-1967; 1 April 1966 - 31 March 1967.

9. Organisation for Economic Co-Operation and Development, Agency, N. E., O.E.C.D. Dragon High Temperature Reactor Project Thirteenth Annual Report 1971-1972; 1 April 1971 - 31 March 1972.

10. Simnad, M. T., "The Early History of High-Temperature Helium Gas-Cooled Nuclear Power Reactors," Energy, Vol. 16, 1/2, 1991, pp. 25-32.

11. Wachholz, W., "The Present State of the HTR Concept Based on Experience Gained from AVR and THTR," Design Requirements, Operation and Maintenance of Gas-Cooled Reactors, San Diego, CA, 21-23 September, 1988, International Atomic Energy Agency: pp. 61-70.

12. Bäumer, B., Barnet, H., Baust, E., et al., AVR - Experimental High-Temperature Reactor; 21 Years of Successful Operation for a Future Energy Technology. Düsseldorf, Germany: Association of German Engineers (VDI), The Society for Energy Technologies, 1990.

13. Hochtemperatur-Kemkraftwerk GmbH (HKG), 300-MW-THTR-Kernkraftwerk Hamm-Uentrop April 1979.

14. Baumer, R., Kalinowski, I., "THTR Commissioning and Operating Experience," Energy, Vol. 16, $1 / 2,1991$, pp. $59-70$.

15. Bodmann, E., Diehl, H., Blume-Firla, I., et al., "Service Conditions and Relevant Properties of HTGR Metallic Materials," High Temperature Metallic Materials for Gas-Cooled Reactors., Cracow, Poland, 20-23 June 1988, International Atomic Energy Agency: 18, pp. 14-26. 
16. Thiele, B. A., Diehl, H., Ohly, W., et al., "Investigations into the Irradiation Behavior of HighTemperature Alloys for High-Temperature Gas-Cooled Reactor Applications," Nuclear Technology, Vol. 66, 1984, pp. 597-606.

17. Nickel, H., Bodmann, E., Seehafer, H. J., "The Materials Program for the HTR in the FRG: Integrity Concept, Status of the Development of High Temperature Materials and Design Codes," Energy, Vol. 16, 1/2, 1991, pp. 221-242.

18. Breitenfelder, R., Wachholz, W., Weicht, U., "Accident Analysis and Accident Control for the THTR - 300 Power Plant," Summary Report, Lausanne, Switzerland, January 1981; I. W. G. 0. G.C. Reactors, Ed., International Atomic Energy Agency: pp. 16-22.

19. Takeda, T., Nakagawa, S., Honma, F., et al., "Safety Shutdown of the High Temperature Engineering Test Reactor During Loss of Off-Site Electric Power Simulation Test," Journal of Nuclear Materials and Technology, Vol. 39, 9, 2002, pp. 986-995.

20. Saito, S., Tanaka, R., Sudo, Y., et al., Japan Atomic Energy Research Institute, Design of High Temperature Engineering Test Reactor (HTTR); JAERI--1332; September 1994.

21. Boiler \& Pressure Vessel Code, Section III, Division 1, Code Case N-47-32, ASME International, 1994.

22. IAEA, International Atomic Energy Agency, Current Status and Future Development of Modular High Temperature Gas Cooled Reactor Technology; IAEA-TECDOC-1198; February, 2001.

23. Sawa, K., Principal Research Engineer, Leader, High Temperature Fuel \& Material Group, Nuclear Applied Heat Technology Division, Nuclear Science and Engineering Directorate, Japan Atomic Energy Agency, Shinhori 3607, Oarai-machi, Ibaraki-ken, 311-1394, Japan, 2006, personal communication with R. Wright.

24. Hu, S., Wang, R., Gao, Z., "Safety Demonstration Tests on HTR-10," 2nd International Topical Meeting on High Temperature Reactor Technology, Beijing, China, September 22-24, 2004.

25. Zhang, Z., Wu, Z., Xu, Y., et al., "Design of Chinese Modular High-Temperature Gas-Cooled Reactor HTR-PM," 2nd International Topical Meeting on High Temperature Reactor Technology, Beijing, China, September 22-24, 2004.

26. Homan, F. J., Tumer, R. F., "Technology Development for the Modular High-Temperature GasCooled Reactor," Design Requirements, Operation and Maintenance of Gas-Cooled Reactors, San Diego, CA, 2I-23 September, 1988, International Atomic Energy Agency: pp. 71-79.

27. Brey, H. L., "Fort St. Vrain Operations and Future," Energy, Vol. 16, I/2, 1991, pp. 47-58.

28. Fuller, C. H., "Fort Saint Vrain Operational Experience," Design Requirements, Operation and Maintenance of Gas-Cooled Reactors, San Diego, CA, 2I-23 September, 1988, International Atomic Energy Agency: pp. 55-61

29. Moore, R. A., Kantor, M. E., Brey, H. L., et al., "HTGR Experience, Programs, and Future Applications," Nuclear Engineering and Design, Vol. 72, 1982, pp. 153-1974. 
30. Olson, H. G., Brey, H. L., Warembourg, D. W., "The Fort St. Vrain High Temperature Gas-Cooled Reactor: X. Core Temperature Fluctuations," Nuclear Engineering and Design, Vol. 72, 1982, pp. 125-137.

31. Shenoy, A. S., Director, Modular Helium Reactor Programs, General Atomics, San Diego, CA, 2006, personal communication with J. K. Wright.

32. General Atomics Program Staff, General Atomics, MHTGR - New Production Reactor Summary of Experience Base; GA-A19152; March 1988.

33. Williams, P. M., Silady, F. A., Dunn, T. D., et al., "MHTGR Development in the United States," Progress in Nuclear Energy, Vol. 28, 3, 1994, pp. 265-346.

34. Turner, R. F., Baxter, A. M., Stansfield, O. M., et al., "Annular Core for the Modular HighTemperature Gas-Cooled Reactor (MHTGR)," Nuclear Engineering and Design, Vol. 109, 1988, pp. 227-231.

35. Bechtel National Inc., DOE, Conceptual Design Summary Report Modular HTGR Plant; DOEHTGR-87-092; September 1987.

36. Idaho National Engineering Laboratory, Inc., E. G. I., WINCO, et al., Idaho National Engineering Laboratory, NPR-MHTGR Generic Reactor Plant Description \& Source Terms; EGG-NPR-8522, Rev. B, Vol. 1; March 1991.

37. GA Technologies Inc., DOE, Reactor Core Subsystem Design Description (Modular HTGR Plant); DOE-HTGR-86-036; July 1987.

38. Watson, J. F., Senior Project Manager, General Atomics, San Diego, CA, 2006, personal communication with J. K. Wright.

39. Bechtel National Inc., Combustion Engineering Inc., Department of Energy, et al., Preliminary Safety Information Document for the Standard MHTGR; DOE-HTRG-86-024.

40. Richards, M. C., Shenoy, A. S., Brown, L. C., et al., US DOE Contract No. DE-FG0302SF22G09/A000 Nuclear Energy Research Initiative Project 2002-196, H2-MHR Pre-Conceptual Design Report: Si-Based Plant; GA-A25401; April 2006.

41. Shenoy, A. S., General Atomics, Gas Turbine - Modular Helium Reactor (GT-MHR) Conceptual Design Description Report; RGE-910720; July 1996.

42. Baccaglini, G., Ball, S., Burchell, T., et al., Idaho National Engineering and Environmental Laboratory, Very High Temperature Reactor Survey (VHTR) of Materials Research and Development Needs to Support Early Deployment; January 31, 2003.

43. Matzner, D., "PBMR Existing and Future R\&D Test Facilities," Proceedings of the Conference on High Temperature Reactors HTR-2004, 22-24 September 2004, International Atomic Energy Agency: pp. 1-26.

44. Slabber, J., "Pebble Fuel Advantages," 2nd International Topical Meeting on High Temperature Reactor Technology, Beijing, China, September 22-24, 2004. 
45. Kriel, W., "Material Selection: High Temperature Metallic Materials," slides from PBMR PreApplication Planning Meeting 2, September 21-22, 2005.

46. Ion, S., Nicholls, D., Matzie, R., et al. "Pebble Bed Modular Reactor the First Generation IV Reactor to Be Constructed," http:/Www.world-nuclear.org/sym/2003/matzie.htm.

47. Gougar, H., Manager, Fission and Fusion Systems, Idaho National Laboratory, Idaho Falls ID 2006, personal communication with J. K. Wright.

48. Matzner, D., "PBMR Project Status and the Way Ahead," Proceedings of the 2nd International Topical Meeting on High Temperature Reactor Technology, Beijing China, September 22-24, 2004, International Atomic Energy Agency: pp. 1-13.

49. PBMR, "PBMR Control Rod Design and Requirements," Nuclear Engineering, pp. 1-19.

50. PBMR, Data and Boundary Conditions to Be Used in VSOP, TINTE and MCNP PBMR $400 \mathrm{MW}$ (Th) Reactor Models.

51. IST Nuclear, The Pebble Bed Modular Reactor - a Solution for the 21st Century.

52. Broom, N., Smit, K., "PBMR Design Methodology," slides from Generation IV International Forum, Oak Ridge, TN, 12th April 2005.

53. Fazluddin, S., Smit, K., Slabber, J., "The Use of Advanced Materials in VHTR's," 2nd International Topical Meeting on High Temperature Reactor Technology, Beijing, China, September 22-24, 2004.

54. Slabber, J., PBMR (Pty) Ltd., Technical Description of the PBMR Power Plant; 016956; Feb 14 2006.

55. Caspersson, S. A., Fellow Engineer, New Plant Engineering, Westinghouse Electric Company, Nuclear Power Plants, Windsor, CT, 2006, personal communication with J. K. Wright.

56. Boiler \& Pressure Vessel Code, Section III, Division I, Subsection NH-Class 1 Components in Elevated Temperature Service, ASME International, 2004.

57. Windes, W. E., Lessing, P. A., Katoh, Y., et al., Idaho National Laboratory, Structural Ceramic Composites for Nuclear Applications; DRAFT - INL/EXT-05-00652; August 2005.

58. INL, Idaho National Laboratory, Next Generation Nuclear Plant Materials Research and Development Program Plan; NL/EXT-05-00758; September 2005.

59. Gougar, H. D., Davis, C. B., Idaho National Laboratory, Reactor Pressure Vessel Temperature Analysis for Prismatic and Pebble-Bed VHTR Designs; NL/EXT-06-11057; April 2006.

60. Davis, C. B., Revised RELAP5-3D Thermal Analysis Results for Prismatic VHTR, 2006, unpublished work.

61. RELAP5-3D Code Development Team, Idaho National Laboratory, RELAP5-3D Code Manual Code Structure, System Models, and Solution Methods; INEEL-EXT-98-00834; April, 2005. 
62. Gougar, H. D., Terry, W. K., Idaho National Laboratory, Completion of Pebbed-Thermix Coupling; INL/EXT-05-02584; December, 2005.

63. INEEL, Idaho National Engineering and Environmental Laboratory, NGNP Point Design - Results of the Initial Neutronics and Thermal-Hydraulic Assessments During FY-03; INEEL/EXT-03-00870; September 2003.

64. Hironaka, K., Nozawa, T., Hinoki, T., et al., "High-Temperature Tensile Strength of nearStoichiometric SiC/SiC Composites," Journal of Nuclear Materials, Vol. 307-31 1, 2002, pp. 10931097.

65. Burnette, R. D., Baldwin, N. L., "Primary Coolant Chemistry of the Peach Bottom and Fort St. Vrain High Temperature Gas-Cooled Reactors," Specialists Meeting on Coolant Chemistry, Plate-out and Decontamination in Gas Cooled Reactors, Juelich, FRG, December 1980, International Atomic Energy Agency: pp. 132-137.

66. Nieder, R., "Prediction on an HTR Coolant Composition after Operational Experience with Experimental Reactors," Specialists Meeting on Coolant Chemistry, Plate-out and Decontamination in Gas Cooled Reactors, Juelich, FRG, December 1980, International Atomic Energy Agency: pp. 144-152.

67. Nieder, R., Stroter, W., "Long-Term Behavior of Impurities in an HTR Primary Circuit," VGB Kraftwerstechnik, Vol. 68, 1988, pp. 671-676.

68. Smit, K., PBMR - Materials, 2005, personal communication with R. N. Wright.

69. Klett, J., Windes, W. E., Lessing, P., Oak Ridge National Laboratory, Next Generation Nuclear Plant Carbon Composites Vendor Survey; May 25, 2005.

70. Klett, J., Windes, W. E., Lessing, P., Oak Ridge National Laboratory, Next Generation Nuclear Plant Carbon Composites Literature Review and Composite Acquisition; ORNL-GEN4/LTR-05-008; August 15, 2005.

71. Thiele, B. A., Schubert, F., Derz, H., et al., "Influence of Test Temperature on Post 1rradiation, High Temperature Tensile and Creep Properties of X8CrNiMoNb 1616, X10NiCrAlTi 3232 (Alloy 800) and NiCr22Fe18Mo (Hastelloy X)," Journal of Nuclear Materials, Vol. 171, 1990, pp. 94-102.

72. Snead, L. L., Burchell, T. D., Qualls, A. L., "Strength of Neutron-Irradiated High-Quality 3D Carbon Fiber Composite," Journal of Nuclear Materials, Vol. 321, 2003, pp. 165-169.

73. Maruyama, T., Harayama, M., "Neutron Irradiation Effect on the Thermal Conductivity and Dimensional Change of Graphite Materials," Journal of Nuclear Materials, Vol. 195, 1992, pp. 4450.

74. Virgil'ev, Y. S., Kalyagina, I. O., "Carbon-Carbon Composite Materials," Inorganic Materials, Vol. 40, 2004, pp. S33-S49.

75. Burchel1, T. D., Eatherly, W. P., Robbins, J. M., et al., "The Effect of Neutron Irradiation on the Structure and Properties of Carbon-Carbon Composite Materials," Journal of Nuclear Materials, Vol. 191-194, 1992, pp. 295-299. 
76. Katoh, Y., Snead, L. L., Oak Ridge National Laboratory, Status of Irradiation of Multilayer SiC/SiC and FMI-222 Graphite Composites; ORNL/TM-2005/508; June 30, 2005.

77. Eto, M., Ishiyama, S., Ugachi, H., "Status of the Research and Development at JAERI on the C/C Composite Control Rod for HTGR," Graphite moderator lifecycle behaviour, Bath, UK, 24-27 September, 1996, International Atomic Energy Research Instutute: pp. 205-214.

78. Snead, L. L., Swelling of Irradiated $C_{f} /$ C Composite, 2006, unpublished work.

79. Snead, L. L., Katoh, Y., Connery, S., Oak Ridge National Laboratory, Swelling of SiC at Intermediate and High Irradiation Temperatures; 2005.

80. Nozawa, T., Hinoki, T., Katoh, Y., et al., "Effects of Fibers and Fabrication Processes on Mechanical Properties of Neutron Irradiated SiC/SiC Composites," Journal of Nuclear Materials, Vol. 307-311, 2002, pp. 1173-1177.

81. Hinoki, T., Snead, L. L., Katoh, Y., et al., "The Effect of High Dose/High Temperature Irradiation on High Purity Fibers and Their Silicon Carbide Composites," Journal of Nuclear Materials, Vol. 307311,2002 , pp. 1157-1162.

82. Katoh, Y., Snead, L. L., Lara-Curzio, E., et al., Oak Ridge National Laboratory, Summary of SiC Tube Architecture and Fabrication; ORNL-GEN4/LTR-05-xxx DRAFT; August 30, 2005.

83. Ren, W., Swindeman, R. W., Oak Ridge National Laboratory, High Temperature Metallic Materials Test Plan for Generation Iv Nuclear Reactor; ORNL/TM-2004/507; November 30, 2004.

84. Standard Specification for Nickel-Iron-Chromium Alloy Seamless Pipe and Tube, B 407-04, ASTM International, 2004.

85. Nickel, H., Kondo, T., Rittenhouse, P. L., "Status of Metallic Materials Development for Application in Advanced High-Temperature Gas-Cooled Reactors," Nuclear Technology, Vol. 66, 1984, pp. 1222 .

86. Shenoy, A. S., Betts, W. S., "Design Requirements for High Temperature Metallic Component Materials in the US Modular HTGR," High Temperature Metallic Materials for Gas-Cooled Reactors, Cracow, Poland, 20-23 June, 1988, International Atomic Energy Agency: pp. 35-42.

87. Nickel, H., Ennis, P., Schubert, F., et al., "Qualification of Metallic Materials for Application in Advanced High Temperature Gas-Cooled Reactors," Nuclear Technology, Vol. 58, 1982, pp. 90-106.

88. Tsuji, H., Nakajima, H., Kondo, T., "Current Status of Studies on High Temperature Metallic Materials for HTGR Applications in JAERI," High Temperature Metallic Materials for Gas-Cooled Reactors, Cracow, Poland, 20-23 June 1988, International Atomic Energy Agency: pp. 81-91.

89. Japan Atomic Energy Research Institute, JAERI, Present Status of HTGR Research \& Development; INS-JP-053; February 1996.

90. Davies, M., "Pebble Bed Modular Reactor High Temperature Materials," slides October 2001. 
91. Nickel, H., Schubert, F., Breitling, H., et al., "Development and Qualification of Materials for Structural Components for the High-Temperature Gas-Cooled Reactor," Nuclear Engineering and Design, Vol. 121, 1990, pp. 183-192.

92. Watanabe, K., Kondo, T., Ogawa, Y., "Postirradiation Tensile and Creep Properties of HeatResistant Alloys," Nuclear Technology, Vol. 66, 1984, pp. 630-638.

93. Tanaka, R., Kondo, T., "Research and Development on Heat-Resistant Alloys for Nuclear Process Heating in Japan," Nuclear Technology, Vol. 66, 1984, pp. 75-87.

94. Harman, D. G., Oak Ridge National Laboratory for the U.S. Atomic Energy Commission, $A$ Single Irradiation Experiment Comparing Six High-Temperature Alloys at $760^{\circ} \mathrm{C}$; ORNL-TM-4593; October 1974.

95. Harman, D. G., "Incoloy 800: Enhanced Resistance to Radiation Damage," Nuclear Applications and Technology, Vol. 9, 1970, pp. 561-571.

96. Harman, D. G., Oak Ridge National Laboratory for the U.S. Atomic Energy Commission, Postirradiation Tensile and Creep-Rupture Properties of Several Experimental Heats of Incoloy 800 at 700 and $760^{\circ} \mathrm{C}$; ORNL-TM-2305; December 1968.

97. Lindgren, J. R., "Irradiation Effects on High-Temperature Gas-Cooled Reactor Structural Materials," Nuclear Technology, Vol. 66, 1984, pp. 607-618.

98. General Electric Company, AEC Fuels and Materials Development Program 8th Annual Report; GEMP-1012 (Parts 1 and 2); March 31, 1969.

99. Brinkman, C. R., Korth, G. E., Beeston, J. M., "Influence of Irradiation on the Creep/Fatigue Behavior of Several Austenitic Stainless Steels and Incoloy 800 at 700 C," Effects of Radiation on Substructure and Mechanical Properties of Metals and Alloys, American Society for Testing and Standards: ASTM STP 529, pp. 473-492.

100. Mills, W. J., "Fracture Toughness of Two Ni-Fe-Cr Alloys," Engineering Fracture Mechanics, Vol. $26,2,1987$, pp. 223-238.

101. Bates, J. F., Powell, R. W., "Irradiation-Induced Swelling in Commercial Alloys," Journal of Nuclear Materials, Vol. 102, 1981, pp. 200-213.

102. Garner, F. A., Gelles, D. S., "Neutron-Induced Swelling of Commercial Alloys at Very High Exposures," Effects of Radiation on Materials: 14th International Symposium, Philadelphia; N. H. Packan and Stoller, R. E., et al., Eds., American Society for Testing and Materials: Volume II, STP 1046, pp. 673-683.

103. Gelles, D. S., "Microstructural Examination of Several Commercial Alloys Neutron Irradiated to 100 Dpa," Journal of Nuclear Materials, Vol. 148, 1987, pp. 136-144.

104. Schwindeman, R. W., "Verification of Allowables," slides from Generation IV Reactor Materials Program Presentation, Portland, OR, February, 2006.

105. Incoloy Alloy $800 \mathrm{H} \& 800 \mathrm{HT}$, product sheet, Special Metals, 2004. 
106. Hayner, G., Idaho National Laboratory, NGNP Materials Program Monthly Report for April; May 2006.

107. Boiler \& Pressure Vessel Code, Section III, Division 1, Code Case N-201-4, ASME International, 1994.

108. Boiler \& Pressure Vessel Code Section VIII, Rules for Construction of Pressure Vessels, ASME International, 2004.

109. Boiler \& Pressure Vessel Code Section I, Rules for Construction of Power Boilers, ASME International, 2004.

110. Shah, V. N., Majumdar, S., Natesan, K., Argonne National Laboratory, Review and Assessment of Codes and Procedures for HTGR Components; NUREG/CR-6816; June 2003.

111. Boiler \& Pressure Vessel Code, Section III, Division 1, Code Case N-499-2, ASME International, 2004.

112. Lara-Curzio, E., Jenkins, M. G., "Development of Test Standards for Continuous Fiber Ceramic Composites in the United States," Composites: Part A, Vol. 30, 1999, pp. 561-567.

113. Boiler \& Pressure Vessel Code Section X, Fiber-Reinforced Plastic Pressure Vessels, ASME International, 2004.

114. Cordovi, M. A., "Historical Development of Alloy 800: An Overview," A Status Review of Alloy 800, University of Reading, September $25 \& 26,1974$; S. F. Pugh, Ed., AERE Harwell:

1 15. Moeller, R. H., Martin, J. M., "Optimization of Incoloy Alloy 800 Mechanical Properties for Various Power Plant Requirements," A Status Review of Alloy 800, University of Reading, September 25, 26, 1974; S. F. Pugh, Ed., AERE Harwell: .

116. Nicrofer 3220H/3220HP - Alloys 800H/800HP, product sheet, ThyssenKrupp VDM, 2002.

117. Shinavski, R. J., $\mathrm{SiC}_{\mathrm{f}} / \mathrm{SiC}$ Expert, Hyper-Therm High-Temperature Composites, Inc., Huntington Beach, CA, 2006, personal communication with R. Lloyd.

118. Landini, D., Technical Marketing, GE Energy, Ceramic Composite Products, LLC., Newark, DE, 2006, personal communication with R. Lloyd.

119. Klett, J., drawing of "Carbon-Carbon Control Rod" 2005.

120. Ceramic-Matrix Composites, product sheet, Hyper-Therm High-Temperature Composites Inc., 2003.

121. Ishikawa, T., Kohtoku, Y., Kumagawa, K., et al., "High-Strength Alkali-Resistant Sintered SiC Fibre Stable to $2200^{\circ} \mathrm{C}$," Nature, Vol. 39, 1998, pp. 773-775.

122. Besmann, T. M., Kupp, E. R., Lara-Curzio, E., et al., "Ceramic Composites with Multilayer Interface Coatings," Journal of the American Ceramic Society, Vol. 83, 12, 2000, pp. 3014-3020. 
123. Taguchi, T., Nozawa, T., Igawa, N., et al., "Fabrication of Advanced SiC Fiber/F-CVI SiC Matrix Composites with SiC/C Multi-Layer Interphase," Journal of Nuclear Materials, Vol. 329-333, 2004, pp. 572-576.

124. Katoh, Y., Kotani, M., Kishimoto, H., et al,, "Properties and Radiation Effects in High-Temperature Pyrolyped Pip-SiC/SiC," Joumal of Nuclear Materials, Vol. 289, 2001, pp. 42-47.

125. Araki, H., Noda, T., Yang, W., et al., "Homogeneity and Flexural Properties of SiC/SiC Composites Prepared by CVI Method," Journal of Nuclear Materials, Vol. 307-311, 2002, pp. 1210-1214.

126. Igawa, N., Taguchi, T., Snead, L. L., et al., "Optimizing the Fabrication Process for Superior Mechanical Properties in the FCVI SiC Matrix/Stoichiometric SiC Fiber Composite System," Journal of Nuclear Materials, Vol. 307-311, 2002, pp. 1205-1209.

127. Besmann, T. M., McLaughlin, J. C., Lin, H.-T., "Fabrication of Ceramic Composites: Forced CVI," Journal of Nuclear Materials, Vol. 219, 1995, pp. 31-35.

128. Katoh, Y., Nuclear Materials Research Staff Member, Oak Ridge National Laboratory, Oak Ridge TN, 2006, personal communication with J. K. Wright.

129. Allen, T., Bruemmer, S., Kassner, M., et al., "Summary of the Higher Temperature Reactor Materials Workshop," LaJolla, CA, March 18-21, 2002pp. 1-27.

130. Reitsma, F. R., PBMR, Pty, Ltd. South Africa, 2006, personal communication with H. Gougar.

13I. Windes, W. E., Staff Scientist, Materials Science, Idaho National Laboratory, Idaho Falls ID 2006, personal communication with J. K. Wright. 